Margareth de Mello Ferreira dos Reis

\title{
Disfunção erétil, auto-referida e segundo o Índice Internacional de Função Erétil, em doadores de sangue
}

Tese apresentada à Faculdade de Medicina da Universidade de São Paulo para obtenção do título de Doutor em Ciências

Área de Concentração: Fisiopatologia Experimental Orientadora: Prof ${ }^{a}$ Dra. Carmita Helena Najjar Abdo

São Paulo

2008 
Dados Internacionais de Catalogação na Publicação (CIP)

Preparada pela Biblioteca da

Faculdade de Medicina da Universidade de São Paulo

Creprodução autorizada pelo autor

Reis, Margareth de Mello Ferreira dos

Disfunção erétil, auto-referida e segundo o Índice Internacional de Função Erétil, em doadores de sangue / Margareth de Mello Ferreira dos Reis. -- São Paulo, 2008.

Tese(doutorado)--Faculdade de Medicina da Universidade de São Paulo para obtenção do título de Doutor em Ciências.

Área de concentração: Fisiopatologia Experimental.

Orientadora: Carmita Helena Najjar Abdo.

Descritores: 1.Disfunção erétil/epidemiologia 2.Auto-avaliação (Psicologia) 3.Estudos transversais 4.Disfunção erétil/diagnóstico 5.Sexualidade

USP/FM/SBD-253/08 


\section{DEDICATÓRIA}

Ao meu querido, mais que querido "encantador de leões"

Julho de 1996

O mês e o ano que marcaram o começo da nossa história

Sem que eu desconfiasse

Estava começando uma inenarrável trajetória

Mais que um romance

A vida com você é uma doce aventura

Rindo ou "encantando leões"

Igual a você, não há!

Orgulho-me de receber o seu amor: preciosidade neste mundo de tantas paixões

Remamos por caminhos desafiadores até aqui

Encontrando, porém, um no olhar do outro

Inspiração para "encantar leões" e reinventar o nosso amor

Sempre

Aos meus queridos, mais que queridos: filhos, genro, neto, pai (in memoriam), mãe, irmã, cunhado, cunhada, concunhado, sobrinhos e amigos

Mais que grandes companheiros

Admiro a todos pela generosidade e amor, sempre 


\section{AGRADECIMENTOS}

À Prof ${ }^{a}$ Dra Carmita Helena Najjar Abdo pela preciosa chance de receber de sua fonte de conhecimento e competência a orientação para a realização deste trabalho.

Ao Dr. Thomaz Nicoletti Filho por ter-me aceito no Banco de Sangue (Hemotech) do Hospital Bandeirantes, na cidade de São Paulo, para coletar os dados desta pesquisa em doadores de sangue.

\section{À Prof ${ }^{\text {a }}$ Dra Gleice Margareth de Souza Conceição pelo} envolvimento e profissionalismo no tratamento dos dados estatísticos.

Ao Prof Dr Sidney Glina e à Prof ${ }^{\mathrm{a}}$ Dra Maria Alves de Toledo Bruns pelas valiosas oportunidades de aprendizado na área da Sexualidade Humana e pelas importantes contribuições no Exame de Qualificação.

À Prof ${ }^{a}$ Dra Patrícia Brunfentrinker Hochgraf pela presença e sugestões reverberantes no Exame de Qualificação.

Ao colega Eduardo T. Yabusaki pelo apoio em muitos momentos deste trabalho.

Às secretárias da Fisiopatologia Experimental, Sonia Fernandes e Thania R. Souza, pela inestimável disposição para comunicar e esclarecer informações. 
Esta tese está de acordo com:

Referências: adaptado de International Committee of Medical Journals Editors (Vancouver)

Universidade de São Paulo. Faculdade de Medicina. Serviço de Biblioteca e Documentação. Guia de apresentação de dissertações, teses e monografias. Elaborado por Anneliese Carneiro da Cunha, Maria Júlia de A. L. Freddi, Maria F. Crestana, Marinalva de Souza Aragão, Suely Campos Cardoso, Valéria Vilhena. São Paulo: Serviço de Biblioteca e Documentação; 2004.

Abreviaturas dos títulos dos periódicos de acordo com List of Journals Indexed in Index Medicus. 


\section{SUMÁRIO}

Dedicatória

Agradecimentos

Lista de tabelas

Lista de figuras

Resumo

Summary

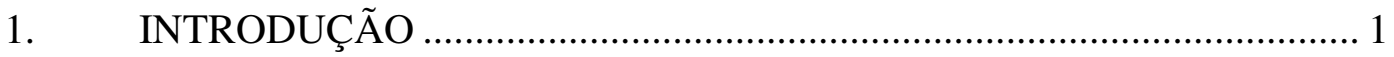

1.1. Definição da Disfunção Erétil (DE) ......................................................... 2

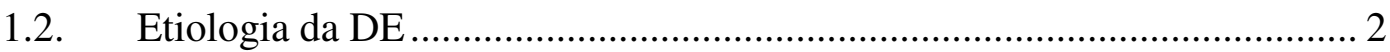

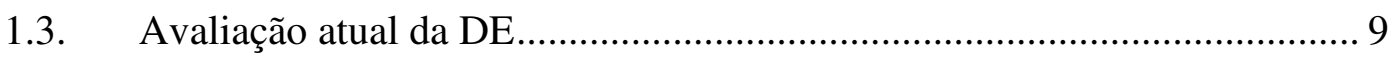

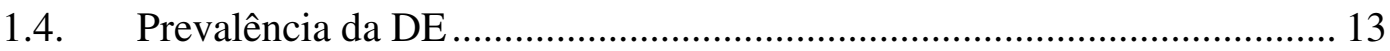

1.4.1. Prevalência da DE utilizando questão única sobre a dificuldade de obter

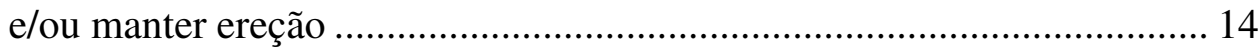

1.4.2. Prevalência da DE, utilizando o IIFE e o IIFE-5 .................................... 21

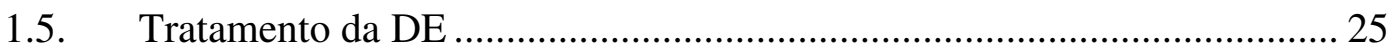

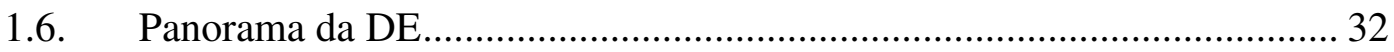

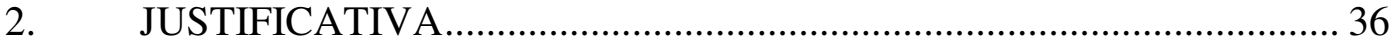

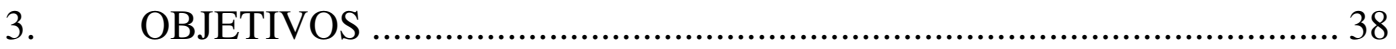

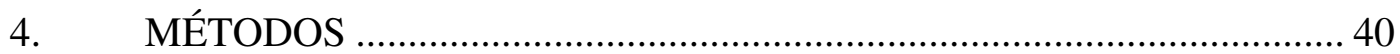

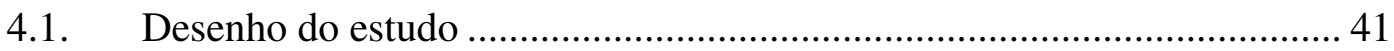

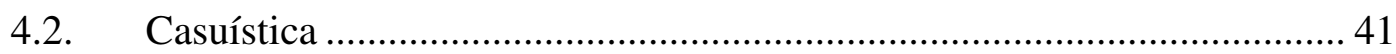

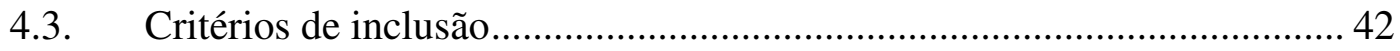




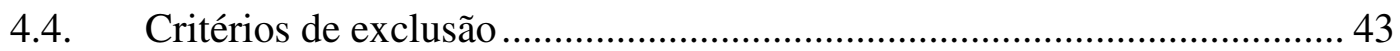

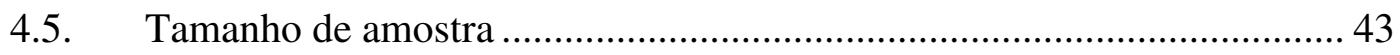

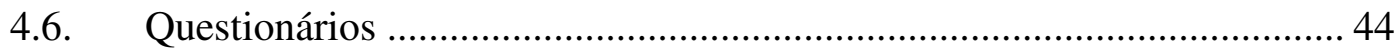

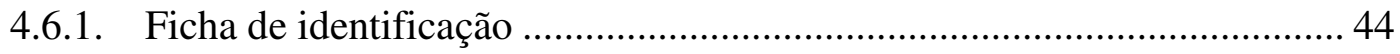

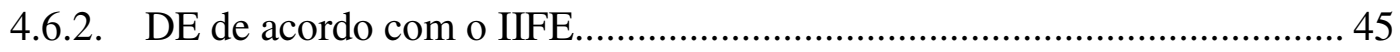

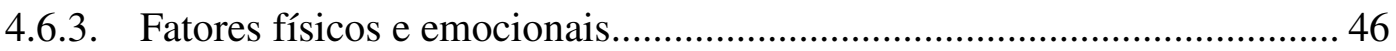

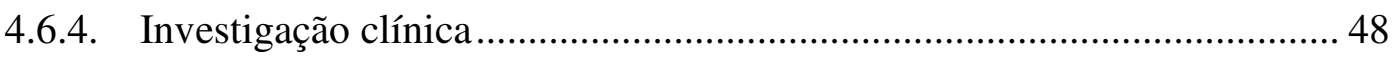

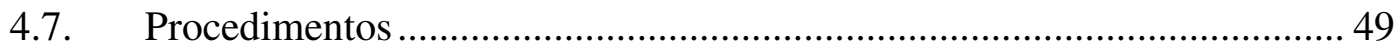

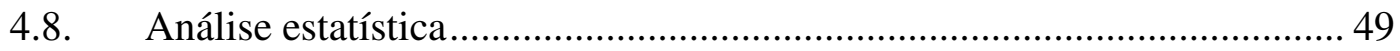

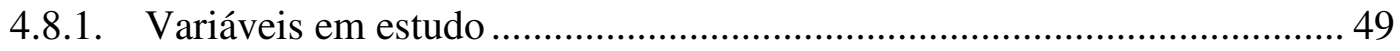

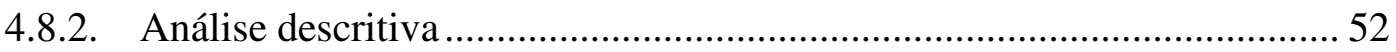

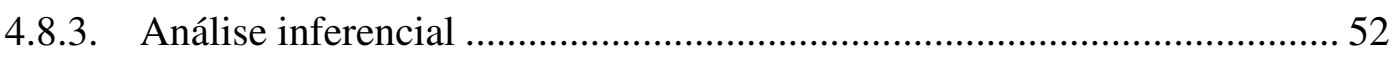

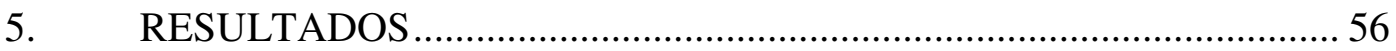

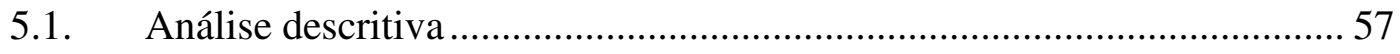

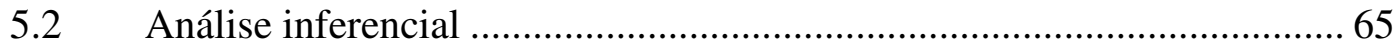

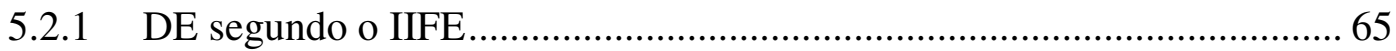

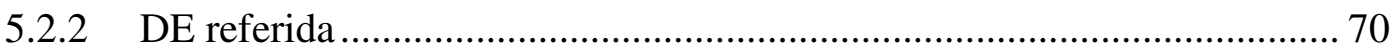

5.2.3 Idade, qualidade de vida, stress e transtornos depressivos e/ou ansiosos . 74

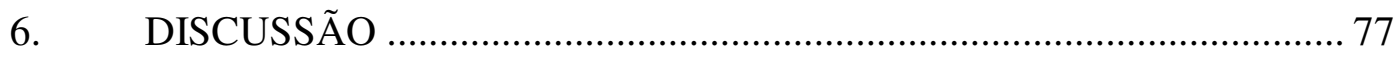

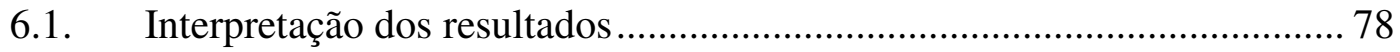

6.1.1. Prevalência da DE, segundo o IIFE ...................................................... 78

6.1.2. Comparação entre a prevalência da DE, segundo o IIFE, e a prevalência da

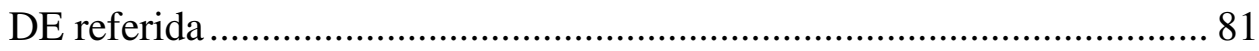

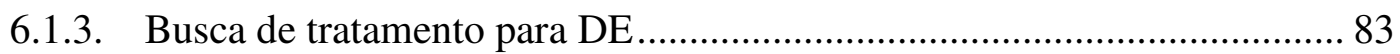


6.1.4. Fatores associados à DE

6.1.5. Relação entre DE, idade e capacidade funcional .................................... 90

6.2. Limitações Metodológicas ................................................................. 91

6.3. Considerações finais - Implicações para a pesquisa e abordagem da DE em

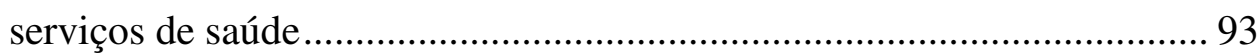

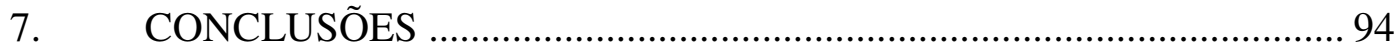

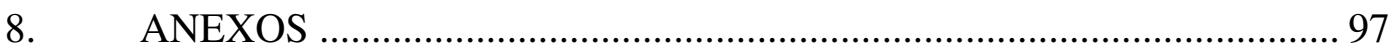

9. REFERÊNCIAS BIBLIOGRÁFICAS .............................................. 138 


\section{LISTA DE TABELAS}

Tabela 1 - Distribuição conjunta dos indivíduos do estudo segundo a DE detectada pelo IIFE e a referida .......................................................58

Tabela 2 - Medidas descritivas para as variáveis quantitativas em estudo, segundo a presença de DE detectada pelo IIFE e referida.

Tabela 3 - Distribuição dos casos de DE detectada pelo IIFE segundo as variáveis explicativas e estimativas do modelo de regressão logística simples

Tabela 4 - Estimativas do modelo final de regressão logística múltipla obtido por um procedimento stepwise forward, tendo como variável resposta a presença de DE detectada pelo IIFE

Tabela 5 - Distribuição dos casos de DE referida pelo respondente segundo as variáveis explicativas e estimativas do modelo de regressão logística

simples.....

Tabela 6 - Medidas de qualidade de vida, stress e transtornos depressivos e/ou ansiosos, segundo a idade e nível descritivo do teste

Qui-quadrado 


\section{LISTA DE FIGURAS}

Figura 1 - Distribuição percentual dos indivíduos segundo DE (detectada pelo IIFE e DE referida) e região de procedência..

Figura 2 - Distribuição percentual dos indivíduos segundo DE (detectada pelo IIFE e DE referida) e raça/cor.

Figura 3 - Distribuição percentual dos indivíduos segundo DE (detectada pelo IIFE e DE referida) e estado civil.

Figura 4 - Distribuição percentual dos indivíduos segundo DE (detectada pelo IIFE e DE referida) e religião.

Figura 5 - Distribuição percentual dos indivíduos segundo DE (detectada pelo IIFE e DE referida) e escolaridade.

Figura 6 - Distribuição percentual dos indivíduos segundo DE (detectada pelo IIFE e DE referida) e condição profissional...............................122

Figura 7 - Distribuição percentual dos indivíduos segundo DE (detectada pelo IIFE e DE referida) e renda mensal............................................123

Figura 8 - Distribuição percentual dos indivíduos segundo DE (detectada pelo IIFE e DE referida) e idade.

Figura 9 - Distribuição percentual dos indivíduos segundo DE (detectada pelo IIFE e DE referida) e IMC.

Figura 10 - Distribuição percentual dos indivíduos segundo DE (detectada pelo IIFE e DE referida) e a condição de saúde atual quando comparada com um ano atrás.

Figura 11 - Distribuição percentual dos indivíduos segundo DE (detectada pelo IIFE e DE referida) e escore de capacidade funcional...............125

Figura 12 - Distribuição percentual dos indivíduos segundo DE (detectada pelo IIFE e DE referida) e escore de aspectos físicos

Figura 13 - Distribuição percentual dos indivíduos segundo DE (detectada pelo IIFE e DE referida) e escore de dor...

Figura 14 - Distribuição percentual dos indivíduos segundo DE (detectada pelo IIFE e DE referida) e escore de aspectos sociais.

Figura 15 - Distribuição percentual dos indivíduos segundo DE (detectada pelo IIFE e DE referida) e escore de aspectos emocionais.

Figura 16 - Distribuição percentual dos indivíduos segundo DE (detectada pelo IIFE e DE referida) e escore de estado geral de saúde......

Figura 17 - Distribuição percentual dos indivíduos segundo DE (detectada pelo IIFE e DE referida) e escore de vitalidade...............................128

Figura 18 - Distribuição percentual dos indivíduos segundo DE (detectada pelo IIFE e DE referida) e escore de saúde mental............................128

Figura 19 - Distribuição percentual dos indivíduos segundo DE (detectada pelo IIFE e DE referida) e stress.

Figura 20 - Distribuição percentual dos indivíduos segundo DE (detectada pelo IIFE e DE referida) e transtornos depressivos e/ou ansiosos....129

Figura 21 - Distribuição percentual dos indivíduos segundo DE (detectada pelo IIFE e DE referida) e tempo de relacionamento.

Figura 22 - Distribuição percentual dos indivíduos segundo DE (detectada pelo IIFE e DE referida) e grau de satisfação no relacionamento a dois. 
Figura 23 - Distribuição percentual dos indivíduos segundo DE (detectada pelo IIFE e DE referida) e atração sexual pela parceira.

Figura 24 - Distribuição percentual dos indivíduos segundo DE (detectada pelo IIFE e DE referida) e preliminares.

Figura 25 - Distribuição percentual dos indivíduos segundo DE (detectada pelo IIFE e DE referida) e como se sentem ao falar sobre sexo.......132

Figura 26 - Distribuição percentual dos indivíduos segundo DE (detectada pelo IIFE e DE referida) e curvatura no pênis.

Figura 27 - Distribuição percentual dos indivíduos segundo DE (detectada pelo IIFE e DE referida) e desejo sexual atual.

Figura 28 - Distribuição percentual dos indivíduos segundo DE (detectada pelo IIFE e DE referida) e satisfação com o tamanho do pênis.

Figura 29 - Distribuição percentual dos indivíduos segundo DE (detectada pelo IIFE e DE referida) e satisfação com o próprio corpo

Figura 30 - Distribuição percentual dos indivíduos segundo DE (detectada pelo IIFE e DE referida) e satisfação profissional...

Figura 31 - Distribuição percentual dos indivíduos segundo DE (detectada pelo IIFE e DE referida) e satisfação pessoal.

Figura 32 - Distribuição percentual dos indivíduos segundo DE (detectada pelo IIFE e DE referida) e qualidade do sono.

Figura 33 - Distribuição percentual dos indivíduos segundo DE (detectada pelo IIFE e DE referida) e realização de algum tipo de tratamento

Figura 34 - Distribuição percentual dos indivíduos segundo DE (detectada pelo IIFE e DE referida) e realização de tratamento para colesterol

Figura 35 - Distribuição percentual dos indivíduos segundo DE (detectada pelo IIFE e DE referida) e realização de outro tipo de tratamento

Figura 36 - Distribuição percentual dos indivíduos segundo DE (detectada pelo IIFE e DE referida) e uso de medicamentos 
Reis MMF. Disfunção erétil, auto-referida e segundo o Índice Internacional de Função Erétil, em doadores de sangue [tese]. São Paulo: Faculdade de Medicina, Universidade de São Paulo; 2008. 157p.

INTRODUÇÃO: Inúmeros estudos epidemiológicos realizados nos mais diversos países sugerem alta prevalência de disfunção erétil (DE), mas não há consenso acerca de sua exata magnitude. MÉTODOS: Foi conduzido um estudo para estimar a prevalência de DE e investigar seus fatores associados em homens com idade entre 40 e 60 anos, considerados sadios. Tal estudo de corte transversal com doadores de sangue, heterossexuais, com parceira estável há pelo menos seis meses, incluídos entre janeiro de 2006 e julho de 2007, investigou a presença da DE por meio do Índice Internacional de Função Erétil (IIFE) e também com pergunta direta, para auto-avaliação. Foram investigados fatores sócio-demográficos, história clínica, características do relacionamento afetivo e sexual, qualidade de vida, presença de sintomas depressivos e/ou ansiosos e de stress. RESULTADOS: A amostra incluiu 300 sujeitos, dos quais 12 foram excluídos da análise porque faziam uso de medicação oral para ereção, metade dos quais sem orientação médica. Dos 288 sujeitos analisados, 92 (31,9\%; $\mathrm{IC}_{95 \%}: 26,6 \%$ a 37,7\%) foram classificados pelo IIFE como tendo algum grau de disfunção erétil: 87 (30,2\%; IC ${ }_{95 \%}: 25,0 \%$ a 35,9\%) indivíduos possuíam disfunção leve, quatro $\left(1,4 \%\right.$; $\mathrm{IC}_{95 \%}$ : 0,4\% a 3,5\%), disfunção moderada e um $\left(0,3 \%\right.$; $\mathrm{IC}_{95 \%}: 0,01 \%$ a $\left.1,9 \%\right)$, disfunção completa. Entretanto, apenas nove $\left(3,1 \%\right.$; $\mathrm{IC}_{95 \%}: 1,4 \%$ a $\left.5,8 \%\right)$ referiram não se sentirem potentes sexualmente. A concordância entre DE detectada pelo IIFE e DE referida foi baixa (kappa $=0,11 ; p$ $<0,001)$. Dos nove indivíduos que não se sentiam potentes sexualmente, apenas dois $(22,2 \%)$ procuraram tratamento. Os fatores associados à presença da DE detectada pelo IIFE, após regressão logística multivariada, foram: inatividade profissional (OR $=3,3 ; \mathrm{IC}_{95 \%}: 1,4$ a 7,$\left.8 ; \mathrm{p}=0,005\right)$; suspeita de transtorno depressivo e/ou ansioso $\left(\mathrm{OR}=2,6 ; \mathrm{IC}_{95 \%}: 1,1\right.$ a 6,$\left.3 ; \mathrm{p}=0,033\right)$; desejo sexual bom (não excelente) $(\mathrm{OR}=$ 2,5; $\mathrm{IC}_{95 \%}$ : 0,9 a 7,0; $\left.\mathrm{p}=0,082\right)$, ou baixo/moderado (OR = 5,5; $\mathrm{IC}_{95 \%}: 1,2$ a 25,$1 ; \mathrm{p}=$ 0,027) e referir $\mathrm{DE}\left(\mathrm{OR}=7,5 ; \mathrm{IC}_{95 \%}: 0,8\right.$ a 71,$\left.7 ; \mathrm{p}=0,080\right)$. CONCLUSÕES: A prevalência da DE, segundo o IIFE, foi alta, embora inferior à observada em outros estudos conduzidos com voluntários e usuários de serviços de saúde. A concordância entre DE, segundo o IIFE e auto-referida, foi baixa, possivelmente porque as duas formas de investigação avaliam diferentes dimensões da função erétil (aspectos funcionais versus aspectos subjetivos). Há grande interação entre os fatores biológicos, culturais e psicológicos no surgimento e manutenção da DE. É importante que os profissionais de saúde estejam atentos para a saúde sexual dos homens, especialmente após os 40 anos de idade, e para as possíveis condições que podem acompanhar a DE (doenças sistêmicas, sofrimento psíquico e outros aspectos psicossociais).

Descritores: 1. Disfunção erétil/epidemiologia; 2. Auto-avaliação (Psicologia); 3. Estudos transversais; 4. Disfunção erétil/diagnóstico; 5. Sexualidade. 
Reis MMF. Self-reported erectile dysfunction and according to the International Index of Erectile Function in blood donors. [thesis]. São Paulo: Medical School, Universidade de São Paulo; 2008. 157p.

INTRODUCTION: Several epidemiological studies from different countries indicate high prevalence of erectile dysfunction (ED) but there is no consensus about its actual magnitude. The objective of the present study was to estimate the prevalence of ED and describe its associated factors in healthy men. METHODS: Crosssectional study comprising a sample of heterosexual blood donors, aged between 40 and 60 years, with a steady partner for at least six months, was carried out between January 2006 and July 2007. ED was assessed using the International Index of Erectile Function (IIEF) as well as direct inquiring for self-assessment. Data was collected on sociodemographic characteristics, medical history, affective and sexual behavior, quality of life, presence of depression and/or anxiety symptoms and stress. The study sample comprised 300 subjects, of which 12 were excluded from the analysis since they were taking oral medication for erectile dysfunction, and half of them took this medication without any prior medical advice. RESULTS: Of 288 subjects analyzed, 92 (31.9\%; 95\% CI: $26.6 \%-37.7 \%)$ had any degree of erectile dysfunction according to IIEF: 87 (30.2\%; 95\% CI: $25.0 \%-35.9 \%)$ had mild; four (1.4\%; $95 \%$ CI: $0.4 \%-3.5 \%)$ had moderate; and one $(0.3 \%$; $95 \%$ CI: $0.01 \%-1.9 \%)$ had severe dysfunction. Only nine subjects $(3.1 \%$; $95 \%$ CI: $1.4 \%-5.8 \%)$ reported not feeling sexually potent. The concordance between ED assessed using IIEF and self-reported ED was low (kappa $=0.11 ; \mathrm{p}<0.001$ ). Of the nine subjects who reported not feeling sexually potent, only two $(22.2 \%)$ sought treatment. The factors associated to ED assessed using IIEF in the multivariate logistic regression analysis were: professional inactivity $(\mathrm{OR}=3.3 ; 95 \% \mathrm{CI}: 1.4-7.8 ; \mathrm{p}=0.005)$; suspected depressive and/or anxiety disorder $(\mathrm{OR}=2.6 ; 95 \% \mathrm{CI}: 1.1-6.3 ; \mathrm{p}=0.033)$; satisfactory (but not strong) sexual desire $(\mathrm{OR}=2.5 ; 95 \% \mathrm{CI}: 0.9-7.0 ; \mathrm{p}=0.082)$ or low/moderate $(\mathrm{OR}=5.5 ; 95 \% \mathrm{CI}: 1.2-25.1 ; \mathrm{p}=0.027)$; and self-reported $\mathrm{ED}(\mathrm{OR}$ $=7.5 ; 95 \%$ CI: $0.8-71.7 ; \mathrm{p}=0.080)$. CONCLUSIONS: ED prevalence according to IIEF was high though lower than that found in other studies conducted in voluntary health service users. The concordance between ED according to IIEF and selfreported ED was low, probably because these two approaches assess different dimensions of the erectile function (functional versus subjective components). Biological, cultural and psychological factors strongly interact in the development and maintenance of ED. Health providers should give special attention to sexual health of men, particularly those over 40, and to potential conditions accompanying ED (systemic diseases, psychic distress, and other psychosocial conditions).

Key words: 1. Erectile dysfunction/epidemiology; 2. Self Assessment (Psychology); 3. Cross-sectional studies; 4. Erectile dysfunction/diagnostic; 5. Sexuality. 
1. INTRODUÇÃO 


\subsection{Definição da Disfunção Erétil (DE)}

O termo disfunção erétil (DE) foi sugerido a partir de 1992 - quando foi realizada uma reunião do Grupo de Consenso em Impotência coordenado pelo Instituto Nacional de Saúde Norte-Americano (NIH, 1993) -, para substituir o termo "impotência", tendo em vista o seu sentido pejorativo e impreciso para ser aplicado ao homem cujo pênis não responde adequadamente.

A DE refere-se à incapacidade persistente ou recorrente de obter e/ou manter ereção suficiente para uma função sexual satisfatória (NIH, 1993).

\subsection{Etiologia da DE}

A etiologia da DE é multifatorial, incluindo a combinação dos aspectos psicossociais, culturais e orgânicos.

Os fatores de risco mais freqüentemente associados à DE são: diabetes mellitus, hipogonadismo, hipertensão arterial sistêmica, doença vascular periférica, dislipidemia, baixos níveis de lipoproteína de alta densidade, doenças neurológicas, doença de Peyronie, tabagismo, priapismo, insuficiência renal, infarto do miocárdio, neoplasias, uso de drogas e medicamentos, obesidade, depressão, desconhecimento da sexualidade e idade (Feldman et al., 1994; Jonler et al., 1995; Melman, 1995; Feldman et al., 1998; Helgason et al., 1997; Johannes et al., 2000; Moreira Junior et al., 2001; Morillo et al., 2002).

Dentre as causas orgânicas da DE, a de origem vascular é considerada uma das principais (Michal, 1982; Virag et al., 1985; Shabsigh et al., 1991; Carson et al., 
1999). A presença da DE arteriogênica em homens com mais de 50 anos tem sido considerada como um sinal preditivo de doença aterosclerótica em outros órgãos, sugerindo assim uma investigação cuidadosa de sintomas relacionados à doença cardíaca e vascular periférica (Izukawa, 1977; Rehman, Melman, 2002).

A DE é considerada uma das sentinelas da síndrome metabólica (Cunha, 2005; Arcila, 2006). Em síntese, a síndrome metabólica é caracterizada por obesidade, dislipidemia, resistência à insulina, hipertensão arterial e alteração endotelial $^{1}$. A alteração endotelial é caracterizada como sendo um processo inflamatório lento e progressivo, que por consequiência dessa inflamação altera a produção de óxido nítrico - que é um mediador de todos os processos vasodilatadores que ocorrem no organismo -, e, portanto, modifica o estado de vasoconstrição e vasodilatação da rede vascular. Isso terá manifestação clínica em vários territórios vasculares, sendo que um deles é o território vascular peniano, que tem como conseqüência a presença da DE.

Determinados medicamentos e drogas também podem causar problemas sexuais. Morley (1986) advertiu que 16 das 200 substâncias mais freqüentemente prescritas nos Estados Unidos podiam causar DE. Feldman et al. (1994) mostraram que a DE completa foi significativamente mais prevalente em homens que tomavam certos medicamentos, incluindo agentes hipoglicemiantes (26\%), anti-hipertensivos (14\%), vasodilatadores (36\%) e medicamentos cardiológicos (28\%), do que no total da amostra (9,6\%). Segundo a Sociedad Latinoamericana para el Estudio de la Impotencia y Sexualidad (2002), um em quatro pacientes com DE apresenta uma consequiência medicamentosa, sendo que mais de 100 fármacos de uso comum e

\footnotetext{
${ }^{1}$ Todos os vasos sangüíneos - arteriais, venosos e linfáticos - e os túbulos seminíferos são totalmente recobertos por uma estrutura inferior formada por uma monocamada de células epiteliais pavimentosas denominada endotélio (Cunha, 2005).
} 
freqüente podem causar problemas sexuais, como os agentes anti-hipertensivos, psicotrópicos e de ação antiandrogênica. Dentre as drogas, o tabaco, o álcool e a cocaína estão relacionados com a DE (Sociedad Latinoamericana para el Estudio de la Impotencia y Sexualidad, 2002).

Em relação às causas psicogênicas da $\mathrm{DE}$, depressão e ansiedade são consideradas as mais freqüentes, sejam como causadoras e/ou mantenedoras, ou ainda, associadas a outros fatores etiológicos (Oliveira, Abdo, 2000).

A associação significativa entre depressão e DE tem sido amplamente relatada na literatura científica (Feldman et al., 1994; Kaiser, 1996; Araujo et al., 1998; Rosen, 2001; Abdo, 2004; Rosen et al., 2004; Laumann et al., 2005; Moreira Junior et al., 2005; Abdo et al., 2006), mas a natureza exata da relação entre essas condições ainda não é clara. Embora seja possível que a DE possa contribuir com o desenvolvimento da depressão, também é possível que os sintomas depressivos possam levar à DE (Araujo et al., 1998, Seidman, 2002, Moreira Junior et al., 2005).

No que tange à ansiedade, a ansiedade de desempenho foi enfatizada como um fator inibidor da função do sistema nervoso autônomo em um nível que inviabiliza a excitação fisiológica (Masters, Johnson, 1970; Kaplan, 1974, 1981).

No entanto, os efeitos da ansiedade na excitação sexual se mostram em grande parte mediados pelos efeitos de fatores cognitivos (Barlow et al., 1983; Cranston-Cuebas, Barlow, 1990). De acordo com os estudos de Barlow (1986), homens com DE costumam experimentar mais interferências cognitivas durante a atividade sexual, ou seja, pensamentos negativos que geram ansiedade ante a atuação e os predispõem a subestimar de forma consistente seus níveis de excitação sexual, mantendo assim, um ciclo de afeto negativo sobre a DE. 
Carey (2003) explica que, nos homens sem DE, os pensamentos que precedem ou ocorrem durante as interações sexuais concentram-se, em especial, em comportamentos de sedução e na antecipação da excitação e do prazer. Já os homens com DE tendem a apresentar pensamentos intrusos que antecedem ou ocorrem durante as relações sexuais, isto é, pensamentos que não são eróticos e diminuem a excitação.

A tendência de questionamento do homem com episódios de DE, quanto à sua "virilidade", provoca medo de novos fracassos no seu desempenho sexual, o que pode levar à redução do interesse sexual, à perda de auto-estima e a tentativas de controle da ansiedade, criando constrangimento na atividade sexual e, conseqüentemente, mais ansiedade. A tentativa de controlar a ansiedade leva o indivíduo à preocupação em observar e avaliar o que está acontecendo, colocando-o na posição de espectador. O resultado disso é ficar à margem do ato sexual e dos estímulos sexuais indispensáveis para um desempenho satisfatório, como se fosse a terceira pessoa na situação. A posição de espectador (ou ansiedade de desempenho) leva o indivíduo a se descomprometer da relação, o que naturalmente contribui para perda de ereção, cuja sustentação depende da concentração nos estímulos sexuais (Rangé, Conceição, 2001).

Do ponto de vista cultural, a "virilidade", entendida como a capacidade reprodutiva, sexual e social que impõe a todo homem a obrigação de afirmá-la em toda e qualquer circunstância, é, acima de tudo, uma "carga" (Bourdieu, 1999).

Os homens freqüentemente sucumbem à "fantasia de modelo sexual”, na qual o desempenho masculino é visto como a base de toda experiência sexual e uma ereção firme é interpretada como condição sine-qua-non de cada encontro sexual. De 
acordo com essa visão, a dificuldade de desempenho sexual é freqüentemente interpretada como uma perda da "masculinidade" ou redução do interesse da parceira (Zilbergeld, 1992; Rosen, 2001).

Dados de um estudo intitulado Crenças Irracionais como Fontes Internas de Stress Emocional, realizado por Lipp et al. (2005) com 86 adultos de ambos os sexos e idade entre 19 e 66 anos, que procuraram atendimento no Centro Psicológico de Controle do Stress de Campinas (no interior de São Paulo), utilizando o Questionário de Crenças Irracionais e o Inventário de Sintomas de Stress para Adultos de Lipp (ISSL) (Lipp, 2002), apontaram diferenças significativas quanto às crenças irracionais (ou pensamentos disfuncionais) mais freqüentes entre os gêneros.

Enquanto a crença irracional mais freqüente entre as mulheres desse estudo foi: "É horrível quando as coisas não são exatamente como gostaríamos que fossem", refletindo uma maior sensibilidade feminina à frustração, a mais freqüente entre os homens foi: "Deve-se ser absolutamente competente, inteligente e merecedor de todo o respeito", o que denota a ênfase social que é colocada na competência masculina. Os dados desse estudo também indicaram que os pensamentos disfuncionais se consolidam e se tornam mais estressantes com o passar dos anos (Lipp et al., 2005).

O stress emocional é considerado um importante fator de risco para $\mathrm{DE}$ (Ponholzer et al., 2005). O stress emocional é uma reação complexa e global do organismo, envolvendo componentes físicos, psicológicos, mentais e hormonais, que ocorre quando a pessoa depara com situações em que ela necessitará despender de energia adaptativa para poder enfrentá-las (Lipp, 1996, 2002). O stress é eliminado quando a pessoa utiliza estratégias de enfrentamento adequadas para o restabelecimento do seu equilíbrio interno, o que pode acontecer com freqüência, 
uma vez que o ser humano está sujeito a inúmeros fatores estressantes durante a sua existência. Mas, se os esforços para voltar à homeostase persistem por longos períodos ou excedem a resistência da pessoa, os efeitos do stress podem se manifestar tanto na área somática quanto cognitiva e aparecerem em seqüência e grau de importância à medida que as fases do stress se agravam (Selye, 1984; Lipp, 2002).

Fatores interpessoais e de relacionamento vêm sendo associados com frequiência à DE. Dificuldade de comunicação, falta de intimidade ou confiança e conflitos de poder foram enfatizados como concomitantes freqüentes da DE (Rosen, 2001). Os conflitos de relacionamento podem ser uma fonte primária da dificuldade sexual ou servir para exacerbar ou manter a inabilidade do homem em atingir ereções adequadas (Rosen et al., 1994; Rosen, 2001).

Eventos externos ou conjunturais também foram correlacionados significativamente com a DE. Alguns fatores socioeconômicos, como estado civil solteiro, baixo nível de escolaridade, baixa renda e desemprego mostraram associação com a presença da DE (Laumann et al., 1999; Aytac et al., 2000; Johannes et al., 2000; Morillo et al., 2002; Moreira Junior et al., 2003; Abdo et al., 2006). O Global Study of Sexual Attitudes and Behaviors (GSSAB) (Laumann et al., 2005) revelou que o stress decorrente de problemas financeiros está associado positivamente com DE.

Em relação às causas psicológicas remotas associadas à DE, os estudos apontam o papel do trauma sexual na infância, questões de identidade sexual ou orientação sexual, relacionamentos não resolvidos com parceiras ou pais e tabus religiosos ou culturais (Mohr, Beutler, 1990; Laumann et al., 1999; Rosen, 2001). 
Laumann et al. (1999) sugerem que a experiência de disfunção sexual é mais provável entre aqueles que apresentam pior saúde física e emocional.

Um estudo sobre qualidade de vida auto-relatada e DE conduzido por Sánchez-Cruz et al. (2003) com 2476 homens espanhóis não institucionalizados, com idade entre 25 e 70 anos, utilizando o Medical Outcomes Study Questionnaire 36Item Short Form Health Survey (SF-36) (Ware, Sherbourne, 1992) - um instrumento composto de 36 itens englobados em oito dimensões da qualidade de vida: capacidade funcional, aspectos físicos, dor, estado geral de saúde, vitalidade, aspectos sociais, aspectos emocionais e saúde mental, cuja pontuação varia de 0 (pior resultado) a 100 (melhor resultado) -, demonstrou que as pontuações obtidas no SF36 pelos indivíduos com DE foram significativamente mais baixas que nos indivíduos que não apresentavam DE, e com uma diferença significativamente maior nos escores relacionados aos componentes físicos.

A probabilidade da DE ser de origem orgânica aumenta diante da descrição de seu início insidioso e de progressão lenta, ao contrário da DE descrita como uma dificuldade ocasional ou ocorrida bruscamente (Reis et al., 2002).

Há, também, uma forte interação entre fatores orgânicos e psicológicos na etiologia da DE. Por exemplo, um homem diabético com disfunção erétil secundária ao comprometimento neurológico pode ter um agravamento da disfunção sexual, decorrente de uma reação de antecipação do fracasso (Tess, Pugliese, 1998). Estudos sugerem que os fatores psicológicos estão envolvidos isoladamente ou em combinação com causas orgânicas em um número significativo de casos de DE (Ackerman, 1995; Rosen, 2001; Althof, 2002). 
Como descrito até aqui, vários fatores orgânicos, psicológicos e de estilo de vida estão associados à etiologia da $\mathrm{DE}$, o que provoca grande impacto na autoestima, na qualidade de vida e nas relações interpessoais (Rosen et al., 1997; Laumann et al., 1999; Latini et al., 2003; Sánchez-Cruz et al., 2003).

\subsection{Avaliação atual da $\mathrm{DE}$}

O surgimento do citrato de sildenafil (Viagra ${ }^{\circledR}$ ) em 1998, um inibidor da fosfodiesterase tipo 5, inaugurou uma nova era no diagnóstico e no tratamento da DE, diminuindo a necessidade de avaliações de caráter mais invasivo (Sharlip, 1998), assim como, com os grandes avanços que foram realizados no conhecimento da fisiopatologia da DE nas duas últimas décadas, as várias etiologias dessa condição puderam ser avaliadas (Glina, 2002): fatores psicológicos (anamnese e entrevista psicológica); insuficiência arterial, ou seja, acentuada diminuição do fluxo arterial do corpo cavernoso, o que impede que o pênis assuma uma rigidez suficiente para a penetração (teste de ereção fármaco-induzida sem resposta erétil adequada ou medida da tumescência peniana noturna [TPN] anormal com Rigiscan, devendo ser confirmado por ultra-som dúplex e arteriografia se houver planejamento para restauração arterial); distúrbios neurológicos (história de diabetes mellitus mal compensado, alcoolismo, lesão medular e TPN anormal); disfunção caverno-venooclusiva, ou seja, inabilidade de se restringir a drenagem venosa dos corpos cavernosos (teste de ereção fármaco-induzida sem resposta erétil adequada ou TPN anormal e ultra-som dúplex com artérias cavernosas normais); insuficiência hormonal (dosagem de testosterona), uso de drogas ou medicações (anamnese); e 
doença de Peyronie, ou seja, placa fibrosa que envolve o tecido cavernoso (anamnese, exame físico e teste de ereção fármaco-induzida).

Nos estudos para estimar a prevalência da DE vêm sendo utilizados instrumentos padronizados. Vários estudos sobre a prevalência da DE utilizam uma questão global simples, derivada diretamente da definição de DE proposta pela National Institutes of Health Consensus Conference (NIH, 1993). O estudo de coorte sobre envelhecimento masculino na cidade de Boston e arredores, denominado Massachusetts Male Aging Study (MMAS) (Feldman et al., 1994) foi o primeiro a utilizar esta questão para avaliar DE. O quadro 1 apresenta a questão utilizada no MMAS.

\section{Quadro 1. Questão única auto-aplicável sobre DE utilizada no MMAS}

\begin{tabular}{|c|c|}
\hline \multicolumn{2}{|c|}{$\begin{array}{l}\text { Disfunção erétil (às vezes chamada de impotência) significa ser incapaz de obter e manter uma ereção que } \\
\text { seja rígida o suficiente para atividade sexual satisfatória }\end{array}$} \\
\hline Não impotente & Sempre capaz de obter e manter uma ereção boa o suficiente para o intercurso sexual \\
\hline Minimamente impotente & Freqüentemente capaz de obter e manter uma ereção boa o suficiente para o intercurso sexua \\
\hline Moderadamente impotente & Às vezes capaz de obter e manter uma ereção boa o suficiente para o intercurso sexual \\
\hline Completamente impotente & Nunca capaz de obter e manter uma ereção boa o suficiente para o intercurso sexual \\
\hline
\end{tabular}

Essa questão foi validada por O’Donnell et al. (2005) que utilizaram as respostas de 137 homens com idade entre 55 e 85 anos à questão única sobre DE e que foram submetidos à avaliação urológica (história sexual, história médica, história psicossocial e exame físico) feita por profissionais que desconheciam a resposta dada à pergunta. Foi obtida uma forte correlação entre a avaliação da DE pela pergunta auto-aplicada e pela avaliação urológica (coeficiente de correlação de Spearman =

\footnotetext{
${ }^{2}$ Traduzido e adaptado de O’Donnell et al. 2005.
} 
0,80). O estudo também mostrou que a questão auto-aplicada prediz corretamente o resultado da avaliação urológica em $88 \%$ dos sujeitos.

Além disso, o desenvolvimento de uma escala multidimensional, o Índice Internacional de Função Erétil (IIFE) (Rosen et al., 1997), com objetivo de ser uma medida auto-administrável confiável e concisa da função erétil, com sensibilidade e especificidade para detectar mudanças durante o tratamento de pacientes com DE, proporcionou uma nova forma de investigação da DE para os clínicos e pesquisadores. O IIFE é utilizado em muitos países para estimar a prevalência da DE em estudos conduzidos na comunidade e entre pacientes com determinados tipos de doenças, e desde a sua introdução teve um impacto significativo no campo do diagnóstico e classificação da gravidade da DE (Rosen et al., 2002).

O IIFE propõe-se a avaliar os vários domínios da função sexual masculina, quais sejam: função erétil, função orgástica, desejo sexual, satisfação na relação e satisfação geral. Trata-se de um questionário com 15 itens que investigam, em sua maioria, a frequiência de atividade sexual nas últimas quatro semanas. Em geral, cada item pode assumir valores tais como: nenhuma vez, quase nunca/nunca, poucas vezes, algumas vezes, na maioria das vezes e quase sempre/sempre.

O IIFE avalia, nos itens que englobam o domínio função erétil, os principais aspectos da definição da DE: a habilidade do indivíduo para obter ou manter uma ereção suficiente para o intercurso sexual, o grau de satisfação obtido, a habilidade para obter ereções independentemente do intercurso sexual e, ainda, o nível de confiança para obter e manter ereções.

Considerado psicometricamente sólido (Rosen et al., 1997), esse questionário multidimensional é auto-administrável, lingüisticamente validado, e, atualmente, está 
disponível em 32 idiomas no mundo todo (Rosen et al., 2002). Foram conduzidos estudos de validade, confiabilidade e sensibilidade (resposta ao tratamento). Dois aspectos da confiabilidade da escala - consistência interna e confiabilidade teste e reteste - foram examinados para cada domínio da escala e para a escala total. Foi observado um alto grau de consistência interna (o coeficiente alfa de Cronbach variou de 0,73 a 0,99 entre os domínios) e de confiabilidade teste re-teste (o coeficiente de correlação de Pearson variou de 0,64 a 0,84 entre os domínios) (Rosen et al., 1997). Rosen et al. (2002) mencionam que o IIFE foi desenvolvido em conjunto com o programa experimental clínico para o medicamento oral citrato de sildenafil e, desde então tem sido adotado como medida "padrão-ouro" para a avaliação da eficácia em experimentações clínicas sobre a DE e para detectar a presença e a gravidade da DE. Desde o desenvolvimento do IIFE inúmeros estudos têm utilizado esse instrumento em ensaios clínicos randomizados com agentes de tratamento para a DE e para classificar a gravidade e prevalência dessa disfunção (Rosen et al., 2002).

As limitações descritas sobre esse instrumento apontam para os seguintes aspectos: foco exclusivo na função sexual atual, enfoque restrito para os componentes não eréteis da resposta sexual e avaliação limitada do relacionamento a dois (Rosen et al., 1997; Rosen et al., 2002).

Com o objetivo de obter um instrumento auto-aplicável simples para o diagnóstico da DE facilmente utilizável por profissionais de saúde, Rosen et al. (1999) desenvolveram a versão abreviada do IIFE, composta por cinco itens (IIFE5). As cinco questões selecionadas do IIFE (quais sejam: 15, 2, 4, 5 e 7) para inclusão no IIFE-5 avaliam: 1) confiança em conseguir ter e manter ereção, 2) 
freqüência da firmeza das ereções, 3) freqüência da capacidade para manter a ereção após penetração, 4) freqüência da manutenção da ereção até o fim da relação, e 5) frequiência da satisfação na relação sexual, nos últimos seis meses de atividade sexual. Segundo Rosen et al. (1999, 2002) essa versão simplificada demonstrou possuir propriedades favoráveis para detectar a presença e a gravidade da DE.

Derby et al. (2000) compararam os resultados da aplicação da questão única com aqueles observados com o IIFE. Duzentos e cinqüenta e quatro homens responderam à questão única e ao IIFE. A correlação entre as respostas à questão única e ao escore do IIFE foi moderadamente alta (coeficiente de correlação de Spearman $=0,71)$.

Embora vários estudos para estimar a prevalência da DE tenham utilizado apenas uma única questão para avaliar a função erétil, instrumentos de pesquisa multidimensionais são considerados mais objetivos, mais válidos sob o ponto de vista psicométrico e capazes de fornecer maior potencial de uso na prática clínica (Ramanathan et al., 2007).

\subsection{Prevalência da DE}

Apesar dos inúmeros estudos epidemiológicos realizados nos mais diversos países sugerirem uma alta prevalência da DE na população, não existe um consenso acerca dessa magnitude. A grande variação dos percentuais relatados sobre a prevalência da DE pode ser decorrente de diferenças metodológicas (Prins et al., 2002; Kubin et at., 2003; Rosen et al., 2004). 
O primeiro e mais extenso estudo científico sobre a prevalência da DE foi conduzido por Kinsey et al. (1948) que entrevistaram 15.781 homens com idade entre 10 e 80 anos, oriundos de uma amostra representativa da população norteamericana estratificada por idade, instrução, atividade e domicílio. Os autores concluíram que a DE estava presente em 1\% da população masculina antes dos 19 anos, em $3 \%$ até 45 anos, 6,7\% entre 45 e 55 anos e $25 \%$ até 75 anos. Esse estudo demonstrou o aumento na prevalência da DE com o avançar da idade: a dificuldade de ereção foi referida por um em cada 50 indivíduos aos 40 anos de idade, e por um em cada quatro aos 65 anos.

Há grande variabilidade na forma de obter a informação sobre a presença da DE, mas a maioria dos estudos utiliza ou uma questão única sobre a auto-percepção do indivíduo em relação à sua capacidade erétil ou questionários padronizados para a coleta de informações, dos quais o mais conhecido e utilizado é o IIFE (Rosen et al., 1997).

\subsubsection{Prevalência da DE utilizando questão única sobre a dificuldade de} obter e/ou manter ereção

O estudo de coorte sobre envelhecimento masculino (MMAS) (Feldman et al., 1994) conduzido na cidade de Boston e arredores, cuja avaliação inicial aconteceu entre 1987 e 1989 avaliou vários aspectos da saúde masculina, dentre eles a presença da DE. Os autores apresentaram os resultados da avaliação de 1.290 homens com idade entre 40 e 70 anos e parceiras fixas. As informações desse estudo foram obtidas por meio de um questionário auto-responsivo com nove questões sobre 
a atividade sexual e a pergunta adicional para caracterizar a autopercepção do indivíduo sobre se considerar sem impotência, minimamente impotente, moderadamente impotente ou completamente impotente. Os autores mostraram que $52 \%$ dos homens referiam ter algum grau de DE - 10\% DE completa, 25\% DE moderada e $17 \%$ DE mínima -, com aumento da prevalência proporcional ao envelhecimento. Na amostra do MMAS, a probabilidade de DE completa triplicou de cinco para $15 \%$ entre indivíduos com idades entre 40 e 70 anos.

Posteriormente, Aytac et al. (2000) publicaram os resultados da avaliação de 797 participantes do MMAS que não apresentavam DE na avaliação inicial do estudo e que foram entrevistados novamente entre 1995 e 1997. A incidência da DE foi 24,4\% (IC $95 \%: 20,9 \%$ a $27,2 \%)$.

Estudo de prevalência da DE com populações de homens com idade entre 40 e 70 anos, do Brasil, Itália, Japão e Malásia foi conduzido por Nicolosi et al. (2003) no período entre outubro de 1997 e junho de 1998, utilizando a questão única sobre a autopercepção do indivíduo em ser capaz de obter e manter uma ereção adequada para uma relação sexual satisfatória (Feldman et al., 1994). A prevalência da DE moderada a completa nesse estudo, ajustada por idade, foi $34 \%$ no Japão, $22 \%$ na Malásia, $17 \%$ na Itália e 15\% no Brasil. O aumento da prevalência da DE moderada a completa em cada década da vida foi demonstrado: 9\% para os indivíduos entre 40 e 44 anos; $12 \%$ entre 45 e 49 anos; $18 \%$ entre 50 e 54 anos; $29 \%$ entre 55 e 59 anos; $38 \%$ entre 60 e 64 anos; 54\% para aqueles entre 65 e 70 anos. Foram avaliados aproximadamente 600 homens de cada país, sendo que as entrevistas foram realizadas pessoalmente com a população brasileira, por telefone na Itália, por 
telefone e pessoalmente na Malásia, e por questionários enviados aos participantes no Japão.

No Brasil, dados do primeiro estudo realizado em 1998 sobre DE, em Salvador, - incluindo uma amostra aleatória de 602 sujeitos com idade entre 40 e 70 anos, indicou que $39,5 \%$ da população masculina apresentava algum grau de DE 1,3\% DE completa, $13,1 \%$ DE moderada e 25,1\% DE mínima - com elevação da prevalência de acordo com a idade, ou seja, de 30,8\% em homens com idade entre 40 e 49 anos, $43,5 \%$ em homens com 50 a 59 anos e $56,7 \%$ em homens entre 60 e 70 anos (Moreira Junior et al., 2002). Os grupos dessa pesquisa foram retirados de relatórios de censo representativos das 16 áreas de Salvador. Cada área contribuiu proporcionalmente com sujeitos a partir da distribuição da idade dos homens por área. Entrevistadores treinados e certificados foram pessoalmente às casas indicadas no conjunto de amostras. Em cada casa, explicavam a pesquisa, identificavam o homem elegível da casa, com idade entre 40 e 70 anos. Se mais de um homem era elegível, aquele com a data de aniversário mais perto da data da entrevista era selecionado. Os sujeitos elegíveis recrutados responderam a questionário autoaplicável. A DE foi avaliada pela questão única sobre DE (Feldman et al., 1994).

Em outro estudo (Moreira Junior et al., 2001; Abdo et al., 2002), realizado em nove cidades brasileiras (São Paulo, Salvador, Porto Alegre, Rio de Janeiro, Curitiba, Santos, Recife, Belo Horizonte e Ribeirão Preto), entre fevereiro e abril de 2000, em que foram incluídos 1.170 sujeitos com 18 anos ou mais de idade, observou-se que $46,2 \%$ dos homens apresentavam algum grau de DE - 2,6\% DE completa, $12,1 \% \mathrm{DE}$ moderada e 31,5\% DE mínima. A amostra consistiu de transeuntes de lugares públicos, tais como praias, praças e parques, que aceitaram o convite de monitores da 
equipe, previamente treinados, para participar da pesquisa anônima sobre saúde, hábitos de vida e sexualidade do brasileiro, ao passarem por quiosques ocupados pelo projeto. Esse mesmo estudo revelou que, antes dos 40 anos, $60 \%$ dos sujeitos não apresentavam DE, mas para aqueles com 70 anos ou mais a percentagem dos sem DE diminuiu para 28\%. Aplicando esses resultados a toda população masculina brasileira, Moreira Junior et al. (2001) estimaram que a prevalência de DE no Brasil seria de $48,8 \%$. Para avaliar a DE foi utilizada a questão única sobre a capacidade de obter e/ou manter a ereção (Feldman et al., 1994).

No maior estudo epidemiológico sobre DE no Brasil (Moreira Junior et al., 2004), realizado entre os meses de agosto de 2002 e janeiro de 2003, 71.503 homens, com 18 anos ou mais de idade, aceitaram participar de uma pesquisa sobre DE, ao serem atendidos em consulta médica de rotina em consultórios e serviços de saúde de 380 cidades brasileiras. Para a avaliação da DE foi utilizada a questão única sobre a capacidade de obter e/ou manter a ereção (Feldman et al., 1994). Do total de participantes nesse estudo, 53,5\% reportaram algum grau de DE. As prevalências de DE mínima, moderada e completa foram, respectivamente, $20,8 \%, 26,3 \%$ e $6,4 \%$. A freqüência de DE moderada e completa aumentou com a idade, passando de 8,8\% e 1,5\%, respectivamente, em indivíduos com menos de 40 anos, para 46,7\% e $26,1 \%$ entre homens com 70 anos ou mais.

O Estudo da Vida Sexual do Brasileiro (EVSB) (Abdo, 2004; Abdo et al., 2006), realizado entre novembro de 2002 e fevereiro de 2003, incluindo uma amostra de 7.022 indivíduos acima de 18 anos (54,6\% de homens e 45,4\% de mulheres), de 13 estados do país - Bahia, Ceará, Goiás, Mato Grosso do Sul, Minas Gerais, Pará, Paraná, Pernambuco, Rio de Janeiro, Rio Grande do Norte, Rio Grande do Sul, Santa 
Catarina e São Paulo -, mensurou hábitos de vida e tendências, preferências, práticas e dificuldades sexuais da população brasileira. Nesse estudo, as condições de saúde geral e de qualidade de vida, acompanhadas das respectivas variáveis sóciodemográficas, também foram avaliadas. A amostra desse estudo foi composta por transeuntes de praças, parques, shoppings centers e ruas que, ao depararem com o stand, identificado por um banner, com o nome e o logotipo do ProSex do Instituto de Psiquiatria do Hospital das Clínicas da Faculdade de Medicina da USP, mostraram-se receptivos a participar. Um total de 2.862 homens respondeu à questão sobre DE (Abdo, 2004; Abdo et al., 2006). Para avaliar a capacidade erétil foi utilizada a questão única do MMAS (Feldman et al., 1994).

A média nacional da presença da DE revelada por esse estudo foi $45,1 \%$ (sendo 31,2\% DE mínima, 12,2\% DE moderada e 1,7\% DE completa). A proporção de DE, por faixa etária, encontrada pelo EVSB (Abdo, 2004), em 2.832 indivíduos com idade conhecida, apontou:

- 34,4\% de DE mínima, $10,7 \%$ de DE moderada e 1,1\% de DE completa na população entre 18 e 25 anos;

- 30,8\% de DE mínima, $11,5 \%$ de DE moderada e $0,7 \%$ de DE completa na população entre 26 e 30 anos;

- $30,5 \%$ de DE mínima, 9,0\% de DE moderada e 1,3\% de DE completa na população entre 31 e 40 anos;

- $28,8 \%$ de DE mínima, $10,1 \%$ de DE moderada e 1,3\% de DE completa na população entre 41 e 50 anos;

- $32,1 \%$ de DE mínima, $15,8 \%$ de DE moderada e 1,8\% de DE completa na população entre 51 e 60 anos; 
-31,7\% de DE mínima, 25,5\% de DE moderada e 8,3\% de DE completa na população entre 61 e 70 anos;

-20,8\% de DE mínima, 35,4\% de DE moderada e 10,4\% de DE completa na população acima de 70 anos.

Esses dados confirmam o crescimento da prevalência da DE moderada e completa com o aumento da idade, enquanto que a prevalência da DE mínima tende ao decréscimo, conseqüentemente.

Outros estudos também utilizaram apenas uma questão para avaliar DE, mas com formulações diferentes daquela proposta pelo MMAS. Chew et al. (2000) conduziram um estudo em que 62 médicos generalistas da área metropolitana de Perth, Austrália, solicitaram a até 50 pacientes de sexo masculino com idade de 18 anos ou mais consecutivamente atendidos que respondessem à seguinte questão: "Você tem problema para obter e/ou manter a sua ereção?" - sendo que quando a resposta era afirmativa, o participante respondia há quanto tempo e se o problema ocorria ocasionalmente, freqüentemente ou sempre. Foram incluídos 1.240 homens e o estudo mostrou que $39,4 \%$ dos respondentes apresentavam DE $(9,6 \%$ ocasionalmente; $8,9 \%$ freqüentemente; $18,6 \%$ sempre [DE completa], sendo que 2,3\% não souberam definir o grau do seu problema). A prevalência da DE completa aumentou de 2,0\% nos indivíduos com idade entre 40 e 49 anos para 44,9\% naqueles que tinham entre 70 e 79 anos de idade.

Na América Latina, o estudo DENSA, realizado na Colômbia, Equador e Venezuela por Morillo et al. (2002), no período entre maio e outubro de 1998, com 1.946 homens com 40 anos ou mais, utilizando uma questão para avaliar a função erétil mostrou uma prevalência total de 53,4\% de DE (33,6\% DE leve; 16,2\% DE 
moderada; 3,2\% DE completa). Esses autores demonstraram que a prevalência da DE completa aumentou acentuadamente entre os homens com idade superior a 79 anos $(31,9 \%)$ e entre 70 e 79 anos (17,2\%) em comparação àqueles com idade compreendida entre 40 e 49 anos $(<3 \%)$. Os grupos desse estudo foram retirados de relatórios de censo representativos de cada país. Os indivíduos das áreas selecionadas só foram efetivamente convidados a participar do estudo após uma semana de anúncios veiculados pela mídia com o intuito de sensibilizar a população sobre saúde sexual masculina e promover a importância desse estudo.

O estudo Men's Attitudes to Life Events and Sexuality (MALES) conduzido por Rosen et al. (2004) entre fevereiro e abril de 2001, envolveu 27.839 homens com idade entre 20 e 75 anos de oito países: Estados Unidos, Reino Unido, Alemanha França, Itália, Espanha, México e Brasil, que foram entrevistados utilizando-se um questionário padronizado, aplicado por telefone. Uma das partes do questionário perguntava sobre a presença de várias doenças comuns em homens, dentre elas DE, e se os homens haviam procurado alguma forma de tratamento.

A prevalência da DE nesse estudo foi $16 \%$ para os oito países em conjunto. A comparação entre os países indicou uma maior prevalência da DE nos Estados Unidos (22\%) e menor na Espanha (10\%). A prevalência da DE na França foi 11\%; no Reino Unido, na Alemanha e, na Itália, 13\%; no Brasil e no México, 14\%. O aumento da prevalência da DE com o avançar da idade também foi demonstrado: $11 \% ; 15 \% ; 22 \% ; 30 \%$ e $37 \%$ entre os indivíduos com idades entre 30 e 39, 40 e 49, 50 e 59, 60 e 69,70 e 75 anos, respectivamente.

Um estudo populacional representando várias regiões do mundo, o Global Study of Sexual Attitudes and Behaviors (GSSAB) (Laumann et al., 2005) - que 
investigou homens e mulheres de meia-idade e mais velhos sobre atividade sexual, prevalência de problemas sexuais e procura por ajuda para tratá-los -, incluiu 13.618 homens com idade entre 40 e 80 anos, de 29 países. No Brasil, o estudo foi conduzido por Moreira Junior et al. (2005), no período entre 2001 e 2002, sendo que as entrevistas foram baseadas em um questionário padronizado e realizadas por telefone (discagem aleatória). Foi perguntado aos participantes se eles haviam tido relações sexuais nos últimos 12 meses e se haviam apresentado algum problema sexual nos dois meses anteriores à entrevista. Os problemas sexuais, dentre eles a DE, estavam organizados em uma lista e quando o participante relatava ter apresentado algum deles, relatava também se havia sido ocasionalmente, às vezes ou freqüentemente. Foram contatadas 8.637 pessoas, das quais 2.127 não eram elegíveis para participar (por estarem fora da faixa etária). Dos 6.510 indivíduos elegíveis, 5.088 recusaram-se a participar quando o tema do estudo foi informado, e 223 interromperam a entrevista. Um total de 1.199 indivíduos (471 homens e 728 mulheres) completou o estudo, o que representou uma taxa global de resposta de 18,4\%. Do total de homens nessa amostra, 13,1\% relataram dificuldades de ereção, sendo que em 9,8\% ocorria com freqüência ou periodicamente.

\subsubsection{Prevalência da DE, utilizando o IIFE e o IIFE-5}

Foi conduzido um estudo para estimar a prevalência da DE em uma pequena cidade da região Sudeste do Brasil, Poços de Caldas, entre maio de 1998 e março de 1999 (Lopes, 2000). Poços de Caldas tinha uma população, na época de realização do estudo, de 121.831 habitantes: 60.117 (51\%) mulheres, 56.977 (49\%) homens, 
sendo que $63 \%$ da população masculina encontrava-se com idade igual ou superior a 20 anos. A seleção da amostra foi realizada de acordo com as seguintes normas: (1) divisão da zona urbana em quatro regiões: norte, sul, leste e oeste; (2) realização de um sorteio dos bairros de cada zona urbana, obtendo-se $25 \%$ dos bairros de cada região; (3) escolha de 10 ruas de cada bairro através de sorteio aleatório; e (4) entrevistas conduzidas por um único pesquisador com todos os homens, com idade igual ou superior a 20 anos, residentes em todas as casas localizadas na mesma rua. Esse estudo investigou 2.000 homens, por meio de entrevista padronizada, quanto aos aspectos gerais de condições de habitação e saúde. Os entrevistados que apresentaram queixa de DE foram avaliados pelo (IIFE) (Rosen et al., 1997). Do total de indivíduos nessa amostra, $34(1,7 \%)$ referiram DE e tiveram a seguinte classificação pelo IIFE: quatro (12\%) DE leve; 10 (29\%) DE leve a moderada; sete (20\%) DE moderada; e 13 (38\%) DE completa (Lopes, 2000).

Estudo realizado por Teles et al. (2008), no período entre julho de 2004 e janeiro de 2005, com 3.548 homens portugueses selecionados em 50 centros de saúde primária, com idade entre 40 e 69 anos, utilizando o IIFE (Rosen et al., 1997), mostrou que a prevalência da DE ajustada por idade foi $48,1 \%$; sendo $35,0 \% \mathrm{DE}$ leve, 9,0\% DE moderada, 4,0\% DE completa. O aumento da prevalência da DE com a idade também foi demonstrado nesse estudo: $29 \%, 50 \%$ e $74 \%$ em homens com idade entre 40 a 49 anos, 50 a 59 anos e 60 a 69 anos, respectivamente.

Walz et al. (2008) investigaram a prevalência da DE em 1.134 homens canadenses, com idade entre 40 e 89 anos, participantes de um programa de conscientização do Câncer de Próstata que ocorreu durante dois dias no mês de março de 2006, utilizando o IIFE (Rosen et al., 1997). Esse estudo mostrou que 50\% 
dos indivíduos apresentavam algum grau de DE: $8,8 \%$ DE leve; 10,4\% DE leve a moderada; 9,4\% DE moderada; $21,4 \%$ DE completa. O aumento da prevalência de algum grau de DE entre os homens mais velhos também foi demonstrado: $<50$ anos (34,1\%); 60-69 anos (69,7\%); acima de 80 anos $(88,6 \%)$.

Rhoden et al. (2002) conduziram um estudo que incluiu 965 sujeitos, com idade entre 40 e 90 anos, que participaram de um programa intitulado "Semana de Conscientização do Câncer de Próstata do Hospital Santa Casa”, em Porto Alegre, Brasil, de 26 a 30 de julho de 1998, e que concordaram em responder ao IIFE-5. Os autores demonstraram os seguintes resultados obtidos: 53,9\% dos indivíduos apresentavam algum grau de DE, sendo 11,9\% DE completa, 6,3\% DE moderada, $14,1 \%$ DE leve a moderada e $21,5 \%$ DE leve. Também foi possível constatar a alta prevalência da DE em homens acima de 40 anos reiterando os estudos que mostram que essa condição tem uma nítida relação com o envelhecimento.

Ponholzer et al. (2005) avaliaram a prevalência da DE em 2.869 homens austríacos com idade entre 20 e 80 anos, utilizando o IIFE-5 (Rosen et al., 1999). A amostra para esse estudo foi constituída por voluntários que participaram de um estudo sobre saúde na área municipal de Viena. Os autores mostraram que 32,2\% dos homens referiram algum grau de DE, quais sejam: 23,7\% DE leve; 5,0\% DE leve a moderada; $2,2 \%$ DE moderada e 1,3\% DE completa. Uma correlação positiva entre DE e idade foi observada nesse estudo.

Chew et al. (2008) investigaram a prevalência da DE em 1580 homens australianos, com idade entre 20 e 80 anos ou mais, utilizando o IIFE-5 (Rosen et al., 1999). Os questionários sobre DE e fatores sócio-demográficos foram encaminhados 
pelo correio para amostras representativas de homens que residiam na área metropolitana de Perth e fora dela para garantir sua representação proporcional. A prevalência da DE entre os participantes desse estudo foi $40,3 \%$, sendo que $21,2 \%$ relataram DE completa. Os autores demonstraram que tanto a prevalência quanto o grau da DE aumentaram significativamente com a idade, especialmente entre os indivíduos acima de 50 anos.

A combinação de parâmetros para estimar a prevalência da DE também tem sido objeto de estudo. Martin-Morales et al. (2001) utilizaram dois critérios para detectar a DE em estudo com 2.476 homens espanhóis não institucionalizados, com idade entre 25 e 70 anos, entrevistados entre março de 1998 e março de 1999. O primeiro foi uma questão única relacionada à autopercepção do indivíduo sobre considerar-se: (a) sem problema de ereção; (b) com incapacidade mínima; (c) com incapacidade moderada; (d) com incapacidade grave/completa de ereção. O segundo critério foi a pontuação das respostas que compreendem a função erétil do IIFE (Rosen et al., 1997). Esse estudo mostrou que 12,1\% dos homens apresentaram algum grau de DE (5,2\% DE leve; 5,0\% DE moderada; 1,9\% DE completa) quando foi utilizada a questão única sobre autopercepção da capacidade erétil enquanto a prevalência da DE com a aplicação do IIFE foi 18,9\%, sendo 16,2\% DE leve; $2,1 \%$ DE moderada; $0,6 \%$ DE completa.

Wu et al. (2007) compararam a prevalência da DE auto-referida e DE detectada pelo IIFE-5 (Rosen et al., 1999), em uma pesquisa realizada por telefone com 990 homens chineses com idade acima de 40 anos. Nesse estudo, a DE autoreferida foi identificada por meio de um questionamento direto: "Você acha que tem 
DE?", e pela avaliação da função sexual no mês anterior utilizando-se o instrumento IIFE-5. Do total dos respondentes, 13,1\% referiram DE, enquanto o IIFE-5 detectou que $26,0 \%$ tinham DE, sendo $23,8 \%$ DE leve, 1,4\% DE moderada, 0,8\% DE completa. Dos 13,1\% que referiram DE, 26,2\% não apresentavam DE de acordo com a pontuação do IIFE-5; por outro lado, dentre os homens que não relataram DE ao responderem a questão, 18,0\% apresentavam DE leve e $0,8 \%$ tinham DE moderada a completa, usando o IIFE-5. O estudo também mostrou que a prevalência de ambas, DE auto-referida e DE definida pelo IIFE-5, aumentou com a idade, com a prevalência de DE definida pelo IIFE-5 significativamente maior do que a DE autoreferida em cada um dos quatro grupos etários dessa pesquisa (40 a 49, 50 a 59, 60 a 69, e com mais de 70 anos).

\subsection{Tratamento da DE}

No que tange à avaliação e ao tratamento da DE, foram as descobertas de Virag (1982) e Brindley (1983) que permitiram a utilização de fármacos intracavernosos para provocar e avaliar a qualidade e duração das ereções em laboratório.

Esse foi um marco para o aumento das investigações das bases anátomofuncionais da ereção e da fisiopatologia da DE. A partir desse momento os mesmos fármacos passaram a ser considerados úteis no tratamento da DE (Brindley, 1986), proporcionando uma resposta erétil efetiva para a maioria dos pacientes (Jünemann, Alken, 1989) e uma alternativa para o implante de prótese peniana. 
As primeiras tentativas de implante de prótese peniana datam de 1936 e tiveram origem nas reconstruções plásticas do pênis após amputação. Bogoras (1936) inseriu um fragmento de cartilagem costal em um pênis recém reconstituído com o propósito de capacitá-lo para a penetração vaginal.

No entanto, essa alternativa não foi bem sucedida porque a cartilagem acabou sendo reabsorvida após algum tempo. A evolução histórica das próteses penianas apontou para a necessidade do desenvolvimento técnico de materiais aloplásticos biocompatíveis, associados a modelos anatômicos que, em conjunto, permitissem resultado cosmético e funcional satisfatórios, longa duração para os tecidos subjacentes, através de técnicas cirúrgicas precisas que pudessem evitar efeitos colaterais (Reis et al., 1993).

A popularização das próteses penianas ocorreu na década de 70 , especialmente com o advento das próteses inflável e semi-rígida siliconizada, para implantação no interior de cada corpo cavernoso (Scott et al., 1973; Small et al., 1975).

O dispositivo de vácuo foi outro recurso utilizado no tratamento da $\mathrm{DE}$, popularizado na década de 70, quando surgiu o primeiro relato na literatura e, então, foi aceito pela comunidade médica (Nadig et al., 1986). Esse procedimento consiste em bombas de vácuo e anel de constrição que mantêm a ereção através do bloqueio mecânico da drenagem venosa, permitindo o intercurso sexual.

A revascularização arterial foi um procedimento cirúrgico utilizado também nesse período para tratar a $\mathrm{DE}$, cujo intuito era aumentar a pressão sangüínea no pênis. Muito embora as primeiras divulgações dessa técnica tenham gerado expectativa no meio cirúrgico, as discussões sobre a probabilidade de sucesso, 
indicações e possibilidade de resolução do problema em longo prazo com esse método não foram apaziguadas durante um bom período de tempo. Com isso, foi possível constatar que o baixo índice de resultados positivos em longo prazo não justificava a indicação de uma técnica desse porte para o tratamento da DE (PuechLeão, 2002).

O MUSE® (Medicated Urethral System for Erection), um dispositivo capaz de liberar um supositório de prostaglandina (Alprostadil) dentro da uretra masculina, aprovado para o uso nos Estados Unidos, no final de 1996, pelo Food and Drug Administration (FDA), também provocou expectativas por parte de pacientes e médicos (Torres, Glina, 2002). Apesar de ter sido considerada a primeira terapêutica pouco invasiva para induzir a ereção, com o tempo constatou-se que a resposta efetiva que permite a penetração vaginal com o MUSE® acontecia em menos de $30 \%$ dos pacientes (Torres, Glina, 2002).

A revolução no diagnóstico e tratamento da DE só ocorreu em 1998 (Sharlip, 1998), com o advento de uma terapia oral efetiva, o citrato de sildenafil (Viagra ${ }^{\circledR}$ ), que atua como facilitador do processo de ereção ao provocar o relaxamento da musculatura lisa dos corpos cavernosos.

Glina (2002) classifica as formas de tratamento para DE em curativas e paliativas. Para o autor, as primeiras visam a restauração definitiva da ereção através da correção ou suspensão de fatores causais - medicamentos, tabaco etc. -, psicoterapia, próteses penianas, reposição hormonal e restaurações vasculares.

Já as terapêuticas paliativas visam a oferecer uma ereção adequada no momento da relação sexual através de comprimidos orais, injeções intracavernosas 
de drogas vasoativas, supositório intra-uretral de prostaglandina E1 e a vacuoterapia, utilizadas pelo paciente em cada oportunidade de envolvimento sexual.

A ênfase desse autor é colocada no esclarecimento ao paciente das opções terapêuticas e nas informações sobre as vantagens e desvantagens de cada uma delas.

Do ponto de vista psicoterapêutico, o tratamento das disfunções sexuais conta com uma vasta trajetória que serviu de campo de testes para as terapias cognitivocomportamentais (Carey, 2003). Entretanto, as bases empíricas do tratamento cognitivo-comportamental das disfunções sexuais foram constituídas pela pesquisa e os escritos de Kinsey e seus colaboradores (Kinsey et al., 1948, 1953), assim como por Masters e Johnson $(1966,1970)$. O campo da terapia sexual se firmou e vem prosperando desde a publicação de $A$ inadequação sexual humana (Human sexual inadequacy) por Masters e Johnson (1970). Trabalhos posteriores desenvolvidos por LoPiccolo et al. $(1978,1988)$, Leiblum e Rosen $(1988,1991)$ e por outros autores aperfeiçoaram os procedimentos cognitivo-comportamentais sobre os quais muitos terapeutas concordam que constituem o tratamento preferencial para as disfunções sexuais (Carey, 2003).

O pressuposto básico da terapia cognitiva é que as emoções e os comportamentos são influenciados pela percepção que as pessoas têm dos acontecimentos (Beck, 1997), sendo que a terapia cognitivo-comportamental das disfunções sexuais refere-se ao emprego de técnicas comportamentais já consagradas, mas com ênfase nos aspectos cognitivos do problema que a pessoa enfrenta. Essa abordagem considera o comportamento sexual como resultado de 
interações complexas que envolvem aspectos do casal, individuais, familiares e socioculturais (Tess, Pugliese, 1998).

O psicólogo especialista no tratamento das disfunções sexuais não trata dos aspectos orgânicos da DE, mas ao cuidar da estrutura emocional do indivíduo tem que considerar que "a função sexual normal é um processo biopsicossocial baseado no equilíbrio dos fatores psicológicos, endócrinos, vasculares e neurológicos" (Levine, 2000).

Entre os fatores psicossociais-chave que podem predispor ou manter a DE (Carey, 2003), encontram-se o déficit em habilidades, isto é, não saber proporcionar e/ou mostrar afeto na relação; o roteiro sexual disfuncional, cuja dificuldade para reconhecer e negociar preferências sexuais impede a satisfação a dois; o padrão muito alto para a "atuação sexual" que pode inibir a resposta de ereção normal; o conflito no relacionamento a dois, muitas vezes decorrente da falta de privacidade ou de atração, ou ainda devido ao clima de hostilidade na relação a dois; e os mitos ou crenças disfuncionais, como por exemplo, entre os homens mais velhos que acreditam que os jogos eróticos são para os “jovens”, ou que o coito é a única forma verdadeira de sexo. A partir disto, Carey (2003) descreve os seguintes eixos norteadores para o tratamento cognitivo-comportamental das disfunções sexuais: educação, reestruturação cognitiva, treinamento em habilidades, treinamento em comunicação, roteiros sexuais e prevenção de recaídas, conforme explicados abaixo.

A educação, no sentido de melhorar o conhecimento acerca da sexualidade, é considerado o procedimento mais freqüente na terapia sexual. São oferecidas informações básicas, como por exemplo, sobre o ciclo da resposta sexual e diferenças de gênero nas experiências e preferências sexuais, sobre as mudanças 
normais no funcionamento feminino e masculino devido ao envelhecimento ou sobre o uso de medicamentos.

A reestruturação cognitiva visa à superação de sentimentos perturbadores que acompanham o indivíduo. Para alcançar o objetivo de ter uma vida sexual satisfatória, faz-se necessário estabelecer alguns objetivos preliminares que servem de "trampolins" para atingir o objetivo mais avançado, como por exemplo, estar à vontade com a própria sexualidade, reservar mais tempo para a expressão sexual ou eliminar as pressões da atuação que podem interferir na resposta sexual.

O treinamento em habilidades tem como objetivo a diminuição da ansiedade ante a atuação sexual. Um exemplo são as técnicas de Focalização sensorial nãogenital e genital desenvolvidas por Masters e Johnson (1970) e aperfeiçoadas por vários autores. São exercícios sexuais graduais não ameaçadores que visam o desenvolvimento de uma expressão sexual mais ampla e criativa e que permitem que o indivíduo reaprenda os fundamentos de ser afetivo e de dar e receber prazer.

O treinamento em comunicação compreende o desenvolvimento da intimidade do casal para falar sem constrangimentos sobre os problemas comuns. É sempre possível que os problemas que ocorrem na vida sexual do casal sejam silenciados por uma dificuldade de comunicação, comprometendo todas as experiências compartilhadas. A discussão saudável dos problemas sexuais é essencial para a conquista do bem-estar na relação a dois.

$\mathrm{O}$ roteiro sexual refere-se à avaliação quanto às restrições, repetitividade ou inflexibilidade na abordagem íntima do casal, que interferem negativamente no desempenho sexual. A renovação do roteiro sexual do casal é um estímulo para expressar preferências e negociar compromissos que sejam aceitáveis para ambos. 
Finalmente, a prevenção de recaídas visa a preparar o indivíduo para o futuro a partir de todas as experiências vividas com êxito durante o processo psicoterapêutico, ou seja, o reconhecimento da variabilidade inerente às experiências sexuais e a compreensão de que a variabilidade não representa necessariamente um sinal de fracasso ou incompatibilidade otimizam a probabilidade de que as melhoras terapêuticas se mantenham ao longo do tempo (McCarthy, 1993).

Das descobertas de Virag (1982) e Brindley (1983) até o presente momento, houve uma ampliação do conhecimento sobre a fisiologia da resposta erétil disfuncional e da oferta de alternativas para tratar a $\mathrm{DE}$, de acordo com a preferência, tolerabilidade, eficácia e segurança de cada paciente.

Segundo Althof (2002), com as diferentes opções disponíveis para restaurar a função erétil nos dias atuais, proporcionar ereção aos homens tornou-se relativamente simples. Porém, o autor chama a atenção para as baixas taxas de eficácia e continuidade de tratamento dessa condição (em relação às taxas de interrupção dos tratamentos médicos disponíveis, incluindo o citrato de sildenafil, os estudos mostram em torno de $50 \%$ a $60 \%$ ). De acordo com esse autor, a elevada proporção de ineficácia ou descontinuidade nos tratamentos oferecidos para a DE indica que a intervenção médica focada apenas no restabelecimento da função erétil pode não ser suficiente para o indivíduo retomar a atividade sexual devido às possíveis causas de resistência psicológica - como por exemplo: (1) período de tempo que o casal ficou assexuado antes de procurar tratamento; (2) a abordagem do homem na retomada da vida sexual com a parceira; (3) a expectativa masculina em relação à mudança que uma medicação eretogênica vai provocar em sua vida; (4) a 
disposição física e emocional da parceira para retomar o relacionamento sexual; (5) o significado, para cada um dos parceiros, da intervenção médica oferecida para restaurar a ereção; (6) a qualidade do relacionamento global do casal; e (7) padrões não convencionais de excitação sexual no homem. $O$ autor pondera que a significativa demora em procurar tratamento para a DE pode propiciar o desenvolvimento de sentimentos de inadequação, ansiedade de desempenho, ressentimentos e, possivelmente, depressão. Por medo do fracasso sexual, o comportamento típico do homem com DE é o de evitar a parceira, o que costuma acarretar desdobramentos dramáticos na vida do casal e na auto-estima da parceira. Diante desse cenário, Althof (2002) salienta que a interrupção - ou ineficácia -, do tratamento da DE pode ser considerada como o resultado final de um longo processo que teve início muito antes do indivíduo procurar ajuda profissional, daí a importância das terapêuticas combinadas se constituírem uma regra, e não exceção, no tratamento do indivíduo com DE.

\subsection{Panorama da DE}

Atualmente, a DE é considerada uma importante questão de saúde pública, tendo em vista a sua representativa prevalência. No Brasil, estima-se cerca de 25 milhões de homens com algum grau de $\mathrm{DE}$, dos quais 11 milhões apresentam $\mathrm{DE}$ moderada ou completa (Moreira Junior et al., 2001, 2003). Projeções para 2025, realizadas a partir do MMAS, indicam em torno de 322 milhões de homens no mundo com $\mathrm{DE}$, sendo que as maiores taxas de prevalência deverão ocorrer nos 
países em desenvolvimento, como os da África, Ásia e América do Sul (Aytac et al., 1999).

Bertero (2004) menciona em artigo virtual intitulado Impacto econômico da disfunção erétil, que alguns estudos populacionais indicam que apenas $10 \%$ dos homens com DE procuram ajuda médica.

Além disso, tradicionalmente médicos e outros profissionais de saúde não costumam investigar a qualidade da vida sexual de seus pacientes. Moreira Junior et al. (2004) demonstraram que $73 \%$ dos homens incluídos em seu estudo sobre a prevalência da DE (avaliados quando atendidos em consulta médica de rotina em consultórios e serviços de saúde de 380 cidades brasileiras) negaram ter sido questionados sobre a presença de problemas sexuais durante uma consulta médica de rotina nos últimos três anos. Constatou-se, também, que $81 \%$ dos pacientes consideraram que a avaliação sobre possíveis problemas sexuais deveria fazer parte de toda anamnese e $78 \%$ não sentiriam constrangimento em discutir tais problemas com seu médico.

Alguns fatores têm sido demonstrados repetidamente nos estudos populacionais da DE: sua alta prevalência e aumento da incidência proporcional ao envelhecimento.

Sabe-se que dificuldades de ereção podem ocorrer em homens de qualquer idade ou região do mundo. $\mathrm{O}$ que se contempla com o avanço da idade são os riscos de os indivíduos contraírem enfermidades, tornando a função sexual vulnerável às alterações dessa natureza. Além disso, é no período entre os 40 e 60 anos de idade 
que o homem "descobre" que o seu pênis não terá mais a mesma capacidade de enrijecer-se como quando era um jovem de 25 anos (Kusnetzoff, 1987).

Mascaro (2004) afirma que o envelhecimento fisiológico, que é implacável na velhice, está relacionado com as mudanças que ocorrem no organismo como um todo e começam a se tornar evidentes por volta dos 40 anos de idade. No entanto, o que mais aflige o idoso é a associação preconceituosa que ele faz da velhice com doença, fragilidade ou dependência, quando as doenças que ocorrem com o avançar da idade podem ser prevenidas, diagnosticadas e tratadas.

Os primeiros resultados do Estudo Populacional do Envelhecimento (EPE) (Abdo, Abdo, 2007), realizado com 10.161 indivíduos (56,6\% homens e 43,4\% mulheres), habitantes de 18 capitais brasileiras, com idade igual ou superior a 40 anos, sendo que $82,3 \%$ dos homens tinham entre 40 e 60 anos, mostraram que o envelhecimento masculino no Brasil conduz a prejuízo da função sexual, sintomas geniturinários e síndrome metabólica. Entre os resultados mostrados por esse estudo, cabe destacar que $16,2 \%$ dos homens do total amostra eram obesos e 50,3\% tinham sobrepeso. O medo de ficar doente devido à idade era a preocupação de 49,8\% dos respondentes dessa pesquisa.

Nas sociedades contemporâneas, estamos assistindo a um alongamento da esperança de vida alcançado por vários fatores, dentre os quais destacam-se o aumento da rede de saneamento básico, os avanços dos recursos médicos e ampliação do acesso a esses recursos, a melhoria das condições nutricionais e de qualidade de vida.

Em contrapartida, o sexo masculino não tem tradição de cuidado com sua saúde (Abdo, Abdo, 2007). Em relação à DE, o que se constata atualmente é a 
existência de inúmeras formas de tratá-la. No entanto, o que os estudos mostram é uma pequena proporção de homens que procuram ajuda profissional para tratar essa condição (Laumann et al., 2005; Moreira Junior et al., 2005). Além disso, o homem que procura ajuda médica, demora em média três a quatro anos entre o início da DE e a efetiva consulta (Glina, 2002a).

Para Schiavi et al. (1995), embora o declínio progressivo da atividade sexual seja universal para homens e mulheres, muitas pessoas mantêm ou têm até aumentados o interesse e atividade sexual, a menos que ocorra, principalmente, a falta de desejo e a DE.

Chvaicer (2005) enfatiza que não existe uma DE que seja específica do idoso, mas uma diminuição da sua capacidade sexual global, que com o conhecimento e consciência das mudanças que ocorrem em seu organismo, e dos meios disponíveis para manter a sua saúde, a satisfação sexual pode ser preservada. 
2. JUSTIFICATIVA 


\section{Justificativa}

A DE é hoje encarada como uma importante questão de saúde pública, dada a sua alta prevalência e sua associação com sofrimento psíquico e com importantes causas de morbimortalidade masculina, tais como diabetes mellitus, hipertensão arterial sistêmica, aterosclerose (doença arterial crônica coronária, doença arterial crônica periférica, doença arterial crônica cerebral). Os estudos conduzidos no Brasil para estimar a prevalência da DE na população incluíram grandes amostras de homens em diferentes regiões brasileiras. Todavia, os sujeitos selecionados para estes estudos foram usuários de serviços de saúde (possivelmente com quadros clínicos ou em uso de medicações associadas à presença da DE) ou voluntários que aceitaram participar de estudos sobre a sexualidade e que possivelmente o fizeram por apresentarem DE ou por estarem mais preocupados com sua atividade sexual. Faz-se necessário um estudo com população de homens considerados hígidos para estimar a prevalência e a gravidade da DE e a autopercepção em relação a essa condição. 
3. OBJETIVOS 


\section{Objetivos}

\subsection{Geral}

Estimar a prevalência da DE em homens heterossexuais, doadores de sangue, com idade entre 40 e 60 anos, bem como detectar os fatores associados a essa disfunção.

\subsection{Específicos}

a) Estimar a prevalência da DE em homens heterossexuais doadores de sangue, por meio do IIFE.

b) Avaliar a percepção da DE (ou a prevalência da DE referida) entre os mesmos indivíduos.

c) Avaliar a proporção destes homens que procura tratamento para a DE.

d) Investigar a associação entre $\mathrm{DE}$ e fatores socioeconômicos, demográficos, comportamentais e de saúde nestes sujeitos. 
4. MÉTODOS 


\section{Métodos}

\subsection{Desenho do estudo}

Foi conduzido um estudo de corte transversal (Hennekens, Buring, 1987) para estimar a prevalência da DE em homens com idade entre 40 e 60 anos e estudar as associações entre DE e fatores socioeconômicos, demográficos, comportamentais e de saúde nestes sujeitos.

\subsection{Casuística}

O presente estudo foi desenvolvido tendo como participantes doadores de sangue, por serem indivíduos considerados saudáveis, mas que podem apresentar algum grau de DE ou fatores de risco para DE, sem buscarem tratamento para sua causa e sintomas.

A amostra para esse estudo foi constituída a partir dos doadores do Banco de Sangue (Hemotech) do Hospital Bandeirantes, na cidade de São Paulo. Decidiu-se por coletar os dados da pesquisa em um banco de sangue devido ao pré-requisito, ou seja, saúde preservada para esse tipo de procedimento e também pela provável disponibilidade que os doadores teriam em responder questionários contendo itens de caráter íntimo, característicos desta pesquisa.

Em geral, os doadores de sangue submetem-se voluntariamente à investigação dos rigorosos critérios que regulam uma doação de sangue, determinados por normas técnicas do Ministério da Saúde com o intuito de proteger 
o doador e a segurança de quem vai receber o sangue (Brasil, 2004). O período de coleta foi de janeiro de 2006 a julho de 2007.

\subsection{Critérios de inclusão}

Foram incluídos todos os doadores do sexo masculino com idade entre 40 e 60 anos, considerados hígidos por avaliação médica para doação de sangue, que tivessem orientação heterossexual, parceira estável há pelo menos seis meses (para garantir um período de tempo mínimo de interação sexual dos indivíduos com as respectivas parceiras), nível de instrução compatível com resposta a questionários auto-responsivos (isto é, ter completado até a $4^{\mathrm{a}}$ série do ensino fundamental), e que concordassem em participar da pesquisa, através de Termo de Consentimento Livre e Esclarecido (ANEXO A).

Esta faixa etária foi considerada porque, segundo a literatura, a prevalência da DE aumenta consideravelmente em homens acima de 40 anos (Feldman et al., 1994; Melman, Gingell, 1999; Moreira Junior et al., 2001; Abdo et al., 2002; Hauri, 2003; Kubin et at., 2003; Abdo, 2004; Laumann et al., 2005). Foi instituída a idade máxima de 60 anos, pois acima desse limite os indivíduos costumam apresentar mais problemas de saúde que a população geral (Garrido, Menezes, 2002), o que definiria uma outra população de estudo. 


\subsection{Critérios de exclusão}

Foram considerados os seguintes critérios de exclusão: demonstrar incapacidade para compreender ou responder aos questionários, uso de medicamentos que interferissem na função sexual (diuréticos, antidepressivos e antihipertensivos, entre outros) e doenças físicas ou psiquiátricas que limitassem a participação no estudo.

Foi perguntado aos participantes se eles faziam ou fizeram uso de medicamento para obter ereção, uma vez que havia o interesse em estimar a prevalência de uso desses medicamentos. Entretanto, os respondentes que fizeram uso de tais medicações foram excluídos das análises estatísticas posteriores, para evitar viés nos resultados obtidos, pois esses indivíduos poderiam ter sido ou serem portadores de DE, mas com sintomas minimizados ou mascarados pelo uso da medicação.

\subsection{Tamanho de amostra}

O tamanho da amostra foi estimado, por estudo estatístico, com base em um estudo-piloto conduzido pela pesquisadora com 38 pacientes acima de 40 anos atendidos no ProSex para avaliar a associação entre DE e condição profissional (ativo ou inativo). Dezesseis homens eram inativos profissionalmente e 22, ativos, o que representa uma razão entre o número de profissionais inativos e ativos igual a 0,72. Foram encontradas prevalências de DE (moderada ou completa) entre homens ativos e inativos profissionalmente de $36,4 \%$ e $62,5 \%$, respectivamente. 
Para o cálculo de tamanho da amostra foram utilizados valores de prevalência um pouco mais conservadores do que esses (40\% e 60\%) e testados vários valores da razão entre o número de profissionais ativos e inativos (entre 0,70 e 0,30), assumindo que se esperava encontrar uma associação significante entre DE e condição profissional na população com um poder do teste de 0,80 e $\alpha=0,05$. O tamanho final da amostra, considerando a razão entre o número de profissionais ativos e inativos que levasse ao maior número de sujeitos a ser incluído (0,30), foi de 300 indivíduos.

\subsection{Questionários}

\subsubsection{Ficha de identificação}

Através da ficha de identificação (ANEXO B) foram coletadas as seguintes informações: idade, raça/cor, nacionalidade, naturalidade, estado civil, escolaridade, renda mensal, afiliação religiosa e condição profissional. Além disso, foram solicitadas as informações sobre peso e altura, com o propósito de obter o Índice de Massa Corporal (IMC), que é uma medida internacional usada para detectar obesidade. O método de cálculo, de acordo com a definição da Organização Mundial da Saúde (WHO, 1998), consiste em dividir o peso (em kg) pela altura (em metros) ao quadrado e, a partir do resultado, o indivíduo é classificado em uma das seguintes categorias, a saber: IMC $<18,5 \mathrm{~kg} / \mathrm{m}^{2}$ : abaixo do peso; IMC entre 18,5 e $24,9 \mathrm{~kg} / \mathrm{m}^{2}$ : peso normal; IMC entre 25,0 e $29,9 \mathrm{~kg} / \mathrm{m}^{2}$ : sobrepeso; IMC entre 30,0 e $34,9 \mathrm{~kg} / \mathrm{m}^{2}$ : obesidade grau I; IMC entre 35,0 e $39,9 \mathrm{~kg} / \mathrm{m}^{2}$ : obesidade grau II; IMC $>40,0 \mathrm{~kg} / \mathrm{m}^{2}$ : 
obesidade grau III. Também foram obtidas informações sobre a pressão arterial sistólica e diastólica, aferidas rotineiramente nos sujeitos, antes da doação de sangue.

\subsubsection{DE de acordo com o IIFE}

A prevalência e a classificação da DE foram obtidas pelas seis das quinze questões do IIFE (Rosen et al.,1997) relacionadas com a função erétil (ANEXO C), validado originalmente em inglês e que teve a adaptação transcultural para a língua portuguesa feita por Ferraz e Ciconelli (1998) (Quadro 2, Quadro 3).

Quadro 2. Parâmetro relativo à Função Erétil do IIFE

\begin{tabular}{|c|c|c|}
\hline Parâmetro & Questões & Pontuação Total \\
\hline Função Erétil & $01-05,15$ & $1-30$ \\
\hline
\end{tabular}

Quadro 3. Classificação da disfunção erétil usando o parâmetro relativo à Função Erétil do IIFE

\begin{tabular}{|cl|}
\hline Pontuação do parâmetro função erétil & Classificação da disfunção erétil \\
\hline $6-10$ & Completa \\
\hline $11-16$ & Moderada \\
\hline $17-25$ & Leve \\
\hline $26-30$ & Sem disfunção erétil \\
\hline
\end{tabular}




\subsubsection{Fatores físicos e emocionais}

Para medir a qualidade de vida foi utilizado o questionário Medical Outcomes Study Questionnaire 36-Item Short Form Health Survey (SF-36), criado por Ware e Sherbourne (1992). No Brasil, esse instrumento teve sua tradução e validação cultural realizada por Ciconelli (1997). O questionário (ANEXO D), composto por 36 itens englobados em oito modalidades da qualidade de vida, avalia: capacidade funcional (que se refere à capacidade de realização de tarefas básicas do dia-a-dia), aspectos físicos (que se refere à extensão em que a saúde interfere nas atividades diárias), dor (durante as últimas quatro semanas), estado geral de saúde (que se refere à percepção geral da saúde), vitalidade (que se refere à percepção da energia geral nas últimas quatro semanas), aspectos sociais (que se refere à extensão em que a saúde interfere nas atividades sociais), aspectos emocionais (que se refere à extensão em que os problemas emocionais interferem nas atividades diárias) e saúde mental (que se refere à percepção dos sentimentos nas últimas quatro semanas). A pontuação varia de zero a 100, onde zero corresponde ao pior estado de saúde e 100 a um melhor. O SF-36 também inclui uma pergunta que, embora não seja usada para pontuar nenhuma das modalidades que o questionário investiga, permite avaliar as alterações de saúde ocorridas no período de um ano. A utilização do SF-36 neste estudo teve como objetivo investigar a associação entre o estado geral de saúde e a presença da DE.

Para a medida do stress emocional foi utilizado o Inventário de Sintomas de Stress para Adultos de Lipp (ISSL), validado e padronizado para a população brasileira (Lipp, 2002). Este instrumento é baseado no modelo quadrifásico do stress 
(Lipp, 2002), que amplia o modelo trifásico desenvolvido por Selye (1984), no qual o stress se desenvolve em três fases: alerta, resistência e exaustão. No ISSL (ANEXO E) são avaliadas quatro fases do stress, quais sejam: a de alerta (em que o indivíduo se "energiza" através da produção de adrenalina e, assim, a sua sobrevivência é preservada com chances elevadas de alcançar a sensação de plenitude), a de resistência (na qual o indivíduo tenta manter a sua homeostase interna lidando automaticamente com os fatores estressores), a de quase-exaustão (que se refere à quebra da resistência do indivíduo por causa da persistência, em freqüência ou intensidade, dos fatores estressores, dando início ao processo do adoecimento que atinge e começa a mostrar os primeiros sinais nos órgãos que possuírem maior vulnerabilidade genética ou adquirida) e a de exaustão (que se caracteriza pela não remoção dos fatores estressores ou pela ausência de estratégias de enfrentamento que podem levar às doenças graves nos órgãos mais vulneráveis). Os escores brutos obtidos pelo ISSL para cada fase podem assumir os seguintes valores: Fase 1 (Alerta): 7 a 15; Fase 2 (Resistência): 4 a 9; Fase 3 (Quase-Exaustão): 10 a 15; Fase 4 (Exaustão): 9 a 23. A pontuação de cada fase também fornece a predominância de sintomas físicos e psicológicos, em escala de zero a 100. A utilização do ISSL neste estudo teve como objetivo investigar a associação entre a presença de stress e a presença da DE.

Para detectar a presença de transtornos depressivos e/ou ansiosos foi utilizado o Self Reporting Questionnaire (SRQ-20). Desenvolvido por Harding et al. (1980), para avaliar a presença de sintomas psiquiátricos na população atendida em serviços de atenção primária à saúde em países em desenvolvimento, este instrumento é composto por 20 questões (quatro sobre sintomas físicos e dezesseis sobre queixas 
emocionais), com duas possibilidades de respostas: sim ou não, referentes ao último mês (ANEXO F). No Brasil, teve a sua validação por Mari e Williams (1986), como instrumento de rastreamento para doenças como ansiedade e depressão. Um escore final de seis pontos ou mais, para homens, implica na suspeita de transtorno depressivo e/ou ansioso. A utilização do SRQ-20 neste estudo teve como objetivo investigar a associação entre transtornos depressivos e/ou ansiosos e a presença da DE.

\subsubsection{Investigação clínica}

Este questionário foi delineado para alcançar as seguintes informações adicionais sobre os indivíduos (ANEXO G): uso de algum medicamento para conseguir obter ereção e quem recomendou, tempo de relacionamento com a atual parceira, grau de satisfação atual no relacionamento a dois, atração sexual pela parceira, desempenho nas preliminares, sentimento ao falar sobre sexo, percepção de curvatura no pênis, desejo sexual atual, satisfação com o tamanho do pênis, satisfação com o próprio corpo, satisfação profissional, satisfação pessoal, qualidade do sono, tratamentos e uso atual de medicamentos. Além disso, para avaliar a presença da DE referida, o indivíduo foi instado a responder, sim ou não, à pergunta: “Sente-se potente sexualmente?". Em caso de não se sentir potente sexualmente respondia: há quanto tempo, se já havia procurado tratamento, por que não procurou ou por que não procuraria. A utilização deste instrumento teve como objetivo investigar a associação entre a medida da autopercepção dos fatores estudados e a presença da DE pelo IIFE. 


\subsection{Procedimentos}

Os participantes desta pesquisa foram abordados por meio de um breve contato, no qual receberam informações de que esse estudo se tratava de uma Pesquisa sobre Saúde Masculina e formalmente foram convidados a participar.

O consentimento de cada participante foi realizado após leitura, esclarecimento, preenchimento e assinatura do "Termo de Consentimento Livre e Esclarecido" (ANEXO A).

Foram apresentados em uma só vez, para serem respondidos em um único encontro, na mesma sequiência, os seguintes instrumentos: ficha de identificação (ANEXO B), IIFE (ANEXO C), SF-36 (ANEXO D), ISSL (ANEXO E), SRQ-20 (ANEXO F) e investigação clínica (ANEXO G).

\subsection{Análise estatística}

\subsubsection{Variáveis em estudo}

A análise estatística envolveu as seguintes variáveis:

a) Variáveis qualitativas

1. Presença da DE detectada pelo IIFE;

2. Presença da DE referida pelo respondente (sim ou não);

3. Nacionalidade;

4. Naturalidade;

5. Região de procedência (N, NE, SE, S ou CO); 
6. Raça/cor (branca, parda, negra, amarela ou outra);

7. Nível de escolaridade (completou a faculdade, faculdade incompleta, completou o segundo grau, segundo grau incompleto, completou o primeiro grau, primeiro grau incompleto);

8. Renda Mensal, em salários mínimos (menos do que 5, 6 a 10,11 a 15, 16 a 20 ou 21 ou mais);

9. Estado civil (solteiro, separado/divorciado, viúvo, mora com alguém, casado);

10. Religião (católica, protestante, evangélica, espírita, outra religião ou não tem religião);

11. Condição profissional (ativo profissionalmente, aposentado ativo, aposentado inativo ou outra);

12. Saúde agora quando comparada há um ano atrás (muito melhor, um pouco melhor, quase a mesma, um pouco pior, muito pior);

13. Stress ( $\operatorname{sim}$ ou não);

14. Transtornos depressivos e/ou ansiosos (sim ou não);

15. Grau de satisfação atual no relacionamento a dois (ótimo, bom, moderado, ruim);

16. Atração sexual pela parceira (sim ou não);

17. Preliminares (não há preliminares, rápidas, nem rápidas nem demoradas, demoradas);

18. Como se sente ao falar sobre sexo (envergonhado, nem envergonhado nem à vontade, à vontade);

19. Curvatura no pênis (sim ou não); 
20. Desejo sexual atual (excelente, bom, moderado, baixo, ausente);

21. Satisfação com o tamanho do pênis ( $\operatorname{sim}$ ou não);

22. Satisfação com o próprio corpo (sim ou não);

23. Satisfação profissional (sim ou não);

24. Satisfação pessoal (sim ou não);

25. Qualidade do seu sono (ótima, boa, regular, ruim);

26. Faz algum tipo de tratamento (sim ou não);

27. Tratamento para hipercolesterolemia (sim ou não);

28. Outros tratamentos, diferentes de: doença da tireóide, tumor benigno, câncer de próstata, falta de hormônio sexual, depressão, ansiedade, pânico, fobia, stress após algum acontecimento traumático, alcoolismo, obesidade, tabagismo, uso de drogas, diabetes, hipertensão, doença do coração, colesterol (sim ou não);

29. Toma algum tipo de medicamento (

30. Obesidade segundo o IMC (abaixo do peso, peso normal, sobrepeso, obesidade Grau I, obesidade Grau II ou obesidade Grau III);

b) Variáveis quantitativas

31. Idade (anos);

32. Pressão arterial sistólica $(\mathrm{mmHg})$;

33. Pressão arterial diastólica $(\mathrm{mmHg})$;

34. Escore de capacidade funcional (0 a 100);

35. Escore de aspectos físicos (0 a 100);

36. Escore de estado geral de saúde (0 a 100);

37. Escore de vitalidade (0 a 100); 
38. Escore de aspectos sociais (0 a 100);

39. Escore de aspectos emocionais (0 a 100);

40. Escore de saúde mental (0 a 100);

41. Escore de dor (0 a 100);

42. Tempo de relacionamento.

\subsubsection{Análise descritiva}

Foram estimadas as prevalências da DE segundo o IIFE e da DE auto-referida e seus respectivos intervalos de confiança (nível de confiança 95\%). Foram construídas tabelas contendo medidas descritivas das variáveis quantitativas (que representam resultados de contagem ou mensuração) (Bussab, Morettin, 2005) em estudo (variáveis de 31 a 42) considerando todos os respondentes e segundo a presença da DE detectada pelo IIFE e referida pelo respondente.

Para as variáveis qualitativas (que expressam qualidades ou atributos dos indivíduos pesquisados - por exemplo, sexo, procedência etc.) e para algumas variáveis quantitativas que foram categorizadas foram construídos gráficos contendo a sua distribuição percentual considerando todos os respondentes, e segundo a presença da DE detectada pelo IIFE e referida pelo respondente.

\subsubsection{Análise inferencial}

Para avaliar se os fatores socioeconômicos, demográficos, físicos e emocionais estavam associados à presença da DE foram utilizados modelos de regressão logística. A variável resposta foi a presença da DE detectada pelo IIFE ou a 
presença da DE referida pelo respondente (sim ou não). As variáveis explicativas foram os referidos fatores (variáveis de 5 a 31 e de 34 a 42). As variáveis nacionalidade e naturalidade não foram consideradas devido ao pequeno número de indivíduos em alguma(s) de suas categorias. As variáveis pressão arterial sistólica e diastólica foram utilizadas apenas para descrever características de saúde da população, e não foram consideradas como explicativas da DE.

Para possibilitar o ajuste desses modelos algumas variáveis qualitativas tiveram suas categorias reagrupadas, devido ao pequeno número de indivíduos nas categorias originais. Este foi o caso das variáveis: raça/cor (agora com as categorias "branca" e "outra"), escolaridade (agora com as categorias " $1^{0}$ grau incompleto" e "1 $1^{\text {o }}$ grau completo ou mais"), renda mensal ("1 a 5 S.M.", "6 a 10 S.M.", "mais de 10 S.M.”), estado civil ("solteiro/separado/viúvo", "casado/mora com alguém”), religião (“católica”, “outra”), condição profissional ("ativo", "inativo"), saúde agora quando comparada há um ano atrás ("melhor"/ "a mesma, pior"), grau de satisfação no relacionamento a dois (“ótimo", "bom”, "moderado/ruim”), preliminares ("não há/rápidas", "nem rápidas nem demoradas", “demoradas"), como se sente ao falar sobre sexo ("pouco à vontade" - correspondendo à junção das categorias envergonhado e nem envergonhado nem à vontade, e "à vontade"), desejo sexual atual ("excelente", "bom", "moderado/baixo", sendo que ninguém referiu ausência de desejo), qualidade do sono (“ótima”, "boa”, "regular/ ruim”) e obesidade segundo o IMC ("normal”, "sobrepeso ou algum grau de obesidade", sendo que ninguém foi classificado como estando abaixo do peso).

Além disso, para facilitar a interpretação dos resultados dos modelos, as variáveis quantitativas (variável 31 e variáveis de 34 a 42) foram categorizadas 
segundo informações estabelecidas na literatura (como no caso da idade) ou de forma que cada categoria contivesse mais ou menos o mesmo número de indivíduos (como no caso dos escores de qualidade de vida e do tempo de relacionamento).

Inicialmente, foi realizada a análise univariada, onde foi calculado o número e a porcentagem de indivíduos que apresentaram DE segundo as categorias de cada uma das variáveis explicativas. Uma vez que o número de respondentes que apresentou DE moderada ou completa pelo IIFE foi pequeno, foi necessário agrupar os indivíduos em apenas duas categorias: com disfunção ou sem disfunção, para facilitar a análise estatística e a interpretação dos dados.

Para cada variável explicativa foi ajustado um modelo de regressão logística univariada, a partir do qual foi obtida a estimativa da odds ratio (OR) e do seu respectivo intervalo de confiança (com coeficiente de confiança de 95\%). Esses modelos possibilitaram avaliar a contribuição individual de cada fator para explicar a presença da DE, sem levar em conta os demais fatores.

A seguir, foi realizada a análise de regressão logística múltipla. Dado o grande número de variáveis explicativas, decidiu-se utilizar o método stepwise forward (Hosmer, Lemeshow, 1989). Desse modo, as variáveis explicativas foram introduzidas uma a uma no modelo, da mais importante para a menos importante. A ordem de "importância" das variáveis foi definida segundo o logaritmo da verossimilhança do modelo univariado (quanto menor o valor de " $-2 \times$ logaritmo da verossimilhança”, mais importante a variável em questão). A cada passo desta abordagem, uma nova variável era introduzida ou retirada do modelo.

Foram utilizados como critérios para decidir se uma determinada variável deveria permanecer ou não no modelo: (1) o fato de o seu coeficiente ser significante 
ou marginalmente significante (nível descritivo do teste de Wald $\leq 0,10$ ) e (2) o fato do modelo com esta variável ser "melhor" do que o modelo sem ela, o que foi avaliado pelo teste da razão de verossimilhança.

Após estas análises, foram testadas todas as interações possíveis entre essas variáveis que permaneceram no modelo, duas a duas, permanecendo apenas as que foram significantes. Também foram testados diferentes modelos para verificar qual era o mais estável no caso de variáveis colineares (por exemplo idade e tempo de relacionamento). Em seguida foi definido o modelo final e estimados os seus parâmetros. O modelo final teve seu ajuste testado com uso do teste de HosmerLemeshow (Hosmer, Lemeshow, 1989).

Houve interesse em avaliar se a prevalência de alguns fatores relacionados à saúde dependia da idade dos indivíduos. Para tanto, foi utilizado o teste Quiquadrado. Para avaliar a concordância entre a presença da DE detectada pelo IIFE e a presença da DE auto-referida foi utilizado o coeficiente de concordância kappa (Nascimento, Menezes, 2000).

As análises foram realizadas com o auxílio do programa $\mathrm{R}$ for Windows (versão 2.7.0). Os gráficos e tabelas foram construídos com uso do programa Excel®. 
5. RESULTADOS 


\section{Resultados}

\subsection{Análise descritiva}

A amostra inicial foi constituída por 300 indivíduos. Após a avaliação inicial das respostas, 12 indivíduos (4\% da amostra) foram excluídos do estudo porque tinham feito (ou estavam em) uso de medicamento para obter ereção. Desses, seis indivíduos relataram usar medicamento segundo orientação médica e os demais, por conta própria.

Dos 288 participantes que continuaram na análise, 92 (31,9 \%; IC $95 \%: 26,6 \%$ a $37,7 \%$ ) foram classificados pelo IIFE como tendo algum grau de DE: 87 (30,2\%; IC $95 \%: 25,0 \%$ a $35,9 \%)$ indivíduos possuíam disfunção leve, quatro $\left(1,4 \%\right.$; IC $_{95 \%}$ : 0,4\% a 3,5\%) possuíam disfunção moderada e um (0,3\%; $\mathrm{IC}_{95 \%}: 0,01 \%$ a $\left.1,9 \%\right)$, disfunção completa. Entretanto, apenas nove $\left(3,1 \%\right.$; $\mathrm{IC}_{95 \%}: 1,4 \%$ a 5,8\%) sujeitos referiram não se sentirem potentes sexualmente. Somente oito dos 92 respondentes que foram classificados como tendo pelo menos algum grau de DE pelo IIFE referiram ter DE. Assim, a concordância entre DE detectada pelo IIFE e DE referida foi baixa (kappa $=0,11 ; \mathrm{p}<0,001)$.

A Tabela 1 apresenta a distribuição dos indivíduos participantes da pesquisa, segundo a disfunção detectada pelo IIFE e a referida. O único indivíduo que o IIFE classificou como tendo DE completa, de fato, referiu não se sentir potente sexualmente. Dos quatro indivíduos com DE moderada pelo IIFE, um referiu não se sentir potente sexualmente. Dos 87 com DE leve, apenas seis referiram não se 
sentirem potentes. Um dos indivíduos que não se sentia potente sexualmente foi classificado sem DE pelo IIFE.

Dos nove indivíduos que não se sentiam potentes sexualmente, apenas dois $(22,2 \%$, ANEXO H) procuraram tratamento. Os sete sujeitos que não procuraram tratamento para DE alegaram falta de tempo, dificuldade financeira, vergonha, falta de informação e falta de incentivo. O tempo da DE variou de seis meses a seis anos, com exceção de um indivíduo, que mencionou sempre ter tido DE.

Tabela 1. Distribuição conjunta dos indivíduos do estudo segundo a DE detectada pelo IIFE e DE referida

\begin{tabular}{llcccccc}
\hline & & \multicolumn{5}{c}{ DE referida } & \multicolumn{2}{c}{ Total } \\
\cline { 3 - 6 } & \multicolumn{3}{c}{ não } & \multicolumn{2}{c}{ sim } & \multicolumn{2}{c}{ To, } \\
\cline { 3 - 6 } IIFE & ausente & 195 & $67,7 \%$ & 1 & $0,3 \%$ & 196 & $68,1 \%$ \\
& leve & 81 & $28,1 \%$ & 6 & $2,2 \%$ & 87 & $30,2 \%$ \\
& moderada & 3 & $1,0 \%$ & 1 & $0,3 \%$ & 4 & $1,4 \%$ \\
& completa & 0 & $0,0 \%$ & 1 & $0,3 \%$ & 1 & $0,3 \%$ \\
\hline & Total & 279 & $96,9 \%$ & 9 & $3,1 \%$ & 288 & $100,0 \%$ \\
\hline
\end{tabular}

A Tabela 2 apresenta algumas medidas descritivas (média, desvio padrão [d.p.], mediana, mínimo e máximo) para as variáveis quantitativas em estudo (variáveis de 31 a 42, citadas no item 4.8.1), para todos os indivíduos e segundo a presença da DE (detectada pelo IIFE e referida). 
Tabela 2. Medidas descritivas para as variáveis quantitativas em estudo,segundo a presença de DE detectada pelo IIFE e DE referida

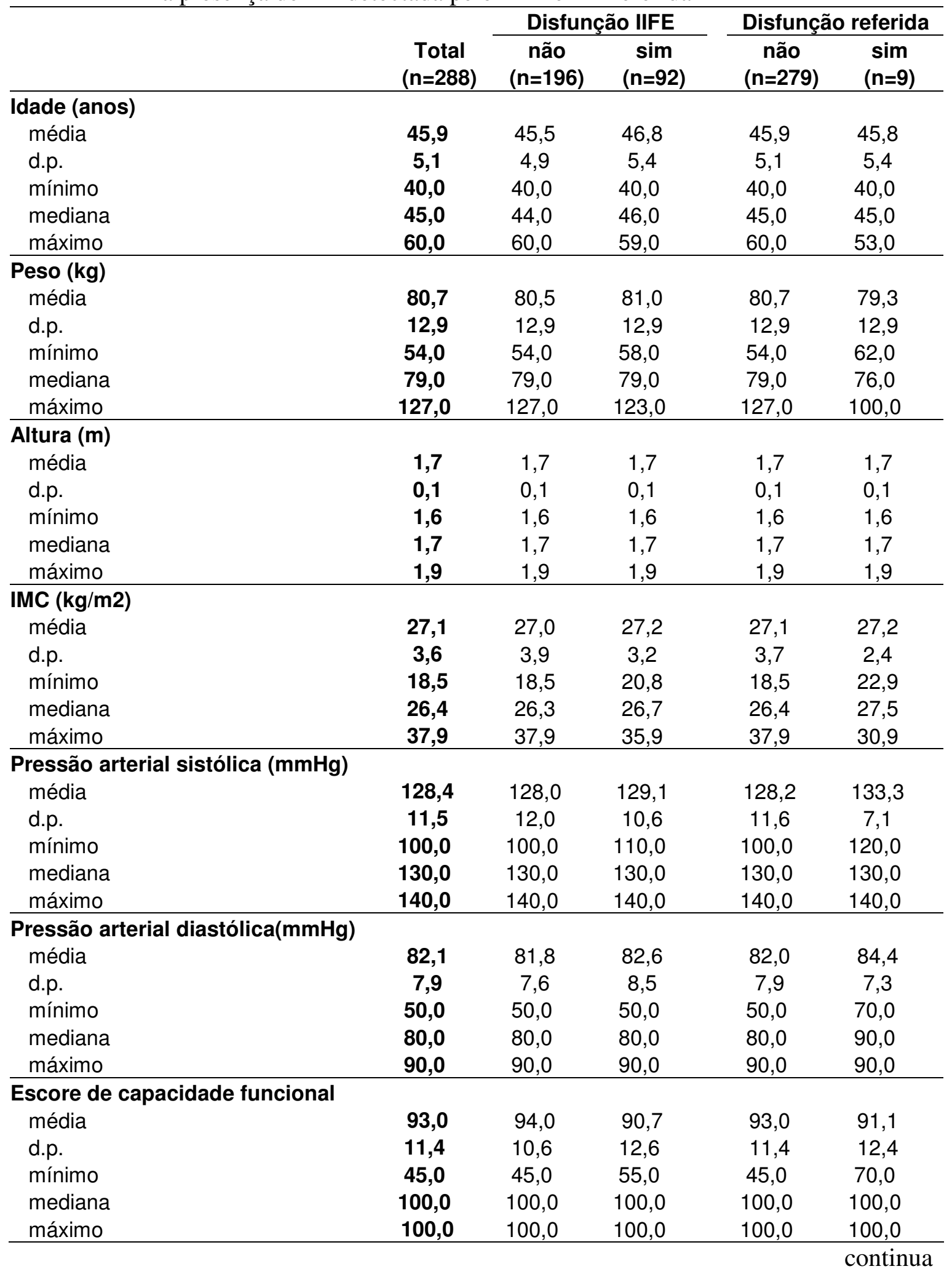


Tabela 2. Medidas descritivas para as variáveis quantitativas em estudo,segundo a presença de DE detectada pelo IIFE e DE referida (conclusão)

\begin{tabular}{|c|c|c|c|c|c|}
\hline & & Disfun & ão IIFE & Disfunçã & referida \\
\hline & $\begin{array}{c}\text { Total } \\
(\mathrm{n}=288)\end{array}$ & $\begin{array}{c}\text { não } \\
(n=196)\end{array}$ & $\underset{(n=92)}{\operatorname{sim}}$ & $\begin{array}{c}\text { não } \\
(\mathrm{n}=279)\end{array}$ & $\begin{array}{c}\operatorname{sim} \\
(n=9)\end{array}$ \\
\hline Escore de & & & & & \\
\hline média & 90,4 & 90,6 & 89,9 & 90,6 & 83,3 \\
\hline d.p. & 23,4 & 23,3 & 23,7 & 23,6 & 17,7 \\
\hline mínimo & 0,0 & 0,0 & 0,0 & 0,0 & 50,0 \\
\hline mediana & 100,0 & 100,0 & 100,0 & 100,0 & 75,0 \\
\hline máximo & 100,0 & 100,0 & 100,0 & 100,0 & 100,0 \\
\hline Escore de & & & & & \\
\hline média & 85,7 & 86,7 & 83,5 & 85,6 & 89,8 \\
\hline d.p. & 19,5 & 18,8 & 20,8 & 19,6 & 16,6 \\
\hline mínimo & 10,0 & 22,0 & 10,0 & 10,0 & 62,0 \\
\hline mediana & 100,0 & 100,0 & 100,0 & 100,0 & 100,0 \\
\hline máximo & 100,0 & 100,0 & 100,0 & 100,0 & 100,0 \\
\hline Escore de & & & & & \\
\hline média & 87,6 & 88,9 & 84,9 & 87,9 & 79,0 \\
\hline d.p. & 13,1 & 12,5 & 14,1 & 13,0 & 15,5 \\
\hline mínimo & 32,0 & 45,0 & 32,0 & 32,0 & 57,0 \\
\hline mediana & 92,0 & 93,5 & 92,0 & 92,0 & 77,0 \\
\hline máximo & 100,0 & 100,0 & 100,0 & 100,0 & 100,0 \\
\hline Escore de & & & & & \\
\hline média & 75,8 & 77,7 & 71,8 & 76,5 & 52,8 \\
\hline d.p. & 16,3 & 14,3 & 19,4 & 15,5 & 25,0 \\
\hline mínimo & 5,0 & 25,0 & 5,0 & 5,0 & 20,0 \\
\hline mediana & 80,0 & 80,0 & 75,0 & 80,0 & 50,0 \\
\hline máximo & 100,0 & 100,0 & 100,0 & 100,0 & 85,0 \\
\hline Escore de & & & & & \\
\hline média & 89,8 & 92,1 & 85,1 & 90,3 & 76,4 \\
\hline d.p. & 17,8 & 16,0 & 20,5 & 17,3 & 27,6 \\
\hline mínimo & 25,0 & 25,0 & 25,0 & 25,0 & 37,5 \\
\hline mediana & 100,0 & 100,0 & 100,0 & 100,0 & 87,5 \\
\hline máximo & 100,0 & 100,0 & 100,0 & 100,0 & 100,0 \\
\hline Escore de & & & & & \\
\hline média & 88,2 & 90,0 & 84,4 & 88,8 & 70,4 \\
\hline d.p. & 27,1 & 25,4 & 30,2 & 26,8 & 30,9 \\
\hline mínimo & 0,0 & 0,0 & 0,0 & 0,0 & 33,3 \\
\hline mediana & 100,0 & 100,0 & 100,0 & 100,0 & 66,7 \\
\hline máximo & 100,0 & 100,0 & 100,0 & 100,0 & 100,0 \\
\hline Escore de & & & & & \\
\hline média & 79,9 & 81,3 & 76,9 & 80,4 & 64,0 \\
\hline d.p. & 15,6 & 14,5 & 17,5 & 15,0 & 25,3 \\
\hline mínimo & 24,0 & 32,0 & 24,0 & 32,0 & 24,0 \\
\hline mediana & 84,0 & 84,0 & 80,0 & 84,0 & 64,0 \\
\hline máximo & 100,0 & 100,0 & 100,0 & 100,0 & 96,0 \\
\hline Tempo de & & & & & \\
\hline média & 17,4 & 16,6 & 19,2 & 17,4 & 18,6 \\
\hline d.p. & 8,5 & 8,5 & 8,3 & 8,5 & 8,2 \\
\hline mínimo & 0,0 & 0,0 & 0,0 & 0,0 & 4,0 \\
\hline mediana & 18,0 & 17,0 & 20,0 & 18,0 & 17,0 \\
\hline máximo & 39,0 & 39,9 & 35,0 & 39,0 & 29,0 \\
\hline
\end{tabular}


As Figuras de 1 a 36, do ANEXO I, apresentam, na primeira coluna, a distribuição percentual dos indivíduos da amostra segundo os níveis de cada uma das variáveis categóricas da pesquisa (variáveis de 1 a 30, citadas no item 4.8.1) e das variáveis quantitativas que foram categorizadas. As demais colunas mostram a distribuição percentual dos indivíduos segundo a DE (detectada pelo IIFE e referida).

Os respondentes em sua maioria eram brasileiros $(99,3 \%)$, provenientes da região Sudeste (79,4\%; ANEXO I, Figura 1), de raça/cor branca (69,8\%; ANEXO I, Figura 2), casados (87,2\%; ANEXO I, Figura 3), e católicos (60,8\%; ANEXO I, Figura 4). Quanto ao nível de escolaridade, $88,5 \%$ dos indivíduos tinham o $1^{\circ}$ grau completo ou mais (ANEXO I, Figura 5). A maioria (91,0\%) era profissionalmente ativa (ANEXO I, Figura 6), sendo que mais da metade dos indivíduos (53,5\%) ganhava menos de cinco salários mínimos (ANEXO I, Figura 7).

A idade dos participantes da pesquisa variou de 40 a 60 anos (Tabela 2), sendo que a maioria $(78,5 \%)$ tinha menos de 50 anos (ANEXO I, Figura 8).

O IMC variou de 18,5 a $37,9 \mathrm{~kg} / \mathrm{m}^{2}$ (Tabela 2). A maioria dos indivíduos $(69,4 \%)$ estava acima do peso normal (ANEXO I, Figura 9).

Os níveis de pressão arterial sistólica dos indivíduos variaram de 100 a 140 mmHg e os de pressão arterial diastólica variaram de 50 a 90 mmHg (Tabela 2).

Em relação à percepção dos indivíduos sobre a sua condição de saúde atual quando comparada com um ano atrás, a maior parte dos respondentes $(63,9 \%)$ considerou estar na mesma condição ou pior do que há um ano (ANEXO I, Figura $10)$.

Quanto aos escores de qualidade de vida, a pontuação foi alta. As médias dos escores de capacidade funcional (ANEXO I, Figura 11), aspectos físicos (ANEXO I, 
Figura 12), dor (ANEXO I, Figura 13), aspectos sociais (ANEXO I, Figura 14) e aspectos emocionais (ANEXO I, Figura 15) foram superiores a 85, com mediana igual a 100 para todos os escores (Tabela 2), ou seja, pelo menos metade dos respondentes obteve a pontuação máxima nesses escores $(61,8 \% ; 81,6 \% ; 56,9 \%$; $66,7 \%$ e $80,6 \%$; respectivamente). Mais de $60 \%$ dos respondentes pontuaram 90 ou mais no escore de estado geral de saúde (ANEXO I, Figura 16).

A pontuação do escore de vitalidade variou entre cinco e 100 (Tabela 2), sendo que $36,1 \%$ dos respondentes obtiveram pontuação 85 ou mais (ANEXO I, Figura 17). A pontuação do escore de saúde mental variou entre 24 e 100 (Tabela 2) e os indivíduos com pontuação 92 ou mais totalizaram 29,2\% da amostra (ANEXO I, Figura 18).

Do total de respondentes, $26(9,0 \%)$ referiram stress (ANEXO I, Figura 19). Destes, um (3,8\%) se encontrava na fase de alerta, 21 (80,8\%) na fase de resistência, e quatro $(15,4 \%)$ na fase de quase exaustão. O nível de sintomas físicos destes sujeitos variou entre 10 e 70 e de sintomas psicológicos, entre 20 e 100.

Trinta $(10,4 \%)$ respondentes foram classificados como suspeitos de transtornos depressivos e/ou ansiosos (ANEXO I, Figura 20).

O tempo de relacionamento variou de seis meses até 39 anos (Tabela 2; ANEXO I, Figura 21).

Referiram grau de satisfação moderado ou ruim no relacionamento a dois 25 $(8,7 \%$ ) indivíduos (ANEXO I, Figura 22), e os motivos apontados foram: monotonia, rotina, incompreensão da parceira, desgaste na relação, falta de sintonia sexual, problemas com os filhos, pressão do dia-a-dia, problemas financeiros e cansaço físico. 
Não sentiam atração sexual pela parceira oito $(2,8 \%)$ indivíduos (ANEXO I, Figura 23), sendo que o período de tempo em que isto ocorria variou entre quatro meses e seis anos, exceto para um respondente que não soube mensurar este período.

As preliminares sexuais eram rápidas para 14,6\% e não existiam para $0,7 \%$ dos respondentes (ANEXO I, Figura 24). Estes últimos responsabilizaram a parceira por ir direto ao ato sexual.

Falar sobre sexo deixava $24,3 \%$ dos respondentes pouco à vontade e $3,5 \%$ envergonhados (ANEXO I, Figura 25). Curvatura no pênis foi referida por $20(6,9 \%)$ respondentes (ANEXO I, Figura 26), sendo que destes, apenas dois (10\%) procuraram médico para obter um diagnóstico.

O nível de desejo sexual atual moderado ou baixo foi referido por $19(6,6 \%)$ participantes da amostra (ANEXO I, Figura 27), sendo que isto ocorria em um período que variou de três meses a dez anos, e apenas dois $(11,8 \%)$ haviam procurado tratamento.

Sete $(2,4 \%)$ indivíduos consideravam-se insatisfeitos com o tamanho do pênis (ANEXO I, Figura 28), sendo que um justificou que era por não saber o tamanho normal de um pênis e o restante por considerá-lo pequeno, mas todos declararam nunca ter conversado com um médico a este respeito. Estavam insatisfeitos com o próprio corpo $35(12,2 \%)$ respondentes (ANEXO I, Figura 29), por se sentirem acima do peso. Referiram insatisfação profissional $32(11,1 \%)$ indivíduos (ANEXO I, Figura 30), sendo que o período de tempo em que isto ocorria variou entre três meses até "desde sempre", e os motivos alegados foram: baixo salário, frustração na atividade profissional, falta de estudo para crescer na profissão, desemprego e não atuar em atividade própria. A insatisfação pessoal foi declarada por nove $(3,1 \%)$ 
respondentes (ANEXO I, Figura 31), sendo que o período de tempo em que isto ocorria variou de dois anos até "desde sempre", e os motivos apontados foram: não gostar da vida que levava, sentir-se diferente dos demais, arrependimento por não ter ido atrás dos ideais e conflitos conjugais.

A qualidade do sono foi declarada regular ou ruim por $35(12,1 \%)$ indivíduos (ANEXO I, Figura 32), sendo que o período de tempo em que isto ocorria variou de alguns meses até "desde sempre", e as justificativas apresentadas foram: insônia, excesso de trabalho, trabalho noturno e poucas horas para dormir.

Do total de respondentes, $48(16,7 \%)$ declararam fazer ou terem feito algum tipo de tratamento de saúde (ANEXO I, Figura 33). Os mais citados foram: colesterol (3,5\%) (ANEXO I, Figura 34), depressão (2,1\%), ansiedade/pânico/fobia $(2,1 \%)$ e stress $(2,4 \%)$. Outros tratamentos foram referidos por $4,5 \%$ dos participantes (ANEXO I, Figura 35).

Vinte e cinco $(8,7 \%)$ afirmaram usar algum tipo de medicamento (ANEXO I, Figura 36). Destes, um $(0,3 \%)$ usava antiagregante plaquetário, dois $(0,7 \%)$, antienxaqueca; um (0,3\%), antihistamínico; seis $(2,1 \%)$, antiinflamatório; um $(0,3 \%)$, antireumático; um $(0,3 \%)$, florais e fitoterápicos; um $(0,3 \%)$, fórmula para emagrecimento; cinco (1,7\%), hipolipidêmico; três $(1,0 \%)$, inibidor da secreção gástrica; dois $(0,7 \%)$ inibidor enzimático uricosúrico; um $(0,3 \%)$, vasodilatador e um $(0,3 \%)$ utilizava vitaminas em geral. 


\subsection{Análise inferencial}

\subsubsection{DE segundo o IIFE}

A Tabela 3 apresenta a distribuição dos casos de DE detectada pelo IIFE segundo as categorias de cada variável explicativa. Quanto menor o desejo sexual atual, maior é a chance de ter DE segundo o IIFE $(\mathrm{p}<0,01)$. Analogamente, os indivíduos que não se consideram potentes sexualmente têm maior chance de ter DE detectada pelo IIFE do que aqueles que se sentem potentes $(p=0,01)$. Outros fatores que aumentam a chance de ter DE segundo o IIFE são: ser suspeito de transtornos depressivos e/ou ansiosos $(\mathrm{p}<0,01)$, pontuar 88 ou menos no escore de aspectos sociais $(\mathrm{p}<0,01)$, ter um grau de satisfação no relacionamento bom (e não ótimo) (p $=0,01)$ ou ruim/moderado $(p=0,02)$, ser inativo profissionalmente $(p<0,01)$, sentirse pouco à vontade ao falar sobre sexo $(\mathrm{p}=0,01)$, não ter atração sexual pela parceira $(\mathrm{p}=0,02)$, pontuar 70 ou menos no escore de vitalidade $(\mathrm{p}=0,05)$, não estar satisfeito profissionalmente $(\mathrm{p}=0,02)$, pontuar 90 ou menos no escore de capacidade funcional $(\mathrm{p}=0,02)$, manter o relacionamento há 22 anos ou mais $(\mathrm{p}=0,05)$, ter stress $(p=0,04)$ e pontuar 67 ou menos no escore de aspectos emocionais $(p=0,05)$. 
Tabela 3. Distribuição dos casos de DE detectada pelo IIFE segundo as variáveis explicativas e estimativas do modelo de regressão logística simples

\begin{tabular}{|c|c|c|c|c|c|c|c|}
\hline & $\mathbf{N}$ & $\begin{array}{c}\text { DE } \\
\text { IIFE }\end{array}$ & $\begin{array}{l}\text { \%DE } \\
\text { IIFE }\end{array}$ & $\mathbf{O R}$ & $\mathbf{p}$ & $-2 \log \lambda$ & ordem \\
\hline Características sócio-demo & & & & & & & \\
\hline Idade (anos) & & & & & & & \\
\hline$<=49$ & 226 & 68 & $(30,1)$ & 1 & & & \\
\hline 50 ou mais & 62 & 24 & $(38,7)$ & 1,47 & 0,20 & 359,21 & 19 \\
\hline Região de procedência & & & & & & & \\
\hline outra & 59 & 21 & $(35,6)$ & 1 & & & \\
\hline Sudeste & 227 & 70 & $(30,8)$ & 0,81 & 0,49 & 357,30 & 16 \\
\hline Raça/cor & & & & & & & \\
\hline outra & 87 & 25 & $(28,7)$ & 1 & & & \\
\hline branca & 201 & 67 & $(33,3)$ & 1,2 & 0,44 & 360,24 & 29 \\
\hline Escolaridade & & & & & & & \\
\hline $3^{\circ}$ grau & 82 & 26 & $(31,7)$ & 1 & & & \\
\hline $2^{\circ}$ grau & 139 & 38 & $(27,3)$ & 0,8 & 0,49 & & \\
\hline $1^{\circ}$ grau & 67 & 28 & $(41,8)$ & 1,5 & 0,20 & 356,58 & 12 \\
\hline Renda mensal (salários mí & & & & & & & \\
\hline mais de 5 & 134 & 39 & $(29,1)$ & 1 & & & \\
\hline 1 a 5 & 154 & 53 & $(34,4)$ & 1,3 & 0,34 & 359,90 & 26 \\
\hline Estado civil & & & & & & & \\
\hline solteiro/separado/viúvo & 26 & 5 & $(19,2)$ & 1 & & & \\
\hline casado/mora com alguém & 262 & 87 & $(33,2)$ & 2,1 & 0,15 & 358,53 & 18 \\
\hline Religião & & & & & & & \\
\hline católica & 175 & 55 & $(31,4)$ & 1 & & & \\
\hline outra & 113 & 37 & $(32,7)$ & 1,1 & 0,82 & 360,78 & 35 \\
\hline Condição profissional & & & & & & & \\
\hline ativo & 262 & 77 & $(29,4)$ & 1 & & & \\
\hline inativo & 26 & 15 & $(57,7)$ & 3,3 & $\mathbf{0 , 0 0}$ & 352,76 & 6 \\
\hline Investigação clínica sobr & & & & & & & \\
\hline Tempo de relacionament & & & & & & & \\
\hline 0,5 a 14 & 96 & 24 & $(25,0)$ & 1 & & & \\
\hline 15 a 21 & 93 & 30 & $(32,3)$ & 1,4 & 0,27 & & \\
\hline 22 a 39 & 99 & 38 & $(38,4)$ & 1,9 & $\mathbf{0 , 0 5}$ & 356,78 & 13 \\
\hline Grau de satisfação no relac & & & & & & & \\
\hline ótimo & 159 & 39 & $(24,5)$ & 1 & & & \\
\hline bom & 104 & 41 & $(39,4)$ & 2,0 & $\mathbf{0 , 0 1}$ & & \\
\hline ruim/moderado & 25 & 12 & $(48,0)$ & 2,8 & $\mathbf{0 , 0 2}$ & 351,26 & 5 \\
\hline Atração sexual pela parcei & & & & & & & \\
\hline $\operatorname{sim}$ & 280 & 86 & $(30,7)$ & 1 & & & \\
\hline não & 8 & 6 & $(75,0)$ & 6,8 & $\mathbf{0 , 0 2}$ & 354,40 & 8 \\
\hline
\end{tabular}


Tabela 3. Distribuição dos casos de DE detectada pelo IIFE segundo as variáveis explicativas e estimativas do modelo de regressão logística simples (continuação)

\begin{tabular}{|c|c|c|c|c|c|c|c|}
\hline & $\mathbf{N}$ & $\begin{array}{c}\text { DE } \\
\text { IIFE }\end{array}$ & $\begin{array}{l}\text { \%DE } \\
\text { IIFE }\end{array}$ & OR & p & $-2 \log \lambda$ & ordem \\
\hline $\begin{array}{l}\text { DE referida } \\
\text { não } \\
\text { sim }\end{array}$ & $\begin{array}{c}279 \\
9\end{array}$ & $\begin{array}{c}84 \\
8\end{array}$ & $\begin{array}{l}(30,1) \\
(\mathbf{8 8}, 9)\end{array}$ & $\begin{array}{c}1 \\
18,6\end{array}$ & $\mathbf{0 , 0 1}$ & 347,65 & 2 \\
\hline $\begin{array}{l}\text { Preliminares } \\
\text { demoradas } \\
\text { nem rápidas nem demoradas } \\
\text { não há/rápidas } \\
\end{array}$ & $\begin{array}{c}63 \\
181 \\
44\end{array}$ & $\begin{array}{l}17 \\
58 \\
17\end{array}$ & $\begin{array}{l}(27,0) \\
(32,0) \\
(38,6)\end{array}$ & $\begin{array}{c}1 \\
1,3 \\
1,7\end{array}$ & $\begin{array}{l}0,45 \\
0,20\end{array}$ & 359,22 & 20 \\
\hline $\begin{array}{l}\text { Como se sente ao falar sobre sexo } \\
\text { à vontade } \\
\text { pouco à vontade }\end{array}$ & $\begin{array}{c}208 \\
80\end{array}$ & $\begin{array}{l}57 \\
\mathbf{3 5}\end{array}$ & $\begin{array}{l}(27,4) \\
(\mathbf{4 3 , 8})\end{array}$ & $\begin{array}{c}1 \\
\mathbf{2 , 1}\end{array}$ & $\mathbf{0 , 0 1}$ & 353,94 & 7 \\
\hline $\begin{array}{l}\text { Tem curvatura no pênis } \\
\text { sim } \\
\text { não }\end{array}$ & $\begin{array}{c}20 \\
268\end{array}$ & $\begin{array}{c}5 \\
87\end{array}$ & $\begin{array}{l}(25,0) \\
(32,5)\end{array}$ & $\begin{array}{c}1 \\
1,4\end{array}$ & 0,49 & 360,34 & 30 \\
\hline $\begin{array}{l}\text { Desejo sexual atual } \\
\text { excelente } \\
\text { bom } \\
\text { baixo/moderado }\end{array}$ & $\begin{array}{c}31 \\
238 \\
\mathbf{1 9}\end{array}$ & $\begin{array}{c}5 \\
74 \\
\mathbf{1 3}\end{array}$ & $\begin{array}{l}(16,1) \\
(31,1) \\
(68,4)\end{array}$ & $\begin{array}{c}1 \\
2,3 \\
\mathbf{1 1 , 3}\end{array}$ & $\begin{array}{l}0,09 \\
\mathbf{0 , 0 0}\end{array}$ & 346,13 & 1 \\
\hline $\begin{array}{l}\text { Satisfação com o tamanho do pênis } \\
\text { não } \\
\text { sim }\end{array}$ & $\begin{array}{c}7 \\
281\end{array}$ & $\begin{array}{c}1 \\
91\end{array}$ & $\begin{array}{l}(14,3) \\
(32,4)\end{array}$ & $\begin{array}{c}1 \\
2,9\end{array}$ & 0,33 & 359,65 & 25 \\
\hline $\begin{array}{l}\text { Satisfação com o próprio corpo } \\
\text { sim } \\
\text { não }\end{array}$ & $\begin{array}{c}253 \\
35\end{array}$ & $\begin{array}{l}79 \\
13\end{array}$ & $\begin{array}{l}(31,2) \\
(37,1)\end{array}$ & $\begin{array}{c}1 \\
1,3\end{array}$ & 0,48 & 360,35 & 31 \\
\hline $\begin{array}{l}\text { Satisfação profissional } \\
\text { sim } \\
\text { não }\end{array}$ & $\begin{array}{c}256 \\
\mathbf{3 2}\end{array}$ & $\begin{array}{l}76 \\
16\end{array}$ & $\begin{array}{l}(29,7) \\
(\mathbf{5 0 , 0 )}\end{array}$ & $\begin{array}{c}1 \\
2,4\end{array}$ & 0,02 & 355,76 & 10 \\
\hline $\begin{array}{l}\text { Satisfação pessoal } \\
\text { sim } \\
\text { não }\end{array}$ & $\begin{array}{c}279 \\
9\end{array}$ & $\begin{array}{c}88 \\
4\end{array}$ & $\begin{array}{l}(31,5) \\
(44,4)\end{array}$ & $\begin{array}{c}1 \\
1,7\end{array}$ & 0,42 & 360,20 & 28 \\
\hline
\end{tabular}

Investigação clínica geral

\begin{tabular}{lccccccc}
\hline IMC & 88 & 25 & $(28,4)$ & 1 & & & \\
$\quad$ normal & 200 & 67 & $(33,5)$ & 1,3 & 0,39 & 360,10 & 27 \\
$\quad$ sobrepeso+obesidade & & & & & & & \\
\hline Qualidade do sono & 95 & 26 & $(27,4)$ & 1 & & & \\
$\quad$ ótima & 158 & 53 & $(33,5)$ & 1,3 & 0,31 & & \\
$\quad$ boa & 35 & 13 & $(37,1)$ & 1,6 & 0,28 & 359,29 & 21 \\
$\quad$ ruim/regular & 48 & 15 & $(31,3)$ & 1 & & & \\
\hline Faz algum tratamento de saúde & 240 & 77 & $(32,1)$ & 1,0 & 0,91 & 360,82 & 36 \\
$\quad$ sim & & & & & & & \\
$\quad$ não & 278 & 87 & $(31,3)$ & 1 & & & \\
Tratamento colesterol & 10 & 5 & $(50,0)$ & 2,2 & 0,22 & 359,38 & 22 \\
$\quad$ não & & & & & & & \multicolumn{2}{c}{ continua } \\
$\quad$ sim & & & & & &
\end{tabular}


Tabela 3. Distribuição dos casos de DE detectada pelo IIFE segundo as variáveis explicativas e estimativas do modelo de regressão logística simples (continuação)

\begin{tabular}{lccccccc}
\hline & & DE & \%DE & & & & \\
& N & IIFE & IIFE & OR & p & $\mathbf{- 2 l o g} \boldsymbol{\lambda}$ & ordem \\
\hline $\begin{array}{l}\text { Outro tratamento } \\
\text { não }\end{array}$ & 275 & 88 & $(32,0)$ & 1 & & & \\
$\quad$ sim & 13 & 4 & $(30,8)$ & 0,9 & 0,93 & 360,83 & 37 \\
\hline Toma algum medicamento & & & & & & & \\
$\quad$ não & 263 & 83 & $(31,6)$ & 1 & & & \\
$\quad$ sim & 25 & 9 & $(36,0)$ & 1,2 & 0,65 & 360,63 & 34 \\
\hline
\end{tabular}

Qualidade de vida

\begin{tabular}{|c|c|c|c|c|c|c|c|}
\hline $\begin{array}{l}\text { Saúde agora } \\
\text { a mesma/pior } \\
\text { melhor } \\
\end{array}$ & $\begin{array}{l}184 \\
104\end{array}$ & $\begin{array}{l}57 \\
35 \\
\end{array}$ & $\begin{array}{l}(31,0) \\
(33,7)\end{array}$ & $\begin{array}{c}1 \\
1,1\end{array}$ & 0,64 & 360,62 & 33 \\
\hline Escore de Capac & & & & & & & \\
\hline 100 & 178 & 49 & $(27,5)$ & 1 & & & \\
\hline 95 & 23 & 7 & $(30,4)$ & 1,2 & 0,77 & & \\
\hline 45 a 90 & 87 & 36 & $(41,4)$ & 1,9 & $\mathbf{0 , 0 2}$ & 355,76 & 11 \\
\hline Escore de Aspec & & & & & & & \\
\hline 100 & 235 & 73 & $(31,1)$ & 1 & & & \\
\hline 0 a 75 & 53 & 19 & $(35,8)$ & 1,2 & 0,50 & 360,39 & 32 \\
\hline Escore de Estad & & & & & & & \\
\hline$>=90$ & 174 & 49 & $(28,2)$ & 1 & & & \\
\hline$<90$ & 114 & 43 & $(37,7)$ & 1,5 & 0,09 & 357,96 & 17 \\
\hline Escore de Vitalic & & & & & & & \\
\hline 85 a 100 & 104 & 29 & $(27,9)$ & 1 & & & \\
\hline 75 a 80 & 95 & 26 & $(27,4)$ & 1,0 & 0,94 & & \\
\hline 5 a 70 & 89 & 37 & $(41,6)$ & 1,8 & 0,05 & 355,46 & 9 \\
\hline Escore de Aspec & & & & & & & \\
\hline 100 & 192 & 49 & $(25,5)$ & 1 & & & \\
\hline 25 a 88 & 96 & 43 & $(44,8)$ & 2,4 & $\mathbf{0 , 0 0}$ & 350,15 & 4 \\
\hline Escore de Aspec & & & & & & & \\
\hline 100 & 232 & 68 & $(29,3)$ & 1 & & & \\
\hline 0 a 67 & 56 & 24 & $(42,9)$ & 1,8 & $\mathbf{0 , 0 5}$ & 357,16 & 15 \\
\hline Escore de Saúde & & & & & & & \\
\hline 92 a 100 & 84 & 24 & $(28,6)$ & 1 & & & \\
\hline 80 a 88 & 99 & 30 & $(30,3)$ & 1,1 & 0,80 & & \\
\hline 24 a 76 & 105 & 38 & $(36,2)$ & 1,4 & 0,27 & 359,41 & 23 \\
\hline Escore de Dor & & & & & & & \\
\hline 10 a 80 & 89 & 32 & $(36,0)$ & 1 & & & \\
\hline 84 & 35 & 12 & $(34,3)$ & 0,9 & 0,86 & & \\
\hline 100 & 164 & 48 & $(29,3)$ & 0,7 & 0,28 & 359,55 & 24 \\
\hline
\end{tabular}


Tabela 3. Distribuição dos casos de DE detectada pelo IIFE segundo as variáveis explicativas e estimativas do modelo de regressão logística simples (conclusão)

\begin{tabular}{|c|c|c|c|c|c|c|c|}
\hline & $\mathbf{N}$ & $\begin{array}{c}\text { DE } \\
\text { IIFE }\end{array}$ & $\begin{array}{l}\text { \%DE } \\
\text { IIFE }\end{array}$ & OR & $\mathbf{p}$ & $-2 \log \lambda$ & ordem \\
\hline \multicolumn{8}{|c|}{ Outros aspectos emocionais } \\
\hline \multicolumn{8}{|c|}{ Stress } \\
\hline não & 262 & 79 & $(30,2)$ & 1 & & & \\
\hline sim & 26 & 13 & $(\mathbf{5 0 , 0})$ & 2,3 & 0,04 & 356,81 & 14 \\
\hline \multicolumn{8}{|c|}{ Transtorno depressivo e/ou ansioso } \\
\hline Não (SRQ-20 $\leq 5)$ & 258 & 74 & $(28,7)$ & 1 & & & \\
\hline $\operatorname{Sim}(\operatorname{SRQ}-20>5)$ & 30 & 18 & $(60,0)$ & 3,7 & $\mathbf{0 , 0 0}$ & 349,61 & 3 \\
\hline
\end{tabular}

O modelo final (Tabela 4) apresenta os fatores associados à presença da $\mathrm{DE}$ detectada pelo IIFE.

Tabela 4. Estimativas do modelo final de regressão logística múltipla obtido por um procedimento stepwise forward, tendo como variável resposta a presença da DE detectada pelo IIFE

\begin{tabular}{lccc}
\hline Variáveis explicativas & OR & $\mathbf{I C}_{\mathbf{9 5} \%}$ & $\mathbf{p}$ \\
\hline $\begin{array}{l}\text { Desejo sexual atual } \\
\text { excelente }\end{array}$ & 1 & & \\
$\quad$ bom & 2,5 & 0,9 a 7,0 & 0,082 \\
$\quad$ baixo/moderado & 5,5 & 1,2 a 25,1 & 0,027 \\
\hline $\begin{array}{l}\text { DE referida } \\
\quad \text { não }\end{array}$ & 1 & & \\
$\quad$ sim & 7,5 & 0,8 a 71,7 & 0,080 \\
\hline $\begin{array}{l}\text { Transtorno depressivo e/ou ansioso } \\
\quad \text { não }\end{array}$ & 1 & & \\
$\quad$ sim & 2,6 & 1,1 a 6,3 & 0,033 \\
\hline Condição profissional & & & \\
$\quad$ ativo & 1 & & \\
$\quad$ inativo & 3,3 & 1,4 a 7,8 & 0,005 \\
\hline
\end{tabular}

Teste de ajuste do modelo (Hosmer-Lemeshow): $\mathrm{p}=0,83$ 


\subsubsection{DE referida}

A Tabela 5 apresenta a distribuição dos casos de DE referida segundo as categorias de cada variável explicativa. Indivíduos cujo grau de satisfação no relacionamento é moderado ou ruim apresentaram maior chance de referir DE quando comparados àqueles cujo grau de satisfação é ótimo ( $p<0,01)$. Analogamente, os indivíduos que não sentem satisfação pessoal têm mais chance de referir DE do que aqueles que sentem satisfação pessoal $(\mathrm{p}<0,01)$. Indivíduos suspeitos de transtornos depressivos e/ou ansiosos têm maior chance de referir DE quando comparados àqueles não suspeitos $(\mathrm{p}<0,01)$. Outros fatores que aumentam a chance do indivíduo referir DE são: DE detectada pelo IIFE $(\mathrm{p}=0,01)$, não ter atração sexual pela parceira $(\mathrm{p}<0,01)$, sentir-se pouco à vontade para falar sobre sexo $(\mathrm{p}<0,01)$, não ter feito ou não fazer nenhum tipo de tratamento $(\mathrm{p}=0,01)$, pontuar 75 ou menos no escore de aspectos físicos $(p=0,01)$, pontuar 67 ou menos no escore de aspectos emocionais $(\mathrm{p}=0,01)$, ter stress $(\mathrm{p}=0,02)$, não estar satisfeito profissionalmente $(\mathrm{p}=0,05)$.

Convém ressaltar que algumas variáveis, embora pareçam estar associadas à presença da DE auto-referida, não foram significativas devido à ausência de indivíduos na amostra em algumas das suas categorias. Esse é o caso das variáveis desejo sexual atual, escore de saúde mental, escore de vitalidade, preliminares e região de procedência. Não existe nenhum indivíduo que tenha desejo excelente e que tenha referido DE. Isto ocasiona dificuldades na estimação dos parâmetros do modelo e dos seus intervalos de confiança, e os coeficientes acabam por ser superestimados e não significativos. 
Tabela 5. Distribuição dos casos de DE referida pelo respondente segundo as variáveis explicativas e estimativas do modelo de regressão logística simples $^{3}$

\begin{tabular}{|c|c|c|c|c|c|c|c|}
\hline & $\mathbf{N}$ & $\begin{array}{c}\mathrm{DE} \\
\text { referida }\end{array}$ & $\begin{array}{c}\% \mathrm{DE} \\
\text { referida }\end{array}$ & OR & $\mathbf{p}$ & $-2 \log \lambda$ & ordem \\
\hline Características sócio-demo & & & & & & & \\
\hline Idade (anos) & & & & & & & \\
\hline$<=49$ & 226 & 6 & $(2,7)$ & 1 & & & \\
\hline 50 ou mais & 62 & 3 & $(4,8)$ & 1,9 & 0,39 & 79,41 & 18 \\
\hline Região de procedência & & & & & & & \\
\hline outra & 59 & 0 & 0,0 & 1 & & & \\
\hline Sudeste & 227 & 9 & $(4,0)$ & 66693913,1 & 1,00 & 75,74 & - \\
\hline$\overline{\text { Raça/cor }}$ & & & & & & & \\
\hline outra & 87 & 3 & $(3,4)$ & 1 & & & \\
\hline branca & 201 & 6 & $(3,0)$ & 0,9 & 0,84 & 80,06 & 26 \\
\hline Escolaridade & & & & & & & \\
\hline $3^{\circ}$ grau & 82 & 1 & $(1,2)$ & 1 & & & \\
\hline $2^{\circ} \mathrm{grau}$ & 139 & 4 & $(2,9)$ & 2,4 & 0,44 & & \\
\hline $1^{\circ} \mathrm{grau}$ & 67 & 4 & $(6,0)$ & 5,1 & 0,15 & 77,37 & 13 \\
\hline Renda mensal & & & & & & & \\
\hline mais de 5 & 134 & 3 & $(2,2)$ & 1 & & & \\
\hline 1 a 5 & 154 & 6 & $(3,9)$ & 1,8 & 0,43 & 79,43 & 19 \\
\hline Estado civil & & & & & & & \\
\hline solteiro/separado/viúvo & 26 & 0 & 0,0 & 1 & & & \\
\hline casado/mora com alguém & 262 & 9 & $(3,4)$ & 57467499,4 & 1,00 & 78,37 & - \\
\hline Religião & & & & & & & \\
\hline católica & 175 & 6 & $(3,4)$ & 1 & & & \\
\hline outra & 113 & 3 & $(2,7)$ & 0,8 & 0,71 & 79,96 & 23 \\
\hline Condição profissional & & & & & & & \\
\hline ativo & 262 & 8 & $(3,1)$ & 1 & & & \\
\hline inativo & 26 & 1 & $(3,8)$ & 1,3 & 0,83 & 80,05 & 25 \\
\hline Investigação clínica sobre s & lade & & & & & & \\
\hline Tempo de relacionamento & & & & & & & \\
\hline 0 a 14 & 96 & 2 & $(2,1)$ & 1 & & & \\
\hline 15 a 21 & 93 & 4 & $(4,3)$ & 2,1 & 0,39 & & \\
\hline 22 a 39 & 99 & 3 & $(3,0)$ & 1,5 & 0,68 & 79,33 & 16 \\
\hline Grau de satisfação no relac & ento & & & & & & \\
\hline ótimo & 159 & 1 & $(0,6)$ & 1 & & & \\
\hline bom & 104 & 2 & $(1,9)$ & 3,1 & 0,36 & & \\
\hline ruim/moderado & 25 & 6 & $(24,0)$ & 49,9 & $\mathbf{0 , 0 0}$ & $\mathbf{5 9 , 4 5}$ & 1 \\
\hline Atração sexual pela parceir & & & & & & & \\
\hline $\operatorname{sim}$ & 280 & 6 & $(2,1)$ & 1 & & & \\
\hline não & 8 & 3 & $(37,5)$ & 27,4 & $\mathbf{0 , 0 0}$ & 68,57 & 5 \\
\hline
\end{tabular}

\footnotetext{
${ }^{3}$ Foram excluídas da ordem as variáveis em que houve ausência de indivíduos em alguma de suas categorias.
} 
Tabela 5. Distribuição dos casos de DE referida pelo respondente segundo as variáveis explicativas e estimativas do modelo de regressão logística simples (continuação)

\begin{tabular}{|c|c|c|c|c|c|c|c|}
\hline \multirow[b]{2}{*}{ Disfunção pelo IIFE } & \multirow[t]{2}{*}{$\mathbf{N}$} & \multicolumn{2}{|c|}{ DE $\% \mathrm{DE}$} & OR & $\mathbf{p}$ & \multicolumn{2}{|c|}{$-2 \log \lambda$ ordem } \\
\hline & & & & & & & \\
\hline não & 196 & 1 & $(0,5)$ & 1 & & & \\
\hline sim & 92 & 8 & $(8,7)$ & 18,6 & $\mathbf{0 , 0 1}$ & 66,91 & 4 \\
\hline \multicolumn{8}{|l|}{ Preliminares } \\
\hline demoradas & 63 & 0 & 0,0 & 1 & & & \\
\hline nem rápidas nem demoradas & 181 & 7 & $(3,9)$ & 64990363,6 & 1,00 & & \\
\hline não há/rápidas & 44 & 2 & $(4,5)$ & 76927369,1 & 1,00 & 75,53 & - \\
\hline \multicolumn{8}{|l|}{ Como se sente ao falar sobre sexo } \\
\hline à vontade & 208 & 2 & $(1,0)$ & 1 & & & \\
\hline pouco à vontade & 80 & 7 & $(\mathbf{8 , 8})$ & 9,9 & $\mathbf{0 , 0 0}$ & $\mathbf{7 0 , 0 3}$ & 6 \\
\hline \multicolumn{8}{|l|}{ Tem curvatura no pênis } \\
\hline $\operatorname{sim}$ & 20 & 0 & 0,0 & 1 & & & \\
\hline não & 268 & 9 & $(3,4)$ & 56136182,8 & 1,00 & 78,78 & - \\
\hline \multicolumn{8}{|l|}{ Desejo sexual atual } \\
\hline excelente & 31 & 0 & 0,0 & 1 & & & \\
\hline bom & 238 & 2 & $(0,8)$ & 13690465,4 & 1,00 & & \\
\hline baixo/moderado & 19 & 7 & $(36,8)$ & 942360368,5 & 1,00 & 48,11 & - \\
\hline \multicolumn{8}{|c|}{ Satisfação com o tamanho do pênis } \\
\hline não & 7 & 0 & 0,0 & 1 & & & \\
\hline $\operatorname{sim}$ & 281 & 9 & $(3,2)$ & 53453226,4 & 1,00 & 79,65 & - \\
\hline \multicolumn{8}{|l|}{ Satisfação com o próprio corpo } \\
\hline $\operatorname{sim}$ & 253 & 7 & $(2,8)$ & 1 & & & \\
\hline não & 35 & 2 & $(5,7)$ & 2,1 & 0,36 & 79,36 & 17 \\
\hline \multicolumn{8}{|l|}{ 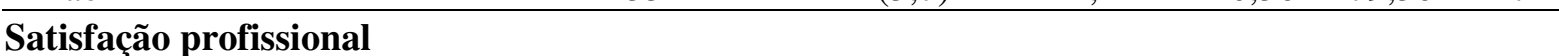 } \\
\hline $\operatorname{sim}$ & 256 & 6 & $(2,3)$ & 1 & & & \\
\hline não & 32 & 3 & $(9,4)$ & 4,3 & $\mathbf{0 , 0 5}$ & $\mathbf{7 6 , 8 1}$ & 12 \\
\hline \multicolumn{8}{|l|}{ Satisfação pessoal } \\
\hline $\operatorname{sim}$ & 279 & 5 & $(1,8)$ & 1 & & & \\
\hline não & 9 & 4 & $(44,4)$ & 43,8 & $\mathbf{0 , 0 0}$ & 62,49 & 2 \\
\hline \multicolumn{8}{|l|}{ Investigação clínica geral } \\
\hline \multicolumn{8}{|l|}{ IMC } \\
\hline normal & 88 & 2 & $(2,3)$ & 1 & & & \\
\hline sobrepeso+obesidade & 200 & 7 & $(3,5)$ & 1,6 & 0,58 & 79,78 & 21 \\
\hline \multicolumn{8}{|l|}{ Qualidadade do sono } \\
\hline ótima & 95 & 1 & $(1,1)$ & 1 & & & \\
\hline boa & 158 & 5 & $(3,2)$ & 3,1 & 0,31 & & \\
\hline ruim/regular & 35 & 3 & $(8,6)$ & 8,8 & 0,06 & 75,94 & 11 \\
\hline \multicolumn{8}{|l|}{ Faz algum tratamento de saúde } \\
\hline $\operatorname{sim}$ & 48 & 5 & $(10,4)$ & 1 & & & \\
\hline não & 240 & 4 & $(1,7)$ & $\mathbf{0 , 1}$ & $\mathbf{0 , 0 1}$ & $\mathbf{7 2 , 7 7}$ & 6 \\
\hline
\end{tabular}


Tabela 5. Distribuição dos casos de DE referida pelo respondente segundo as variáveis explicativas e estimativas do modelo de regressão logística simples (continuação)

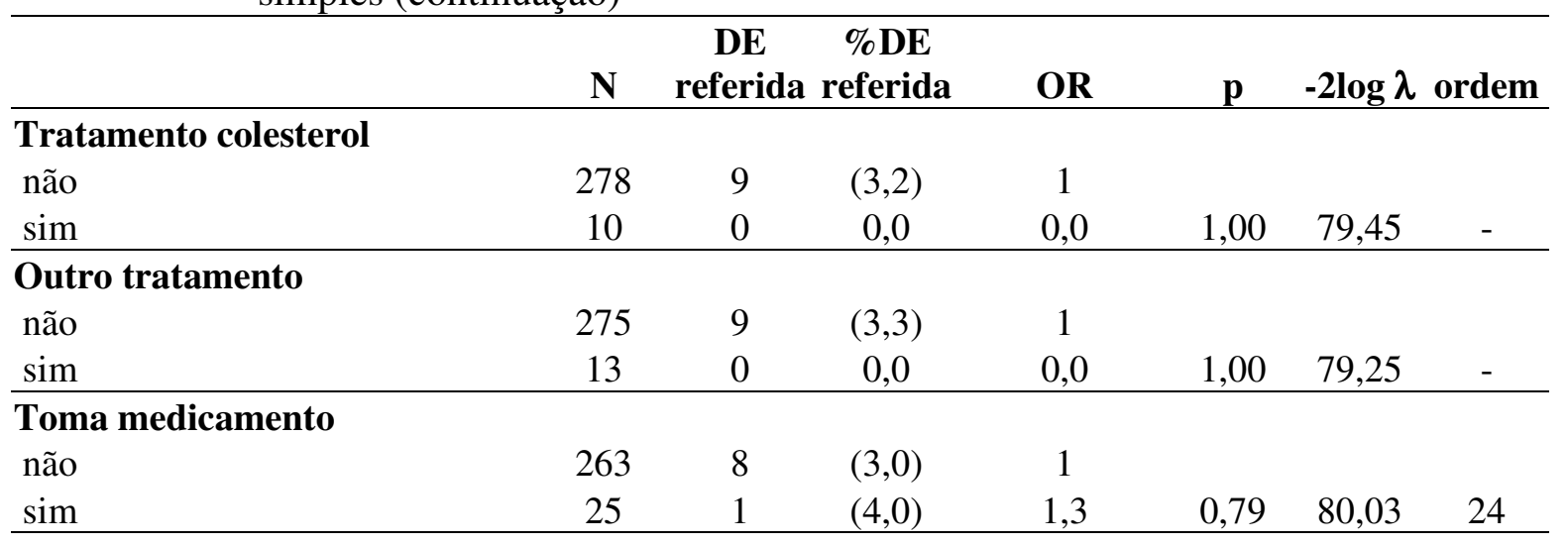

Qualidade de vida

\begin{tabular}{|c|c|c|c|c|c|c|c|}
\hline \multicolumn{8}{|l|}{ Saúde agora } \\
\hline a mesma/pior & 184 & 6 & $(3,3)$ & 1 & & & \\
\hline melhor & 104 & 3 & $(2,9)$ & 0,9 & 0,86 & 80,07 & 27 \\
\hline \multicolumn{8}{|c|}{ Escore de Capacidade Funcional } \\
\hline 100 & 178 & 5 & $(2,8)$ & 1 & & & \\
\hline 95 & 23 & 1 & $(4,3)$ & 1,6 & 0,69 & & \\
\hline 45 a 90 & 87 & 3 & $(3,4)$ & 1,2 & 0,78 & 79,91 & 22 \\
\hline \multicolumn{8}{|c|}{ Escore de Aspectos Físicos } \\
\hline 100 & 235 & 4 & $(1,7)$ & 1 & & & \\
\hline 0 a 75 & 53 & 5 & $(9,4)$ & 6,0 & $\mathbf{0 , 0 1}$ & 73,64 & 7 \\
\hline \multicolumn{8}{|c|}{ Escore de Estado Geral de Saúde } \\
\hline$>=90$ & 174 & 4 & $(2,3)$ & 1 & & & \\
\hline$<90$ & 114 & 5 & $(4,4)$ & 1,9 & 0,33 & 79,13 & 15 \\
\hline \multicolumn{8}{|c|}{ Escore de Vitalidade } \\
\hline 85 a 100 & 104 & 1 & $(1,0)$ & 1 & & & \\
\hline 75 a 80 & 95 & 2 & $(2,1)$ & 2,2 & 0,52 & & \\
\hline 5 a 70 & 89 & 6 & $(6,7)$ & 7,4 & $\mathbf{0 , 0 7}$ & $\mathbf{7 4 , 6 3}$ & 9 \\
\hline \multicolumn{8}{|c|}{ Escore de Aspectos Sociais } \\
\hline 100 & 192 & 4 & $(2,1)$ & 1 & & & \\
\hline 25 a 88 & 96 & 5 & $(5,2)$ & 2,6 & 0,16 & 78,17 & 14 \\
\hline \multicolumn{8}{|c|}{ Escore de Aspectos Emocionais } \\
\hline 100 & 232 & 4 & $(1,7)$ & 1 & & & \\
\hline 0 a 67 & 56 & 5 & $(8,9)$ & 5,6 & $\mathbf{0 , 0 1}$ & 74,11 & 8 \\
\hline \multicolumn{8}{|c|}{ Escore de Saúde Mental } \\
\hline 92 a 100 & 84 & 3 & $(3,6)$ & 1 & & & \\
\hline 80 a 88 & 99 & 0 & 0,0 & 0,0 & 1,00 & & \\
\hline 24 a 76 & 105 & 6 & $(5,7)$ & 1,6 & 0,50 & 71,88 & - \\
\hline \multicolumn{8}{|l|}{ Escore de Dor } \\
\hline 10 a 80 & 89 & 2 & $(2,2)$ & 1 & & & \\
\hline 84 & 35 & 1 & $(2,9)$ & 1,3 & 0,84 & & \\
\hline 100 & 164 & 6 & $(3,7)$ & 1,7 & 0,54 & 79,69 & 20 \\
\hline
\end{tabular}


Tabela 5. Distribuição dos casos de DE referida pelo respondente segundo as variáveis explicativas e estimativas do modelo de regressão logística simples (conclusão)

\begin{tabular}{|c|c|c|c|c|c|c|c|}
\hline & $\mathbf{N}$ & $\begin{array}{c}\mathrm{DE} \\
\text { referida }\end{array}$ & $\begin{array}{c}\% \mathrm{DE} \\
\text { referida }\end{array}$ & OR & $\mathbf{p}$ & $-2 \log \lambda$ & ordem \\
\hline \multicolumn{8}{|c|}{ Outros aspectos emocionais } \\
\hline \multicolumn{8}{|l|}{ Stress } \\
\hline não & 262 & 6 & $(2,3)$ & 1 & & & \\
\hline sim & 26 & 3 & $(\mathbf{1 1 , 5 )}$ & 5,6 & $\mathbf{0 , 0 2}$ & $\mathbf{7 5 , 7 8}$ & 10 \\
\hline \multicolumn{8}{|c|}{ Transtorno depressivo e/ou ansioso } \\
\hline $\begin{array}{l}\text { não } \\
\text { sim }\end{array}$ & $\begin{array}{c}258 \\
\mathbf{3 0}\end{array}$ & $\begin{array}{l}3 \\
6\end{array}$ & $\begin{array}{c}(1,2) \\
(\mathbf{2 0 , 0})\end{array}$ & $\begin{array}{c}1 \\
\mathbf{2 1}, 2\end{array}$ & $\mathbf{0 , 0 0}$ & 62,72 & 3 \\
\hline
\end{tabular}

Devido ao pequeno número de sujeitos que referiram DE optou-se por não realizar a análise multivariada, uma vez que não seria possível ajustar um modelo que estimasse as associações entre DE auto-referida e as outras variáveis com precisão e fidedignidade razoáveis.

\subsubsection{Idade, qualidade de vida, stress e transtornos depressivos e/ou}

ansiosos

A Tabela 6 mostra as medidas de qualidade de vida e a prevalência de stress e suspeita de transtornos depressivos e/ou ansiosos para os dois grupos etários (menores de 50 anos e com 50 anos e mais).

Observou-se uma associação significativa entre o escore de capacidade funcional e a idade, sendo que a prevalência de escores mais baixos (de 45 a 90) é maior entre indivíduos com mais de 50 anos do que entre aqueles mais jovens ( $\mathrm{p}=$ 0,02). Nenhuma associação foi observada entre os demais fatores e a idade. 
Tabela 6. Medidas de qualidade de vida, stress e transtornos depressivos e/ou ansiosos, segundo a idade e nível descritivo do teste Qui-quadrado

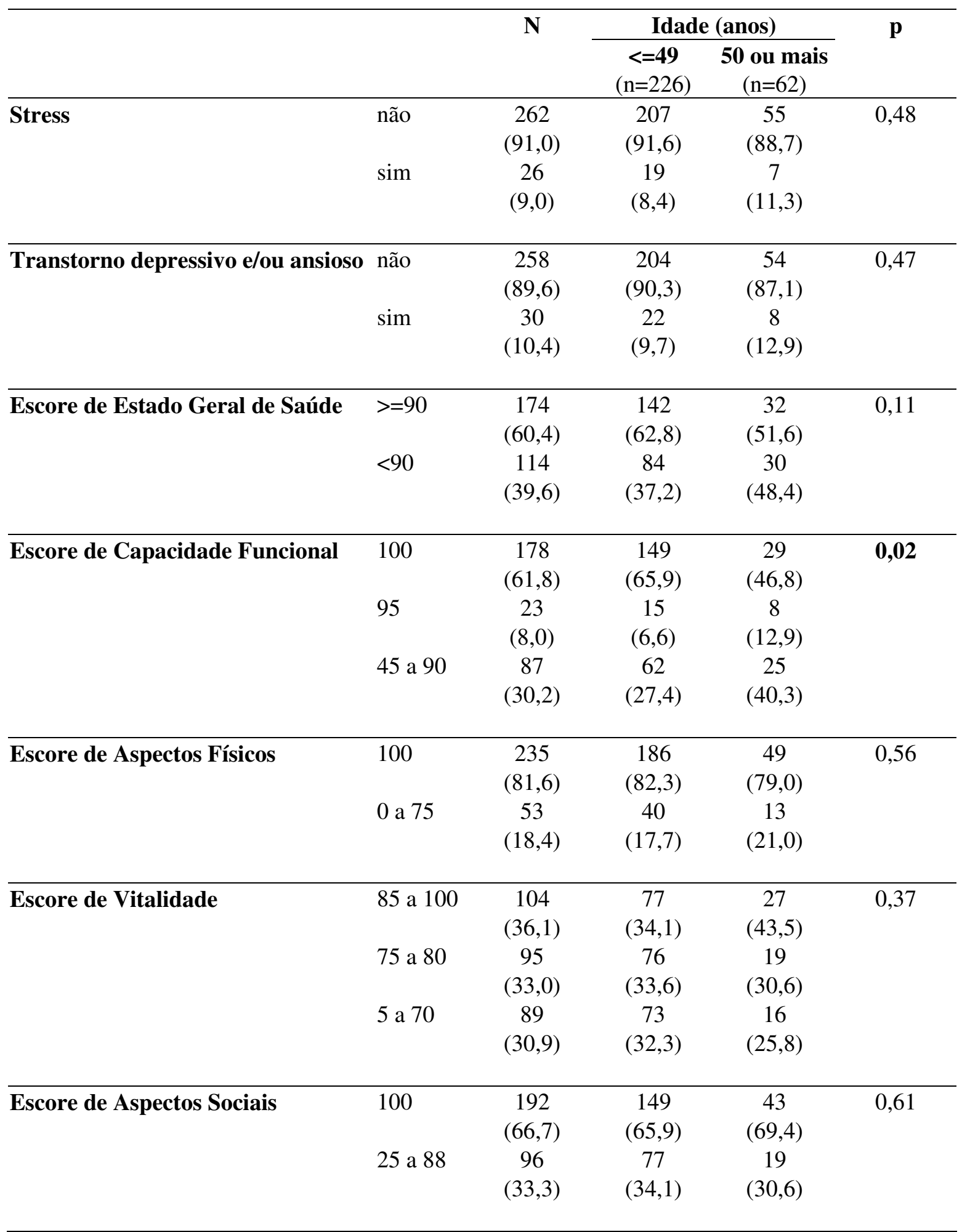


Tabela 6. Medidas de qualidade de vida, stress e transtornos depressivos e/ou ansiosos, segundo a idade e nível descritivo do teste Qui-quadrado (conclusão)

\begin{tabular}{|c|c|c|c|c|c|}
\hline & & $\mathbf{N}$ & Idad & (anos) & $\mathbf{p}$ \\
\hline & & & $\begin{array}{c}<=49 \\
(n=226)\end{array}$ & $\begin{array}{c}50 \text { ou mais } \\
(\mathrm{n}=62)\end{array}$ & \\
\hline Escore de Aspectos Emocionais & 100 & $\begin{array}{c}232 \\
(80,6)\end{array}$ & $\begin{array}{c}182 \\
(80,5)\end{array}$ & $\begin{array}{c}50 \\
(80,6)\end{array}$ & 0,98 \\
\hline & 0 a 67 & $\begin{array}{c}56 \\
(19,4)\end{array}$ & $\begin{array}{c}44 \\
(19,5)\end{array}$ & $\begin{array}{c}12 \\
(19,4)\end{array}$ & \\
\hline Escore de Saúde Mental & 92 a 100 & $\begin{array}{c}84 \\
(29,2)\end{array}$ & $\begin{array}{c}62 \\
(27,4)\end{array}$ & $\begin{array}{c}22 \\
(35,5)\end{array}$ & 0,40 \\
\hline & & $\begin{array}{c}99 \\
(34,4)\end{array}$ & $\begin{array}{c}78 \\
(34,5)\end{array}$ & $\begin{array}{c}21 \\
(33,9)\end{array}$ & \\
\hline & 24 a 76 & $\begin{array}{c}105 \\
(36,5)\end{array}$ & $\begin{array}{c}86 \\
(38,1)\end{array}$ & $\begin{array}{c}19 \\
(30,6)\end{array}$ & \\
\hline Escore de Dor & 10 a 80 & $\begin{array}{c}89 \\
(30,9)\end{array}$ & $\begin{array}{c}66 \\
(29,2)\end{array}$ & $\begin{array}{c}23 \\
(37,1)\end{array}$ & 0,43 \\
\hline & 84 & $\begin{array}{c}35 \\
(12,2)\end{array}$ & $\begin{array}{c}27 \\
(11,9)\end{array}$ & $\begin{array}{c}8 \\
(12,9)\end{array}$ & \\
\hline & 100 & $\begin{array}{c}164 \\
(56,9)\end{array}$ & $\begin{array}{c}133 \\
(58,8)\end{array}$ & $\begin{array}{c}31 \\
(50,0)\end{array}$ & \\
\hline
\end{tabular}


6. DISCUSSÃO 


\subsection{Interpretação dos resultados}

\subsubsection{Prevalência da DE, segundo o IIFE}

A prevalência de algum grau de DE, utilizando-se o IIFE entre doadores de sangue foi 31,9\% (IC $\mathrm{IC}_{95}$ : 26,6\% a 37,7\%). Segundo o índice, 87 (30,2\%; IC $95 \%$ : $25,0 \%$ a $35,9 \%)$ indivíduos possuíam disfunção leve, quatro (1,4\%; IC $95 \%: 0,4 \%$ a $3,5 \%)$ possuíam disfunção moderada e um $\left(0,3 \%\right.$; $\mathrm{IC}_{95 \%}: 0,01 \%$ a $\left.1,9 \%\right)$, disfunção completa. A prevalência da DE leve observada no presente estudo foi semelhante àquelas relatadas em estudos nacionais por Moreira Junior et al. (2001) (31,5\%), Abdo (2004) (31,2\%) e internacionais por Morillo et al. (2002) (33,6\%) e Teles et al. (2008) (35,0\%). É importante notar que estes estudos utilizaram diferentes instrumentos para detecção da DE: questão única nos três primeiros e IIFE no presente trabalho e no estudo de Teles et al. (2008). Também utilizaram diferentes populações para estimar a prevalência da DE: Moreira Junior et al. (2001) e Abdo (2004) entrevistaram voluntários, Morillo et al. (2002) conduziram um inquérito domiciliar e Teles et al. (2008) realizaram seu trabalho com usuários de serviços de atenção primária. Assim, a prevalência da DE leve não apresenta grande variação entre os diferentes estudos, ao passo que as prevalências da DE moderada e completa têm amplas variações em suas estimativas. A prevalência da DE completa variou de 0,6\% (Martin-Morales, 2001) a 21,4\% (Walz et al., 2008). Essa variação nas prevalências das formas mais graves da DE pode ser decorrente dos seguintes fatores: 


\section{Diferenças quanto à idade dos homens incluídos}

Os estudos que incluíram homens mais idosos (até 90 anos) mostraram maiores prevalências da DE moderada e completa (Walz et al., 2008 - 9,4\% e 21,4\%, respectivamente; Rhoden et al., $2002-6,3 \%$ e 11,9\%, respectivamente). Homens mais idosos possivelmente são mais vulneráveis ao aparecimento da DE porque outras condições relacionadas com a idade aumentam a probabilidade da sua ocorrência (NIH, 1993; Kaplan, 1995): presença de doenças sistêmicas, uso de medicamentos que afetam a função erétil e o declínio normal do funcionamento sexual com o envelhecimento (presbyrectia) (Kaplan, 1989).

A partir de sua experiência clínica, Kaplan (1989) definiu presbyrectia como a diminuição, com a idade, da pressão intracavernosa do pênis levando à menor rigidez. Além disso, a presbyrectia também é caracterizada por: (1) diminuição do tempo de manutenção da ereção, com tendência à sua perda com preliminares prolongadas, sendo necessária estimulação tátil da genitália masculina para manter o pênis ereto; (2) maior rapidez ejaculatória e perda parcial progressiva do controle ejaculatório; (3) aumento do tempo para obter uma segunda ereção; (4) necessidade de maior estimulação local física e de maior estimulação psicológica para a obtenção da ereção, devido à diminuição da capacidade sensorial; (5) maior susceptibilidade da resposta sexual à ansiedade.

É provável que as baixas prevalências da DE moderada e completa observadas no presente estudo $(1,4 \%$ e $0,3 \%$, respectivamente) sejam conseqüência da inclusão de homens com idade entre 40 e 60 anos, portanto relativamente jovens. Não foram incluídos homens mais velhos porque o principal objetivo do estudo foi 
estimar a prevalência da DE em homens considerados saudáveis e a participação de sujeitos mais idosos levaria à inclusão potencial de maior número de respondentes com doenças associadas à $\mathrm{DE}$ e/ou que usassem medicamentos que interferem na função erétil.

\section{Diferenças quanto à origem da população estudada}

Estudos que incluíram homens que foram avaliados quanto à presença da $\mathrm{DE}$ ao procurarem atendimento em campanhas de conscientização sobre câncer de próstata apresentaram altas prevalências da DE completa (Rhoden et al., 2002; Walz et al., 2008). Um estudo que avaliou a presença da DE em homens atendidos por médicos generalistas na Austrália (Chew et al., 2000) também encontrou alta prevalência da DE completa $(18,6 \%)$. Estudos conduzidos com voluntários que participaram de campanhas sobre o câncer de próstata possivelmente incluem maior número de homens com sintomas urológicos que podem estar associados à DE. É possível que a inclusão de participantes a partir de recrutamento em serviços de saúde leve à detecção de mais casos de DE moderada e completa porque estes homens podem apresentar doenças clínicas ou queixas psicológicas associadas à presença da DE ou utilizaram medicações que interferem na função erétil. 


\subsubsection{Comparação entre a prevalência da DE, segundo o IIFE, e a prevalência da DE referida}

A prevalência da $\mathrm{DE}$ referida foi 3,1\%; ( $\mathrm{IC}_{95 \%}$ : 1,4\% a 5,8\%), superior à observada em outro estudo nacional (1,7\%) (Lopes, 2000); todavia, neste último, todos os homens que referiram ter DE apresentavam doenças clínicas, especialmente diabetes mellitus e hipertensão arterial sistêmica.

Apenas oito dos 92 sujeitos que foram classificados como tendo pelo menos algum grau de DE referiram ter DE. Assim, a concordância entre DE detectada pelo IIFE e DE referida foi baixa (kappa $=0,11 ; \mathrm{p}<0,001)$. Outros estudos que tentaram avaliar DE usando questões relacionadas à autopercepção dos sujeitos e o IIFE encontraram importantes diferenças nos resultados obtidos com as duas formas de avaliação: na China (Wu et al., 2007) e na Espanha (Martin-Morales et al., 2001), porém, foram observadas prevalências da DE auto-referida mais elevadas que as encontradas no presente estudo (respectivamente $12,1 \%$ e $13,1 \%$ ) e prevalências da DE identificadas com uso do IIFE mais baixas (18,9\% e 26,0\%). É possível que tanto diferenças metodológicas na condução dos estudos como características culturais expliquem as variações observadas.

Martin-Morales et al. (2001) argumentam que a prevalência global da DE foi maior pelo domínio da função erétil do IIFE em comparação com a prevalência observada pela questão única porque os dois instrumentos detectaram diferentes intensidades da DE: um grande número de indivíduos com DE leve foram detectados pelo domínio da função erétil do índice, enquanto que a questão única, baseada na 
auto-avaliação da função erétil, detectou um número maior de indivíduos nas categorias moderada e completa.

Wu et al. (2007) observaram discrepância entre a detecção da DE usando o IIFE-5 e a informação sobre DE auto-referida em duas direções: alguns homens classificados com algum grau de DE pelo IIFE-5 não referiam ter DE, enquanto outros que não relataram DE apresentavam DE quando avaliados pelo índice.

No presente estudo a questão "Você se sente potente sexualmente?" foi utilizada para pesquisar a autopercepção que os homens têm sobre a sua função erétil. Dos nove participantes que referiram não se sentirem potentes sexualmente, seis foram classificados pelo IIFE como tendo DE leve, um, DE moderada e outro, DE completa. Um participante que referiu não se sentir potente foi classificado sem DE pelo IIFE. É possível que isso se deva às diferentes dimensões avaliadas: enquanto a pergunta "Você se sente sexualmente potente?" pode ter sua resposta afetada pelo grau de conhecimento do sujeito sobre potência sexual, por sua autoestima, por seu estado de humor e pela satisfação obtida em suas relações sexuais e afetivas, o IIFE avalia a função erétil dentro de uma perspectiva mais "funcional" (dificuldade para ter ou manter a ereção, por exemplo). Se por um lado perguntar apenas se o homem sente-se potente sexualmente pode levar à obtenção de informação pouco precisa e possivelmente subestimada, por outro a pesquisa da DE utilizando-se apenas o IIFE pode levar à valorização do aspecto funcional ou mecânico da função erétil em detrimento dos aspectos relacionais e comportamentais. A autopercepção é fator indispensável para que o sujeito tome consciência das mudanças em sua função erétil e procure ajuda e tratamento. 


\subsubsection{Busca de tratamento para DE}

Apenas dois sujeitos dentre os nove que relataram não se sentirem potentes sexualmente procuraram tratamento. Um deles, embora não se sentisse sexualmente potente, foi classificado sem DE pelo IIFE. Esses resultados não permitem chegar a uma estimativa confiável da prevalência da busca por tratamento entre indivíduos que não se sentem potentes sexualmente. Outros estudos mostraram a baixa procura de tratamento por homens com dificuldades sexuais (Laumann et al., 1999) e DE (Chew et al., 2008). Talvez esses achados apontem para a não percepção da DE como um problema de saúde passível de tratamento, como já salientado pelo Grupo de Consenso em Impotência coordenado pelo Instituto Nacional de Saúde NorteAmericano (NIH, 1993) e observado por Moreira Junior et al. (2005).

Por outro lado, dos 12 sujeitos excluídos do estudo por já terem feito uso de medicações para obter ereção, seis o fizeram por iniciativa própria. Assim, se a procura por tratamento entre os sujeitos que não se sentiam sexualmente potentes foi baixa, alguns homens usaram medicações indicadas para DE sem orientação médica. Muitos homens fazem uso de medicamentos orais indicados para o tratamento da DE na expectativa de aumentar o vigor sexual. Em 2004, segundo dados das maiores redes de farmácias do Brasil, estimava-se que um terço dos compradores de medicamentos orais indicados para tratar DE eram homens jovens, com cerca de 30 anos (Em busca de diversão. Revista Veja - Edição Especial HOMEM, 2004). Wannmacher (2006), na publicação Uso Racional de Medicamentos do Ministério da Saúde, afirma que: 
Desde sua introdução em 1998, o sildenafil adquiriu a reputação de ser um fármaco capaz de mudar estilos de vida. Isso condicionou uma venda incontrolável, envolvendo somas astronômicas e gerando inúmeros mitos que, compreensivelmente, cercam um terreno delicado e cheio de tabus, qual seja o do desempenho sexual.

Desta forma, a procura por tratamento para DE é afetada por aspectos psicológicos e culturais de duas formas: por um lado, movidos pelo mito da competência masculina incondicional, há evidências que homens sem alterações da função erétil fazem uso "recreativo" do sildenafil e similares para obter uma performance sexual idealizada; por outro, homens que não se sentem potentes sexualmente, por vergonha e por sentirem que não se comportam de acordo com o mesmo mito, não procuram tratamento para a DE e comprometem sua qualidade de vida e relações afetivas, e podem deixar de ter diagnosticadas várias doenças das quais a DE pode ser a manifestação inicial (por exemplo, diabetes mellitus e doenças cardiocirculatórias).

\subsubsection{Fatores associados à DE}

Após a realização da análise multivariada os fatores associados à presença da DE detectada pelo IIFE foram: inatividade profissional $\left(\mathrm{OR}=3,3 ; \mathrm{IC}_{95 \%}: 1,4\right.$ a 7,$8 ; \mathrm{p}$ $=0,005)$; suspeita de transtorno depressivo e/ou ansioso $\left(\mathrm{OR}=2,6 ; \mathrm{IC}_{95 \%}: 1,1\right.$ a 6,3 ; $\mathrm{p}=0,033)$; desejo sexual bom (não excelente) $\left(\mathrm{OR}=2,5 ; \mathrm{IC}_{95 \%}: 0,9\right.$ a 7,0; $\mathrm{p}=$ 
0,082); desejo sexual baixo/moderado ( $\mathrm{OR}=5,5 ; \mathrm{IC}_{95 \%}: 1,2$ a 25,$\left.1 ; \mathrm{p}=0,027\right) \mathrm{e}$ referir $\mathrm{DE}\left(\mathrm{OR}=7,5 ; \mathrm{IC}_{95 \%}: 0,8\right.$ a 71,7; $\left.\mathrm{p}=0,080\right)$. $\mathrm{O}$ fato de as outras variáveis que foram significativas no modelo univariado não terem permanecido no modelo múltiplo (por ex., escore de aspectos sociais, escore de vitalidade, satisfação profissional etc.) não quer dizer que tais variáveis não estejam associadas à presença da DE, mas apenas que, uma vez incluídas no modelo o desejo sexual atual, a DE referida, a suspeita de transtorno depressivo e/ou ansioso e a condição profissional, as demais variáveis medidas não acrescentam nenhuma informação adicional.

Nota-se ainda que, no modelo de regressão múltipla, os coeficientes de algumas variáveis diminuíram, quando comparados com os modelos de regressão simples. Este fato ocorreu com o desejo sexual atual, por exemplo. No modelo simples, a OR para indivíduos com desejo baixo ou moderado foi 11,3 e, no modelo múltiplo, a OR passou para 5,5. Isto ocorreu porque uma parte do efeito da diminuição do desejo observado no modelo simples era, na verdade, devido à percepção da não potência sexual ou porque tais indivíduos eram inativos profissionalmente ou suspeitos de transtorno depressivo e/ou ansioso. O mesmo tipo de raciocínio vale para explicar porque algumas variáveis que eram significantes no modelo simples não permaneceram no modelo múltiplo.

\section{$\underline{\text { Inatividade profissional }}$}

A associação entre inatividade profissional e presença de DE observada no presente estudo fora já relatada em outros estudos. Abdo el al. (2006) observaram que homens desempregados apresentavam maior prevalência da DE que homens 
empregados $\left(\mathrm{OR}=1,3 ; \mathrm{IC}_{95 \%}: 1,0\right.$ a 1,8). Seyam et al. (2003) também observaram uma associação significativa entre desemprego e DE em um estudo de prevalência que incluiu homens residentes em áreas urbanas e rurais do Egito. A mesma associação foi observada por Morillo et al. (2002) no Equador e na Venezuela. Chew et al. (2008) demonstraram que homens aposentados devido a problemas de saúde tinham maior chance de apresentar $\mathrm{DE}$ que homens empregados $\left(\mathrm{OR}=3,4 ; \mathrm{IC}_{95 \%}\right.$ : 2,0 a 5,9). Todavia, é possível que a maior prevalência da DE entre os homens inativos seja conseqüência dos problemas de saúde que levaram à aposentadoria e não da inatividade profissional.

A associação entre inatividade profissional e presença da DE pode ser entendida de várias formas: por um lado, a inatividade profissional pode fazer parte ela própria do contexto de um momento de sofrimento psíquico, do qual a DE pode ser parte, seja como causa (nas situações de desemprego, por exemplo), seja como conseqüência (nos casos de afastamento das atividades em função de doenças clínicas e/ou sintomas depressivos); por outro, culturalmente é esperado que homens trabalhem e sejam provedores. Lipp et al. (2005) observaram que a ênfase social colocada na competência masculina é uma fonte interna de stress muito comum entre homens. Para alguns homens o fato de estarem inativos pode significar ser menos masculino, e a DE pode ser uma extensão dessa sensação de "ser pouco potente".

\section{$\underline{\text { Transtornos depressivos e/ou ansiosos }}$}

A associação entre DE e transtornos depressivos já fora relatada na literatura por Feldman et al (1994), Araujo et al. (1998) e Abdo (2004), dentre outros. Kaiser 
(1996) sugere que a depressão e transtornos de ansiedade (em qualquer de suas apresentações: generalizada, pânico, fobia etc) são duas das causas mais ligadas ao desencadeamento da DE. Sugimori et al. (2005), em um estudo de corte transversal no qual foram incluídos 1419 homens japoneses com idade entre 40 e 64 anos que realizaram exames de check-up em seus locais de trabalho, observaram uma associação significativa entre transtornos depressivos e ansiosos e DE somente para a faixa etária de 45 a 54 anos (os autores postulam que as doenças físicas e o próprio envelhecimento seriam os principais fatores associados à $\mathrm{DE}$ em homens mais velhos).

Não é possível estabelecer relações de causa e efeito entre transtornos depressivos e/ou ansiosos e a presença da DE, uma vez que o presente estudo avaliou estas condições simultaneamente. A DE pode fazer parte de um contexto maior dos

sintomas depressivos e ansiosos, em que podem ocorrer alterações marcantes do desejo e da performance sexual. Nesse sentido, a DE pode ser entendida como um marcador de sofrimento psíquico, mais do que como um transtorno em si. Assim, diante de um paciente com DE é importante que o profissional de saúde investigue se há ou não quadro de sintomas psíquicos associados.

\section{$\underline{\text { Desejo sexual }}$}

Dados do Estudo da Vida Sexual do Brasileiro (EVSB) (Abdo et al., 2006) mostraram que homens com DE apresentam mais freqüentemente queixa de falta de desejo sexual do que homens sem DE. Teles et al. (2008) também relataram associação significativa entre a falta de desejo sexual e DE. Conforme Rangé e 
Conceição (2001) a falta de desejo sexual pode refletir problemas como depressão ou aparecer como defesa contra a DE, ou seja, quando episódios de falha erétil estimulam uma evitação sexual que acaba manifestando uma inibição do desejo. Também é possível que a falta de desejo sexual em alguns homens se deva ao não reconhecimento dos sinais prematuros de excitação sexual limitando os comportamentos sexuais, isto é, quando julgam o comportamento impulsivo como único iniciador da atividade sexual, não atribuindo, por exemplo, a um beijo ou uma carícia seu papel estimulador (Rangé, Conceição, 2001).

\section{$\underline{\text { Sensação de não ser potente sexualmente }}$}

A forma como cada homem se percebe quanto à função erétil pode refletir tanto os aspectos funcionais da ereção como a maneira como ele se vê perante a parceira e outras situações da vida. Enquanto alguns homens foram classificados como tendo DE pelo IIFE e sentiam-se sexualmente potentes, um deles não se sentia potente sexualmente e não apresentava DE de acordo com o IIFE. Porém a sensação subjetiva de não potência sexual esteve associada à detecção da DE pelo índice no presente estudo e pode tanto significar uma percepção realista e acertada da função sexual quanto uma maneira de se enxergar diante da vida e do mundo. Assim, a não potência existencial traduzir-se-ia em DE.

Cabe ressaltar que as relações entre os fatores associados à DE observados no presente estudo não são estanques, mas apresentam interfaces. A inatividade profissional pode estar diretamente associada à DE. No entanto, ela pode primariamente levar à diminuição do desejo sexual e esta ser a causa da DE. A 
inatividade também pode ser causada pela presença de transtornos depressivos e/ou ansiosos e a DE pode ser um dos sintomas destes transtornos. Da mesma forma, transtornos depressivos e/ou ansiosos podem ter como desencadeantes a sensação subjetiva de não potência sexual ou a própria DE (quando, por exemplo, esta é causada por doenças clínicas). Sinteticamente, há grande interação entre os fatores biológicos, culturais e psicológicos no surgimento e manutenção da DE, como apresentado no Esquema 1.

Esquema 1. Relações entre a DE e os fatores associados.

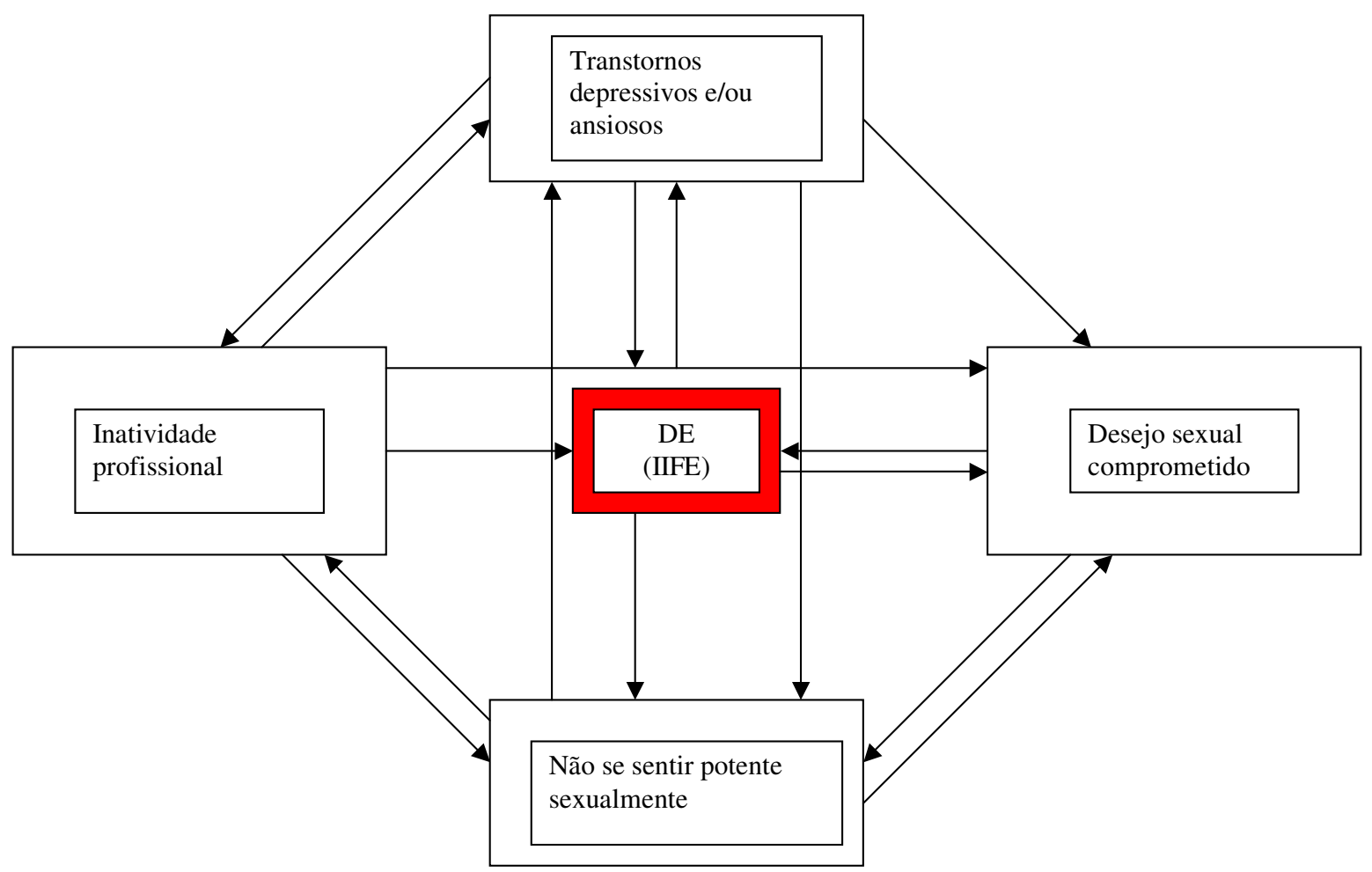




\subsubsection{Relação entre DE, idade e capacidade funcional}

Contrariando os resultados da maior parte dos trabalhos sobre prevalência da DE e fatores associados, no presente estudo não foi observada associação entre idade e DE. É possível que isso se deva às características da amostra incluída, homens de meia idade (40 a 60 anos), considerados saudáveis. Esses homens, possivelmente, ainda não apresentam efeitos do envelhecimento sobre a função erétil, já que ainda não são idosos.

Os homens com 50 anos ou mais de idade apresentaram maior freqüência de escore de capacidade funcional do SF-36 entre 45 e 90 (40,3\%) quando comparados aos homens com idade entre 40 e 49 anos $(30,2 \% ; \mathrm{p}=0,02)$. Na análise univariada também foi observada uma associação entre piores escores de capacidade funcional e DE segundo o IIFE (OR = 1,9; $\mathrm{p}=0,02)$. A associação entre idade e piores escores no domínio da capacidade funcional do SF-36 já havia sido relatada por SánchezCruz et al. (2003), que observaram correlações negativas entre todos os domínios da escala e a idade dos sujeitos incluídos em seu estudo e entre todos os domínios do SF-36 e a pontuação no IIFE, especialmente nos componentes físicos da qualidade de vida. É possível que a associação entre piores escores de qualidade de vida e DE não tenha sido verificada no modelo final do presente estudo porque a amostra incluída foi mais homogênea quanto à distribuição etária (40 a 60 anos) que aquela incluída no estudo de Sánchez-Cruz et al. (2003), com homens de idade entre 25 e 70 anos. 


\subsection{Limitações Metodológicas}

A condução do estudo tendo como sujeitos doadores de sangue foi a estratégia utilizada como alternativa à realização de estudos com usuários de serviços de saúde e voluntários, possivelmente mais propensos a apresentarem DE que a população em geral. É importante ressaltar, porém, que a prevalência encontrada entre doadores de sangue pode ser mais baixa que a da população geral, uma vez que se trata de um grupo bastante selecionado e possivelmente com melhores condições de saúde em geral. Além disso, aproximadamente $70 \%$ dos participantes tinham idade entre 40 e 50 anos, o que pode também levar à subestimação da prevalência de DE encontrada na amostra.

Optou-se por excluir os 12 sujeitos que fizeram ou faziam uso de medicação eretogênica uma vez que o objetivo do estudo era estimar a prevalência da DE percebida, e o uso dessas medicações poderia alterar a performance sexual e a percepção dos sujeitos quanto à própria função erétil.

O fato de ter-se optado pela auto-aplicação dos instrumentos pode ter levado à imprecisão da informação colhida, já que algumas questões contidas nos instrumentos de pesquisa utilizados contêm termos técnicos ou contêm a palavra "não" em sua formulação, o que pode levar a dificuldades de compreensão por parte dos sujeitos. Por outro lado, dado o teor íntimo de várias questões, é possível que os participantes sintam-se mais à vontade para respondê-las a sós que informando um pesquisador.

Este trabalho foi desenvolvido sob a forma de um estudo de corte transversal (ou prevalência) e não permite inferências causais entre o desfecho estudado (DE 
segundo o IIFE) e as características dos sujeitos estudados (por exemplo, a DE precedeu a ocorrência de transtornos depressivos e/ou ansiosos ou desenvolveu-se a partir do surgimento destes sintomas). Todavia, ele aponta a existência de associações importantes, que poderão ser investigadas usando-se outras estratégias de pesquisa.

Convém ressaltar alguns aspectos e limitações na interpretação dos resultados. Uma vez que a presença da DE segundo o IIFE não é um evento raro (a prevalência foi $31,9 \%$ ), sabe-se que as OR estimadas pelos modelos de regressão podem superestimar o verdadeiro valor da associação entre ter DE segundo o índice e as demais variáveis. Entretanto, uma OR significativa indica a presença de associação. Assim, essas análises foram utilizadas preferencialmente para identificar os fatores que se mostram associados à DE sem, no entanto, permitir estimativas precisas sobre a magnitude dessas associações.

Não foi possível investigar a associação entre as características dos sujeitos e a presença da DE referida que foram obtidas após a análise univariada com a construção de um modelo de regressão logística múltipla devido ao pequeno número de participantes do estudo que relataram esta condição. Estudos futuros, com amostras maiores, poderão permitir o aprofundamento da investigação sobre a prevalência da DE referida. 


\subsection{Considerações finais - Implicações para a pesquisa e abordagem}

\section{da DE em serviços de saúde}

Os achados do presente estudo corroboram a hipótese de que a DE pode ser encontrada entre homens considerados saudáveis. Embora os resultados evidenciem uma prevalência da DE mais baixa que a de outros estudos conduzidos com outros tipos de amostras no país, trata-se de uma condição bastante prevalente (três em cada dez homens com idade entre 40 e 60 anos apresenta algum grau de DE segundo o IIFE). Em contrapartida, a procura por tratamento permanece errática, já que indivíduos que referem DE não procuraram tratamento e outros fizeram uso da medicação eretogênica oral sem qualquer orientação médica. É importante que os profissionais de saúde estejam atentos para a saúde sexual dos homens, especialmente após os 40 anos de idade, e para as possíveis condições que podem acompanhar a DE (doenças sistêmicas, sofrimento psíquico e outros aspectos psicossociais). Uma abordagem multidisciplinar pode ser de grande utilidade para definir o problema e chegar a uma solução (NIH, 1993).

Para o aprofundamento dos estudos sobre a relação entre DE e fatores sóciodemográficos, culturais, clínicos e inerentes à afetividade e relacionamentos é importante a realização de estudos que possam investigar associações causais entre esses fatores (por exemplo, estudos de coorte) e sua significação para os homens (por meio de abordagens de pesquisa qualitativa). 
7. CONCLUSÕES 


\section{Conclusões}

1- A prevalência da DE, segundo o IIFE, entre homens heterossexuais, com idade entre 40 e 60 anos, foi de $31,9 \%$ (IC $95 \%: 26,6 \%$ a $37,7 \%)$.

2- $\quad$ A prevalência da DE auto-referida, na mesma amostra, foi de $3,1 \%\left(\mathrm{IC}_{95 \%}: 1,4 \%\right.$ a $\left.5,8 \%\right)$.

3- Dentre os nove sujeitos que não se sentiam potentes sexualmente, apenas dois $(22,2 \%)$ procuraram tratamento para a DE.

4- Os fatores associados à presença da DE, segundo o IIFE, foram: inatividade profissional $\left(\mathrm{OR}=3,3 ; \mathrm{IC}_{95 \%}: 1,4\right.$ a 7,$8 ; \mathrm{p}=$ 0,005); suspeita de transtorno depressivo e/ou ansioso $(\mathrm{OR}=$ 2,6; $\mathrm{IC}_{95 \%}$ : 1,1 a 6,$3 ; \mathrm{p}=0,033$ ); desejo sexual bom (não excelente) $\left(\mathrm{OR}=2,5 ; \mathrm{IC}_{95 \%}: 0,9\right.$ a 7,$\left.0 ; \mathrm{p}=0,082\right)$, ou baixo/moderado $\left(\mathrm{OR}=5,5 ; \mathrm{IC}_{95 \%}: 1,2\right.$ a 25,$\left.1 ; \mathrm{p}=0,027\right) \mathrm{e}$ referir $\mathrm{DE}\left(\mathrm{OR}=7,5 ; \mathrm{IC}_{95 \%}: 0,8\right.$ a 71,$\left.7 ; \mathrm{p}=0,080\right)$.

Depreende-se do acima exposto, que a prevalência da DE segundo o IIFE, nesses homens, foi 10 vezes maior que a da autopercepção dessa condição. Os fatores associados à DE mostraram estreita relação com componentes psicossociais (inatividade profissional, suspeita de transtorno depressivo e/ou ansioso, desejo sexual comprometido e não se sentir potente sexualmente), em homens cuja saúde física é considerada acima da média na população masculina brasileira. Releva 
realçar que os aspectos psicossociais têm um peso de suma importância na etiologia da DE, o que não é mensurável pelos critérios de saúde física. 
8. ANEXOS 
ANEXO A

\section{TERMO DE CONSENTIMENTO LIVRE E ESCLARECIDO}

Esta é uma Pesquisa sobre Saúde Masculina, que visa a conhecer o perfil de saúde do homem na faixa de 40 a 60 anos. A finalidade deste estudo é levantar informações relevantes sobre vários aspectos físicos e emocionais que podem interferir e se estender, negativamente, na qualidade de vida do indivíduo que se encontra na faixa etária estipulada por esta pesquisa, e, colocar essas informações à disposição dos profissionais da saúde.

Para fazer parte do grupo deste estudo, você terá de responder 6 (seis) questionários apresentados de uma só vez, neste único encontro, na seguinte seqüência: o primeiro consiste de 9 (nove) itens sobre a identificação da sua pessoa, o segundo consiste de 15 itens sobre a sua atividade sexual, o terceiro consiste de 11 (onze) itens sobre a sua qualidade de vida, o quarto 6 (seis) quadros que contêm 53 afirmações cujos itens que você assinalar estarão avaliando a presença ou não de sintomas de stress, o quinto 20 (vinte) itens sobre a sua saúde, e, o sexto são 17 (dezessete) itens sobre aspectos mais abrangentes de sua vida.

Para responder aos questionários é importante que você saiba que a sua identificação não será divulgada e que não existem respostas certas ou erradas. Portanto, você pode ficar à vontade para responder o que acontece com você.

Não há risco em participar desta pesquisa. Se houver algum incômodo, este será devido apenas ao tempo que você usará para responder aos questionários.

Os resultados obtidos com este estudo poderão oferecer, tanto para você e outros homens de sua idade, quanto para os especialistas em saúde, conhecimentos mais aprofundados sobre várias dificuldades físicas e emocionais que pode enfrentar a população masculina que transita por essa fase da vida.

O benefício deste trabalho para você e outros homens dessa faixa etária poderá se refletir no sentido de propiciar iniciativas próprias para buscar o bem-estar físico e emocional, evitando assim, sofrimentos desnecessários.

O fato de você aceitar participar desta pesquisa não o obriga a responder os questionários até o final. Caso você decida desistir de participar deste estudo, não haverá nenhum impedimento contra isso e nem para você continuar o procedimento médico que o trouxe a este hospital.

$\mathrm{Eu}$,

concordo em responder os questionários elaborados pela pesquisadora Margareth de Mello Ferreira dos Reis, como forma de participação no referido trabalho de pesquisa, sobre o qual considero estar devidamente informado e esclarecido.

São Paulo, de de

Assinatura do participante da pesquisa

Assinatura do pesquisador (carimbo ou nome legível) 
IDADE:

\section{RAÇA/COR:}

( ) branca

( ) parda (mulato)

( ) negra

( ) amarela

( ) outra. Qual?

NACIONALIDADE:

( ) brasileira

( ) estrangeira

( ) estrangeiro naturalizado

NASCIDO NA CIDADE DE: ESTADO DE:

PAÍS:

ESCOLARIDADE:

( ) completou a faculdade

( ) faculdade incompleta

( ) completou o segundo grau

( ) segundo grau incompleto

( ) completou o primeiro grau

( ) primeiro grau incompleto

\section{RENDA MENSAL:}

( ) entre 1 e 5 salários - mínimos

( ) entre 6 e 10 salários - mínimos

( ) entre 11 e 15 salários - mínimos

( ) entre 16 e 20 salários - mínimos

( ) mais de 21 salários - mínimos

\section{ESTADO CIVIL:}
( ) solteiro
( ) casado
( ) mora com alguém
( ) separado ou divorciado
( ) viúvo 
RELIGIÃO:

( ) católica

( ) protestante

( ) evangélica

( ) espírita

( ) outra religião

( ) não tem religião

\section{CONDIÇÃO PROFISSIONAL}

( ) ativo profissionalmente

( ) aposentado ativo

( ) aposentado inativo

( ) outra. Qual?

( ) desempregado 
ANEXO C

\section{ÍNDICE INTERNACIONAL DE FUNÇÃO ERÉTIL (IIFE)}

(Rosen et al., 1997; Ferraz, Ciconelli, 1998)

Estas questões referem-se ao efeito que os seus problemas de ereção têm acarretado na sua vida sexual nas últimas quatro semanas. Por favor, responda estas questões, o mais honestamente e claramente possível.

Por favor, responda a cada questão marcando com um $\mathbf{X}$ o quadradinho correspondente.

Se você não tem certeza de como responder, por favor, dê a melhor resposta que você puder.

Ao responder estas questões observe as seguintes definições:

* Relação sexual

É definida como penetração (entrada) na vagina da parceira.

** Atividade sexual

Inclui relação sexual, carícias, brincadeiras amorosas e masturbação.

*** Ejaculação

É definida como a ejeção de sêmen pelo pênis (ou a sensação desta ejeção)

**** Estimulação sexual

1) Nas últimas 4 semanas, com que freqüência você foi capaz de ter ereção durante uma atividade sexual**?

(0) Sem atividade sexual

(5) Quase sempre ou sempre

(4) A maioria das vezes (muito mais que a metade das vezes)

(3) Algumas vezes (aproximadamente a metade das vezes)

(2) Poucas vezes (muito menos que a metade das vezes)

(1) Quase nunca ou nunca

2) Nas últimas 4 semanas quando você teve ereções com estimulação sexual****, com que freqüência foram suas ereções, duras o suficiente para penetração?

(0) Sem atividade sexual

(5) Quase sempre ou sempre

(4) A maioria das vezes (muito mais que a metade das vezes)

(3) Algumas vezes (aproximadamente a metade das vezes)

(2) Poucas vezes (muito menos que a metade das vezes)

(1) Quase nunca ou nunca 
3) Nas últimas 4 semanas, quando você tentou ter relação sexual*, com que frequiência você foi capaz de penetrar (entrar) na sua parceira?

(0) Não tentei ter relação sexual

(5) Quase sempre ou sempre

(4) A maioria das vezes (muito mais que a metade das vezes)

(3) Algumas vezes (aproximadamente a metade das vezes)

(2) Poucas vezes (muito menos que a metade das vezes)

(1) Quase nunca ou nunca

4) Nas últimas 4 semanas, durante a relação sexual*, com que freqüência você foi capaz de manter sua ereção após ter penetrado (entrado) na sua parceira?

(0) Não tentei ter relação sexual

(5) Quase sempre ou sempre

(4) A maioria das vezes (muito mais que a metade das vezes)

(3) Algumas vezes (aproximadamente a metade das vezes)

(2) Poucas vezes (muito menos que a metade das vezes)

(1) Quase nunca ou nunca

5) Nas últimas 4 semanas, durante uma relação sexual*, o quanto foi difícil para você manter sua ereção até o fim da relação?

(0) Não tentei ter relação sexual

(1) Extremamente difícil

(2) Muito difícil

(3) Difícil

(4) Pouco difícil

(5) Sem dificuldade

6) Nas últimas 4 semanas, quantas vezes você tentou ter relação sexual*?

(0) Não tentou

(1) 1-2 tentativas

(2) 3-4 tentativas

(3) 5-6 tentativas

(4) 7-10 tentativas

(5) 11 ou mais tentativas

7) Nas últimas 4 semanas, quando você tentou ter relação sexual*, com que frequiência ela foi satisfatória para você?

(0) Não tentei ter relação sexual

(5) Quase sempre ou sempre

(4) A maioria das vezes (muito mais que a metade das vezes)

(3) Algumas vezes (aproximadamente a metade das vezes)

(2) Poucas vezes (muito menos que a metade das vezes)

(1) Quase nunca ou nunca 
8) Nas últimas 4 semanas, o quanto você aproveitou a relação sexual*?

(0) Não teve relação sexual

(5) Aproveitou extremamente

(4) Aproveitou muito

(3) Aproveitou um tanto

(2) Aproveitou muito pouco

(1) Não aproveitou

9) Nas últimas 4 semanas, quando você teve estimulação sexual**** ou relação sexual, com que frequiência você teve uma ejaculação***?

(0) Não teve estimulação sexual ou relação sexual

(5) Quase sempre ou sempre

(4) A maioria das vezes (muito mais que a metade das vezes)

(3) Algumas vezes (aproximadamente a metade das vezes)

(2) Poucas vezes (muito menos que a metade das vezes)

(1) Quase nunca ou nunca

10) Nas últimas 4 semanas, quando você teve estimulação sexual**** ou relação sexual com que freqüência você teve a sensação de orgasmo com ou sem ejaculação***?

(0) Não teve estimulação sexual ou relação sexual

(5) Quase sempre ou sempre

(4) A maioria das vezes (muito mais que a metade das vezes)

(3) Algumas vezes (aproximadamente a metade das vezes)

(2) Poucas vezes (muito menos que a metade das vezes)

(1) Quase nunca ou nunca

As próximas duas questões se referem ao desejo sexual. Vamos definir desejo sexual como uma sensação que pode incluir querer ter uma experiência sexual (por exemplo, a masturbação ou relação), pensamento sobre sexo ou sentimento de frustração devido à falta de sexo.

11) Nas últimas 4 semanas, com que freqüência você tem sentido desejo sexual?

(5) Quase sempre ou sempre

(4) Freqüentemente (muito mais que a metade do tempo)

(3) Algumas vezes (aproximadamente a metade do tempo)

(2) Poucas vezes (muito menos que a metade do tempo)

(1) Quase nunca ou nunca

12) Nas últimas 4 semanas, o quanto você consideraria o seu nível de desejo sexual?

(5) Muito alto

(4) Alto

(3) Moderado

(2) Baixo

(1) Muito baixo ou inexistente 
13) Nas últimas 4 semanas, de modo geral, o quão satisfeito você tem estado com sua vida sexual?

(5) Muito satisfeito

(4) Moderadamente satisfeito

(3) Igualmente satisfeito e insatisfeito

(2) Moderadamente insatisfeito

(1) Muito insatisfeito

14) Nas últimas 4 semanas, de modo geral, o quão satisfeito você tem estado com o seu relacionamento sexual com a sua parceira?

(5) Muito satisfeito

(4) Moderadamente satisfeito

(3) Igualmente satisfeito e insatisfeito

(2) Moderadamente insatisfeito

(1) Muito insatisfeito

15) Nas últimas 4 semanas, como você consideraria a sua confiança em conseguir ter e manter uma ereção?
(5) Muito alta
(4) Alta
(3) Moderada
(2) Baixa
(1) Muito baixa 
ANEXO D

\section{SF-36 PESQUISA EM QUALIDADE DE VIDA}

(Ware, Sherbourne, 1992; Ciconelli, 1997)

Instruções: Esta pesquisa questiona você sobre sua saúde. Estas informações nos manterão informados de como você se sente e quão bem você é capaz de fazer suas atividades de vida diária. Responda cada questão marcando a resposta como indicado. Caso você esteja inseguro em como responder, por favor, tente responder o melhor que puder.

1. Em geral, você diria que sua saúde é:

(circule uma)

.Excelente .1

. Muito boa 2

. Boa 3

. Ruim .4

. Muito Ruim .5

2. Comparada há um ano atrás, como você classificaria sua saúde em geral, agora ?

\section{(circule uma)}

. Muito melhor agora do que a um ano atrás 1

. Um pouco melhor agora do que a um ano atrás 2

. Quase a mesma de um ano atrás .3

. Um pouco pior agora do que há um ano atrás 4

. Muito pior agora do que há um ano atrás 5 
3. Os seguintes itens são sobre atividades que você poderia fazer atualmente durante um dia comum. Devido a sua saúde, você tem dificuldade para fazer essas atividades? Neste caso, quanto?

(Circule um número em cada linha)

\begin{tabular}{|c|c|c|c|}
\hline Atividades & $\begin{array}{l}\text { Sim. } \\
\text { Dificulta } \\
\text { muito }\end{array}$ & $\begin{array}{l}\text { Sim. } \\
\text { Dificulta } \\
\text { um pouco }\end{array}$ & $\begin{array}{l}\text { Não. Não } \\
\text { dificulta } \\
\text { de modo } \\
\text { algum }\end{array}$ \\
\hline $\begin{array}{l}\text { a. Atividades vigorosas, que exigem muito } \\
\text { esforço, tais como correr, levantar objetos } \\
\text { pesados, participar em esportes árduos }\end{array}$ & 1 & 2 & 3 \\
\hline $\begin{array}{l}\text { b. Atividades moderadas, tais como mover } \\
\text { uma mesa, passar aspirador de pó, jogar } \\
\text { bola, varrer a casa }\end{array}$ & 1 & 2 & 3 \\
\hline c. Levantar ou carregar mantimentos & 1 & 2 & 3 \\
\hline d. Subir vários lances de escada & 1 & 2 & 3 \\
\hline e. Subir um lance de escada & 1 & 2 & 3 \\
\hline f. Curvar-se, ajoelhar-se ou dobrar-se & 1 & 2 & 3 \\
\hline g. Andar mais de 1 quilômetro & 1 & 2 & 3 \\
\hline h. Andar vários quarteirões & 1 & 2 & 3 \\
\hline i. Andar um quarteirão & 1 & 2 & 3 \\
\hline j. Tomar banho ou vestir-se & 1 & 2 & 3 \\
\hline
\end{tabular}


4. Durante as últimas 4 semanas, você teve algum dos seguintes problemas com o seu trabalho ou com alguma atividade diária regular, como conseqüência de sua saúde física?

(Circule uma em cada linha)

\begin{tabular}{|l|c|c|}
\hline & Sim & Não \\
\hline $\begin{array}{l}\text { a. Você diminuiu a quantidade de tempo que se } \\
\text { dedicava ao seu trabalho ou a outras atividades? }\end{array}$ & 1 & 2 \\
\hline $\begin{array}{l}\text { b. Realizou menos tarefas do que gostaria? } \\
\begin{array}{l}\text { c. Esteve limitado no seu tipo de trabalho ou em } \\
\text { outras atividades? }\end{array}\end{array}$ & 1 & 2 \\
\hline $\begin{array}{l}\text { d. Teve dificuldade de fazer seu trabalho ou outras } \\
\text { atividades (por ex.: necessitou de um esforço extra?). }\end{array}$ & 1 & 2 \\
\hline
\end{tabular}

5. Durante as últimas 4 semanas, você teve algum dos seguintes problemas com o seu trabalho ou outra atividade regular diária, como conseqüência de algum problema emocional (como sentir-se deprimido ou ansioso)?

(Circule uma em cada linha)

\begin{tabular}{|l|c|c|}
\hline & Sim & Não \\
\hline $\begin{array}{l}\text { a. Você diminuiu a quantidade de tempo que se } \\
\text { dedicava ao seu trabalho ou a outras atividades? }\end{array}$ & 1 & 2 \\
\hline $\begin{array}{l}\text { b. Realizou menos tarefas do que você gostaria? } \\
\begin{array}{l}\text { c. Não trabalhou ou não fez qualquer das atividades } \\
\text { com tanto cuidado como geralmente faz? }\end{array}\end{array}$ & 1 & 2 \\
\hline
\end{tabular}


6. Durante as últimas 4 semanas, de que maneira sua saúde física ou problemas emocionais interferiram nas suas atividades sociais normais, em relação a família, vizinhos, amigos ou em grupo?

\section{(circule uma)}

. De forma nenhuma .1

. Ligeiramente 2

. Moderadamente . 3

. Bastante 4

. Extremamente .5

7. Quanta dor no corpo você teve nas últimas 4 semanas?

(circule uma)

Muito Leve

8. Durante as últimas 4 semanas, quanto a dor interferiu com o seu trabalho normal (incluindo tanto o trabalho, fora de casa e dentro de casa)?

(circule uma)

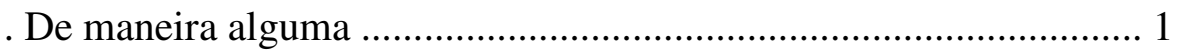

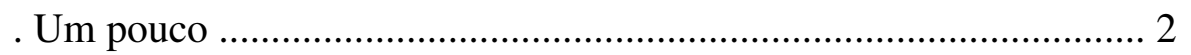

. Moderadamente …................................................................. 3

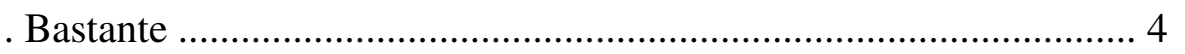

. Extremamente ……........................................................... 5 
9. Estas questões são sobre como você se sente e como tudo tem acontecido com você durante as últimas 4 semanas. Para cada questão, por favor, dê uma resposta que mais se aproxime da maneira como você se sente. Em relação às últimas 4 semanas.

(circule um número para cada linha)

\begin{tabular}{|c|c|c|c|c|c|c|}
\hline & $\begin{array}{c}\text { Todo } \\
\text { tempo }\end{array}$ & $\begin{array}{l}\text { A maior } \\
\text { parte do } \\
\text { tempo }\end{array}$ & \begin{tabular}{|c|} 
Uma \\
boa \\
parte do \\
tempo \\
\end{tabular} & $\begin{array}{l}\text { Alguma } \\
\text { parte do } \\
\text { tempo }\end{array}$ & \begin{tabular}{|c|} 
Uma \\
pequena \\
parte do \\
tempo \\
\end{tabular} & Nunca \\
\hline $\begin{array}{l}\text { a. Quanto tempo você } \\
\text { tem se sentido cheio de } \\
\text { vigor, cheio de } \\
\text { vontade, cheio de } \\
\text { força? }\end{array}$ & 1 & 2 & 3 & 4 & 5 & 6 \\
\hline $\begin{array}{l}\text { b. Quanto tempo você } \\
\text { tem se sentido uma } \\
\text { pessoa muito nervosa? }\end{array}$ & 1 & 2 & 3 & 4 & 5 & 6 \\
\hline $\begin{array}{l}\text { c. Quanto tempo você } \\
\text { tem se sentido tão } \\
\text { deprimido que nada } \\
\text { pode animá-lo? }\end{array}$ & 1 & 2 & 3 & 4 & 5 & 6 \\
\hline $\begin{array}{l}\text { d. Quanto tempo você } \\
\text { tem se sentido calmo e } \\
\text { tranquiilo? }\end{array}$ & 1 & 2 & 3 & 4 & 5 & 6 \\
\hline $\begin{array}{l}\text { e. Quanto tempo você } \\
\text { tem se sentido com } \\
\text { muita energia? }\end{array}$ & 1 & 2 & 3 & 4 & 5 & 6 \\
\hline $\begin{array}{l}\text { f. Quanto tempo você } \\
\text { tem se sentido } \\
\text { desanimado e abatido? }\end{array}$ & 1 & 2 & 3 & 4 & 5 & 6 \\
\hline $\begin{array}{l}\text { g. Quanto tempo você } \\
\text { tem se sentido } \\
\text { esgotado? }\end{array}$ & 1 & 2 & 3 & 4 & 5 & 6 \\
\hline $\begin{array}{l}\text { h.Quanto tempo você } \\
\text { tem se sentido uma } \\
\text { pessoa feliz? }\end{array}$ & 1 & 2 & 3 & 4 & 5 & 6 \\
\hline $\begin{array}{l}\text { i.Quanto tempo você } \\
\text { tem se sentido } \\
\text { cansado? }\end{array}$ & 1 & 2 & 3 & 4 & 5 & 6 \\
\hline
\end{tabular}


10. Durante as últimas 4 semanas, quanto do seu tempo a sua saúde física ou problemas emocionais interferiram com as suas atividades sociais (como visitar amigos, parentes, etc.)?

\section{(circule uma)}

. Todo o tempo …...................................................................... 1

. A maior parte do tempo .......................................................... 2

. Alguma parte do tempo ............................................................... 3

. Uma pequena parte do tempo .................................................... 4

. Nenhuma parte do tempo .......................................................... 5

11. O quanto verdadeiro ou falso é cada uma das afirmações para você?

(Circule um número em cada linha)

\begin{tabular}{|l|c|c|c|c|c|}
\hline & $\begin{array}{r}\text { Definitiva- } \\
\text { mente } \\
\text { verdadeiro }\end{array}$ & $\begin{array}{l}\text { maioria } \\
\text { das vezes } \\
\text { verdadeiro }\end{array}$ & sei & $\begin{array}{r}\text { A } \\
\text { maioria } \\
\text { das vezes } \\
\text { falsa }\end{array}$ & $\begin{array}{c}\text { Definiti- } \\
\text { vamente } \\
\text { falsa }\end{array}$ \\
\hline $\begin{array}{l}\text { a. Eu costumo adoecer um } \\
\text { pouco mais facilmente que as } \\
\text { outras pessoas }\end{array}$ & 1 & 2 & 3 & 4 & 5 \\
\hline $\begin{array}{l}\text { b. Eu sou tão saudável quanto } \\
\text { qualquer pessoa que eu conheço }\end{array}$ & 1 & 2 & 3 & 4 & 5 \\
\hline $\begin{array}{l}\text { c. Eu acho que minha saúde vai } \\
\text { piorar }\end{array}$ & 1 & 2 & 3 & 4 & 5 \\
\hline d. Minha saúde é excelente & 1 & 2 & 3 & 4 & 5 \\
\hline
\end{tabular}


ANEXO E

INVENTÁRIO DE SINTOMAS DE STRESS PARA ADULTOS DE LIPP

(ISSL)

(Lipp 2000)

\section{Instruções}

Quadro 1 - Assinalar com F1 ou P1, como indicado para sintomas que tenha experimentado nas últimas 24 horas.

QUADRO 1a

a) Marque com $\mathbf{F 1}$ os sintomas que tem experimentado nas últimas 24 horas.

( ) 1. MÃOS E PÉS FRIOS

( ) 2. BOCA SECA

( ) 3. NÓ NO ESTÔMAGO

( ) 4. AUMENTO DE SUDORESE

( ) 5. TENSÃO MUSCULAR

( ) 6. APERTO DA MANDÍBULA / RANGER OS DENTES

( ) 7. DIARRÉIA PASSAGEIRA

( ) 8. INSÔNIA

( ) 9. TAQUICARDIA

( ) 10. HIPERVENTILAÇÃO

( ) 11. HIPERTENSÃO ARTERIAL SÚBITA E PASSAGEIRA

( ) 12. MUDANÇA DE APETITE

\section{QUADRO 1b}

b) Marque com P1 os sintomas que tem experimentado nas últimas 24 horas.

( ) 13. AUMENTO SÚBITO DE MOTIVAÇÃO

( 14. ENTUSIASMO SÚBITO

( ) 15. VONTADE SÚBITA DE INICIAR NOVOS PROJETOS 


\section{Instruções}

Quadro 2 - Assinalar com F2 ou P2, como indicado para sintomas que tenha experimentado na última semana.

\section{QUADRO 2a}

a) Marque com um F2 os sintomas que tem experimentado na última semana.

( ) 1. PROBLEMAS COM MEMÓRIA

( ) 2. MAL-ESTAR GENERALIZADO, SEM CAUSA ESPECÍFICA

( ) 3. FORMIGAMENTO DAS EXTREMIDADES

( ) 4. SENSAÇÃO DE DESGASTE FÍSICO CONSTANTE

( ) 5. MUDANÇA DE APETITE

( ) 6. APARECIMENTO DE PROBLEMAS DERMATOLÓGICOS

( ) 7. HIPERTENSÃO ARTERIAL

( ) 8. CANSAÇO CONSTANTE

( ) 9. APARECIMENTO DE ÚLCERA

( ) 10. TONTURA / SENSAÇÃO DE ESTAR FLUTUANDO

\section{QUADRO 2b}

b) Marque com P2 os sintomas que tem experimentado na última semana.

( ) 11. SENSIBILIDADE EMOTIVA EXCESSIVA

( 12. DÚVIDA QUANTO A SI PRÓPRIO

( ) 13. PENSAR CONSTANTEMENTE EM UM SÓ ASSUNTO

( ) 14. IRRITABILIDADE EXCESSIVA

( ) 15. DIMINUIÇÃO DA LIBIDO 


\section{Instruções}

Quadro 3 - Assinalar com F3 ou P3, como indicado para sintomas que tenha experimentado último mês.

\section{QUADRO 3a}

a) Marque com um $\mathbf{F 3}$ os sintomas que tem experimentado no último mês.

( ) 1. DIARRÉIA FREQÜENTE

( ) 2. DIFICULDADES SEXUAIS

( ) 3. INSÔNIA

( ) 4. NÁUSEA

( ) 5. TIQUES

( ) 6. HIPERTENSÃO ARTERIAL CONTINUADA

( ) 7. PROBLEMAS DERMATOLÓGICOS PROLONGADOS

( ) 8. MUDANÇA EXTREMA DE APETITE

( ) 9. EXCESSO DE GASES

( ) 10. TONTURA FREQÜENTE

( ) 11. ÚLCERA

( ) 12. ENFARTE 


\section{QUADRO 3b}

b) Marque com um P3 os sintomas que tem experimentado no último mês.

( ) 13. IMPOSSIBILIDADE DE TRABALHAR

( ) 14. PESADELOS

( ) 15. SENSAÇÃO DE INCOMPETÊNCIA EM TODAS AS ÁREAS

( ) 16. VONTADE DE FUGIR DE TUDO

( ) 17. APATIA, DEPRESSÃO OU RAIVA PROLONGADA

( ) 18. CANSAÇO EXCESSIVO

( ) 19. PENSAR / FALAR CONSTANTEMENTE EM UM SÓ ASSUNTO

( ) 20. IRRITABILIDADE SEM CAUSA APARENTE

( ) 21. ANGÚSTIA / ANSIEDADE DIÁRIA

( ) 22. HIPERSENSIBILIDADE EMOTIVA

( ) 23. PERDA DO SENSO DE HUMOR 
ANEXO F

\section{Self Reporting Questionnaire (SRQ-20)}

(Harding et. al., 1980; Mari, Williams, 1986)

O Sr. poderia, por favor, responder às seguintes perguntas a respeito da sua saúde nos últimos $\mathbf{3 0}$ dias? Assinale a resposta correta com um "X".

\begin{tabular}{|c|c|c|}
\hline 1- Tem dores de cabeça freqüentes? & SIM & $\mathrm{NA} O$ \\
\hline 2- Tem falta de apetite? & SIM & NÃO \\
\hline 3- Dorme mal? & SIM & NÃO \\
\hline 4- Assusta-se com facilidade? & SIM & NÃO \\
\hline 5- Tem tremores na mão? & SIM & $\mathrm{NA \tilde {O }}$ \\
\hline 6- Sente-se nervoso, tenso, ou preocupado? & SIM & NÃO \\
\hline 7- Tem má digestão? & SIM & 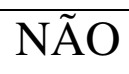 \\
\hline 8- Tem dificuldade de pensar com clareza? & SIM & NÃO \\
\hline 9- Tem se sentido triste ultimamente? & SIM & NÃO \\
\hline 10- Tem chorado mais do que de costume? & SIM & NÃO \\
\hline $\begin{array}{l}\text { 11- Encontra dificuldades para realizar com } \\
\text { satisfacão suas atividades diárias? }\end{array}$ & SIM & NÃO \\
\hline 12- Tem dificuldades para tomar decisões? & SIM & NÃO \\
\hline $\begin{array}{l}\text { 13- Tem dificuldades no serviço (seu trabalho é } \\
\text { penoso, lhe causa sofrimento)? }\end{array}$ & SIM & $\mathrm{NA \tilde {O }}$ \\
\hline $\begin{array}{l}\text { 14- É incapaz de desempenhar um papel útil em } \\
\text { sua vida? }\end{array}$ & SIM & NÃO \\
\hline 15- Tem perdido o interesse pelas coisas? & SIM & NÃO \\
\hline $\begin{array}{l}\text { 16- Você se sente uma pessoa inútil, sem } \\
\text { préstimo? }\end{array}$ & SIM & NÃO \\
\hline 17- Tem tido a idéia de acabar com a vida? & SIM & NÃO \\
\hline 18- Sente-se cansado o tempo todo? & SIM & NÃO \\
\hline 19- Tem sensações desagradáveis no estômago? & SIM & NÃO \\
\hline 20- Você se cansa com facilidade? & SIM & NÃO \\
\hline
\end{tabular}


ANEXO G

\section{INVESTIGAÇÃO CLÍNICA}

TEMPO DE RELACIONAMENTO COM A ATUAL PARCEIRA:

meses de namoro ou anos de namoro meses de casamento (ou coabitação) ou anos de casamento (ou coabitação)

GRAU DE SATISFAÇÃO ATUAL NO RELACIONAMENTO A DOIS:

( ) ótimo

( ) bom

( ) moderado. Por que?

( ) ruim. Por que?

\section{ATRAÇÃO SEXUAL (TESÃO) PELA PARCEIRA:}

( ) $\operatorname{sim}$

( ) não. Há quanto tempo?

AS PRELIMINARES (AQUECIMENTO, COMEÇO DO ATO SEXUAL) COSTUMAM SER:

( ) rápidas

( ) nem rápidas nem demoradas

( ) demoradas

( ) não há preliminares: ( ) porque eu vou direto ou ( ) porque minha parceira vai direto

SENTE-SE POTENTE SEXUALMENTE?

( ) $\operatorname{sim}$

( ) não. Há quanto tempo?

EM CASO DE NÃO SE SENTIR POTENTE SEXUALMENTE: JÁ PROCUROU TRATAMENTO?

( ) $\operatorname{sim}$

( ) não. Por que?

( ) não procuraria tratamento. Por que? 
CASO JÁ TENHA TOMADO (OU ESTEJA TOMANDO) ALGUM MEDICAMENTO PARA CONSEGUIR OBTER EREÇÃO, QUEM O RECOMENDOU:

( ) psiquiatra

( ) psicólogo

( ) urologista

( ) ginecologista

( ) clínico geral

( ) conta própria

( ) outro. Quem?

( ) nunca tomou esse tipo de medicamento

\section{COMO VOCÊ SE SENTE AO FALAR SOBRE SEXO?}

( ) envergonhado

( ) nem envergonhado nem à vontade

( ) à vontade

\section{TEM ALGUMA CURVATURA NO PÊNIS?}

( ) não

( ) sim. Procurou um médico? Teve algum diagnóstico?

Qual

\section{CONSIDERA O SEU DESEJO SEXUAL ATUAL:}

( ) excelente

( ) bom

( ) moderado. Há quanto tempo? Já procurou tratamento?

( ) baixo. Há quanto tempo? Já procurou tratamento?

( ) ausente. Há quanto tempo? Já procurou tratamento?

CONSIDERA-SE SATISFEITO COM O TAMANHO DO PÊNIS: ( ) $\operatorname{sim}$

( ) não. Por que? Já conversou com um médico a respeito dessa insatisfação?

CONSIDERA-SE SATISFEITO COM O PRÓPRIO CORPO:

( ) $\operatorname{sim}$

( ) não. Por que? 
CONSIDERA-SE, PROFISSIONALMENTE, SATISFEITO:

( ) $\operatorname{sim}$

( ) não. Há quanto tempo? Por que?

\section{CONSIDERA-SE SATISFEITO COM VOCÊ MESMO:}

( ) $\operatorname{sim}$

( ) não. Há quanto tempo? Por que?

\section{CONSIDERA A QUALIDADE DO SEU SONO:}

( ) ótima

( ) boa

( ) regular. Há quanto tempo? Por que?

( ) ruim. Há quanto tempo? Por que?

\section{FEZ OU FAZ TRATAMENTO PARA (ASSINALE QUANTAS} ALTERNATIVAS PRECISAR):

( ) doença da tireóide

( ) aumento da próstata (tumor benigno)

( ) câncer de próstata

( ) falta de hormônio sexual (testosterona)

( ) depressão

( ) ansiedade, pânico, fobia

( ) stress (após algum acontecimento traumático)

( ) vício de álcool (alcoolismo)

( ) obesidade

( ) vício de cigarro (tabagismo)

( ) uso de drogas (maconha, cocaína, crack etc.)

( ) diabetes

( ) hipertensão

( ) doença do coração

( ) colesterol alto

( ) outra. Qual?

( ) não faz e nunca fez qualquer tipo de tratamento

TOMA ALGUM TIPO DE MEDICAMENTO ATUALMENTE?

( ) não

( ) sim. Qual(is): 
ANEXO H

Indivíduos que procuraram tratamento por não se sentirem potentes sexualmente:

\begin{tabular}{|c|c|}
\hline Indivíduo 1 & Indivíduo 2 \\
\hline Idade: 45 anos & Idade: 53 anos \\
\hline Peso: $76 \mathrm{~kg}$ & Peso: $75 \mathrm{~kg}$ \\
\hline Altura: $1,68 \mathrm{~m}$ & Altura: $1,63 \mathrm{~m}$ \\
\hline IMC: 26,9 (sobrepeso) & IMC: 28,2 (sobrepeso) \\
\hline PAS: 13 / PAD: 7 & PAS: 13 / PAD: 9 \\
\hline Raça/cor: branca & Raça/cor: parda \\
\hline Nacionalidade: brasileira & Nacionalidade: brasileira \\
\hline Naturalidade: São Paulo (SP) & Naturalidade: Juiz de Fora (MG) \\
\hline Escolaridade: completou o $2^{\circ}$ grau & Escolaridade: completou o $1^{\circ}$ grau \\
\hline Renda mensal: entre 6 e $10 \mathrm{sm}$. & Renda mensal: entre 6 e $10 \mathrm{sm}$. \\
\hline Estado civil: casado & Estado civil: casado \\
\hline Religião: católica & Religião: católica \\
\hline Condição profissional: ativo & Condição profissional: ativo \\
\hline IIFE: DE leve ( 22 pontos) & IIFE: Sem DE ( 27 pontos) \\
\hline Capacidade Funcional: 100 & Capacidade Funcional: 100 \\
\hline Aspectos Físicos: 100 & Aspectos Físicos: 75 \\
\hline Dor: 100 & Dor: 100 \\
\hline Estado Geral de Saúde: 92 & Estado Geral de Saúde: 92 \\
\hline Vitalidade: 85 & Vitalidade: 30 \\
\hline Aspectos Sociais: 100 & Aspectos Sociais: 100 \\
\hline Aspectos Emocionais: 100 & Aspectos Emocionais: 33,33 \\
\hline Saúde Mental: 96 & Saúde Mental: 48 \\
\hline Saúde agora: um pouco melhor que há 1 ano atrás & Saúde agora: um pouco melhor que há 1 ano atrás \\
\hline Stress: não & Stress: $\operatorname{sim}$ (quase-exaustão) Sint F: 50 e Sint P: 100 \\
\hline Transtorno depressivo e/ou ansioso: não suspeito & Transtorno depressivo e/ou ansioso: suspeito \\
\hline Tempo de casamento: 18 anos & Tempo de casamento: 26 anos \\
\hline Grau de satisfação no relacionamento: ótimo & $\begin{array}{l}\text { Grau de satisfação no relacionamento: moderado } \\
\text { (motivo: rotina) }\end{array}$ \\
\hline Atração sexual pela parceira: sim & Atração sexual pela parceira: sim \\
\hline Preliminares: nem rápidas nem demoradas & Preliminares: nem rápidas nem demoradas \\
\hline Potência sexual: não & Potência sexual: não \\
\hline Há quanto tempo: 5 anos & Há quanto tempo: 3 anos \\
\hline Procurou tratamento: sim & Procurou tratamento: sim \\
\hline Falar sobre sexo: pouco à vontade & Falar sobre sexo: à vontade \\
\hline Curvatura no pênis: não & Curvatura no pênis: não \\
\hline Desejo sexual: bom & $\begin{array}{l}\text { Desejo sexual: moderado (Há } 3 \text { anos, já procurou } \\
\text { tratamento) }\end{array}$ \\
\hline Satisfação com o tamanho do pênis: sim & Satisfação com o tamanho do pênis: sim \\
\hline Satisfação com o próprio corpo: sim & Satisfação com o próprio corpo: sim \\
\hline Satisfação profissional: sim & Satisfação profissional: sim \\
\hline Satisfação pessoal: sim & $\begin{array}{l}\text { Satisfação pessoal: não (Há } 3 \text { anos, motivo: falta de } \\
\text { realização) }\end{array}$ \\
\hline Qualidade do sono: regular & Qualidade do sono: regular \\
\hline Há quanto tempo: desde sempre & Há quanto tempo: 2 anos \\
\hline Motivo: insônia & Motivo: trabalhar a noite \\
\hline Fez tratamento: sim & Fez tratamento: sim \\
\hline Motivo: Falta de Hormônio Sexual & Motivo: Depressão \\
\hline Medicamento: não usa & Medicamento: não usa \\
\hline
\end{tabular}


Figura 1. Distribuição percentual dos indivíduos segundo DE (detectada pelo IIFE e DE referida) e região de procedência

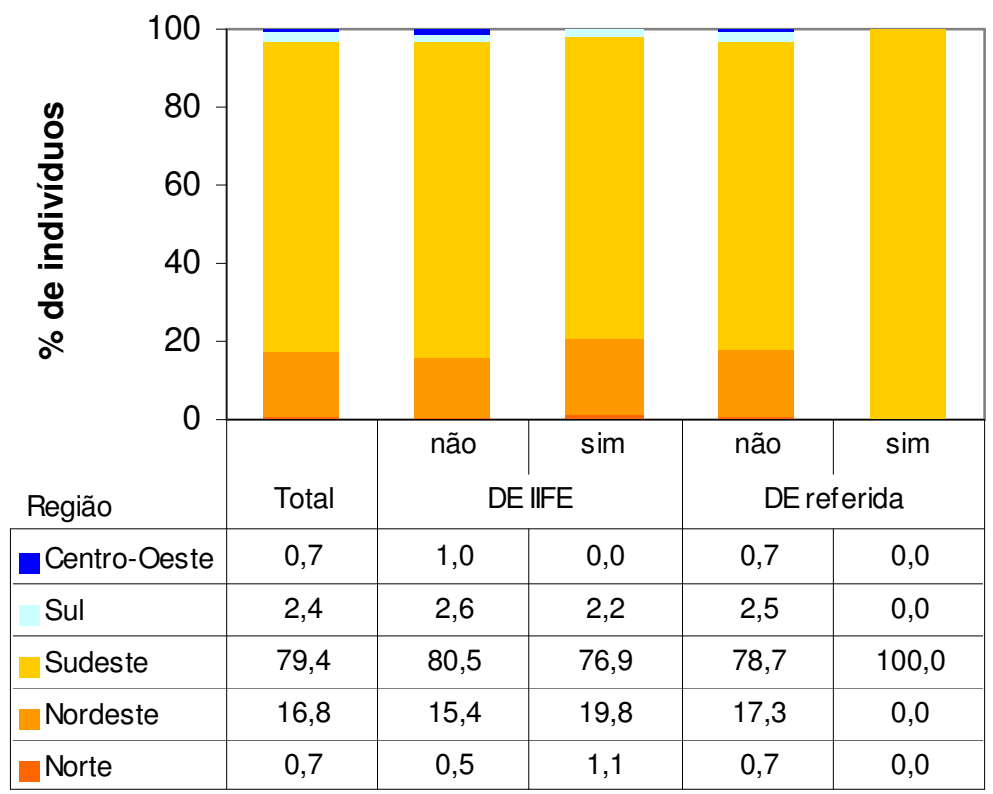

Figura 2. Distribuição percentual dos indivíduos segundo DE (detectada pelo IIFE e DE referida) e raça/cor

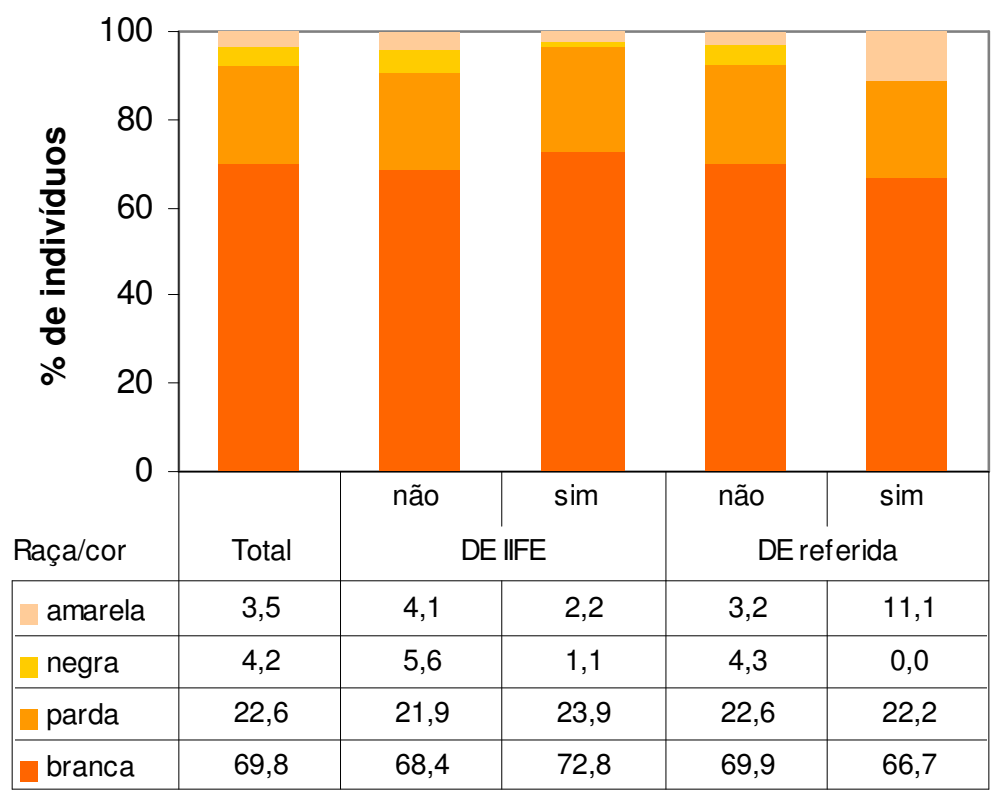


ANEXO I

Figura 3. Distribuição percentual dos indivíduos segundo DE (detectada pelo IIFE e DE referida) e estado civil

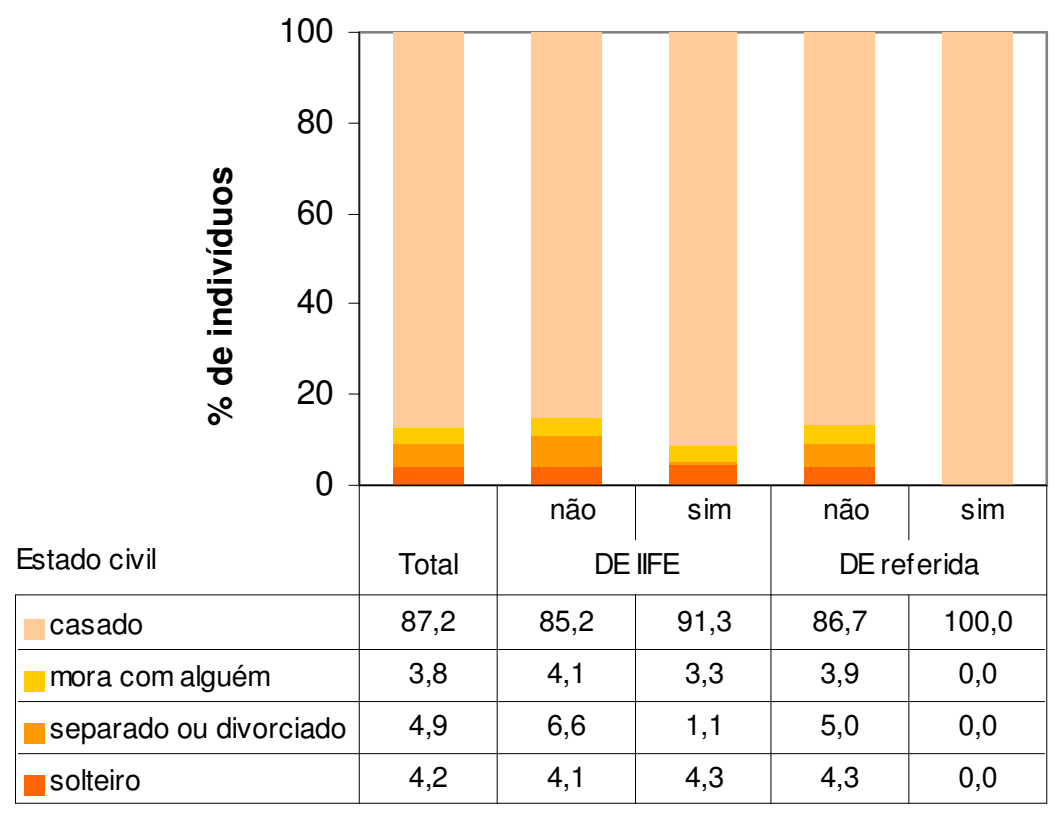

Figura 4. Distribuição percentual dos indivíduos segundo DE (detectada pelo IIFE e DE referida) e religião

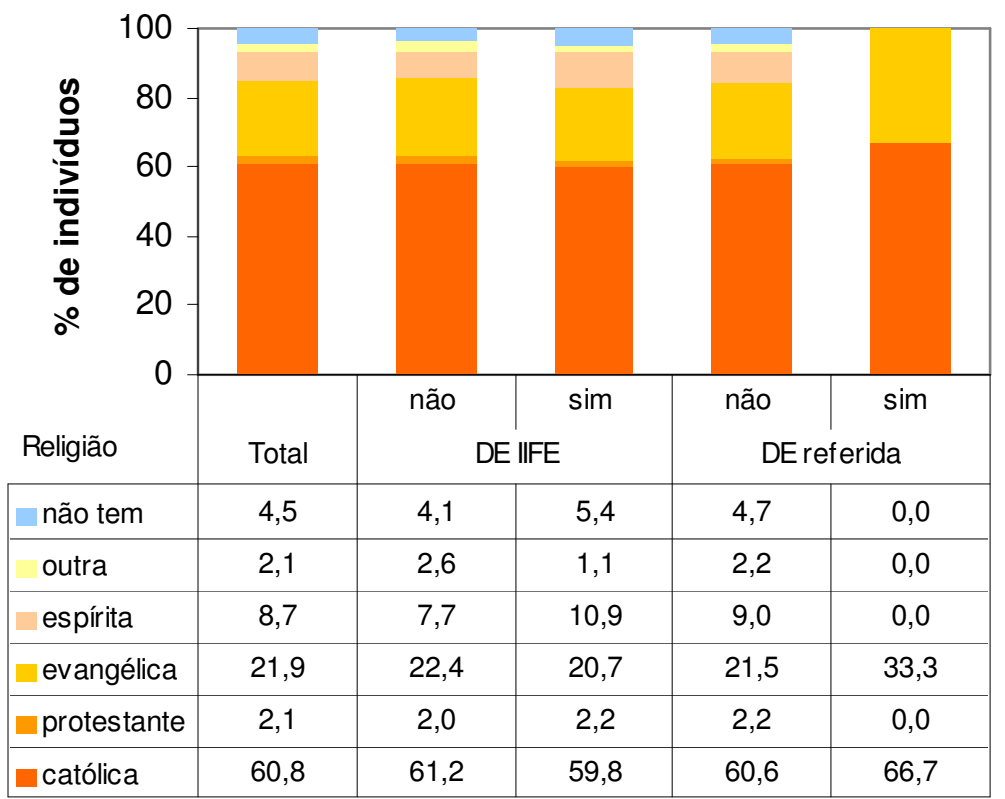


ANEXO I

Figura 5. Distribuição percentual dos indivíduos segundo DE (detectada pelo IIFE e DE referida) e escolaridade

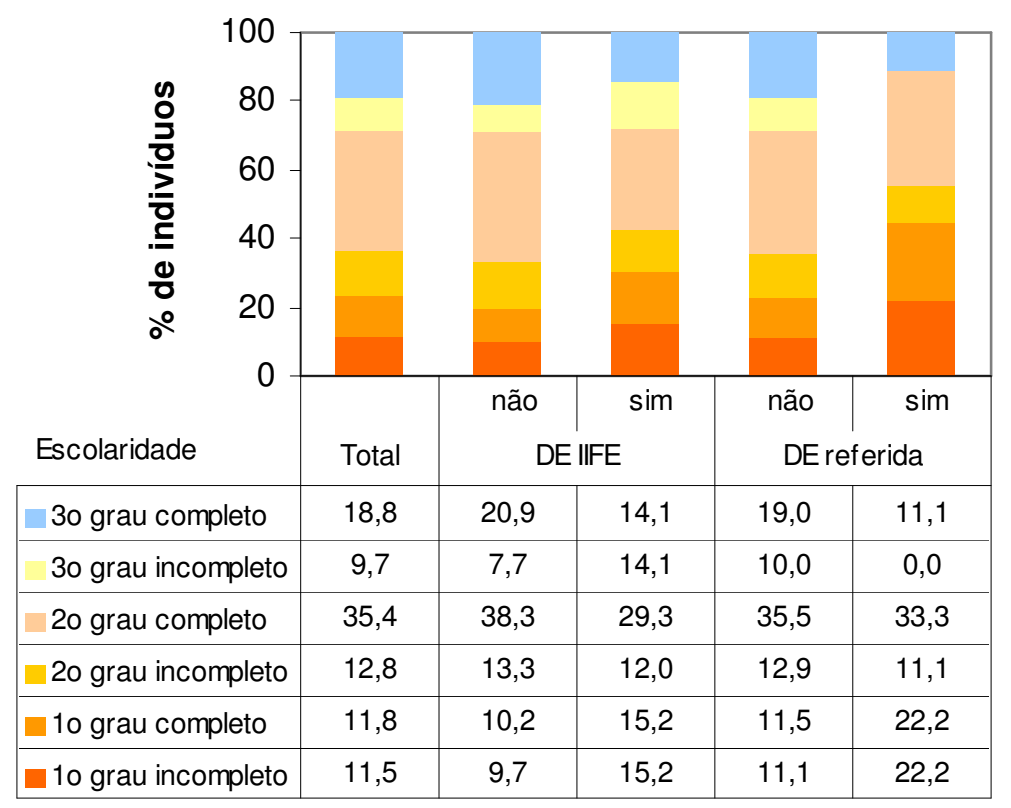

Figura 6. Distribuição percentual dos indivíduos segundo DE (detectada pelo IIFE e DE referida) e condição profissional

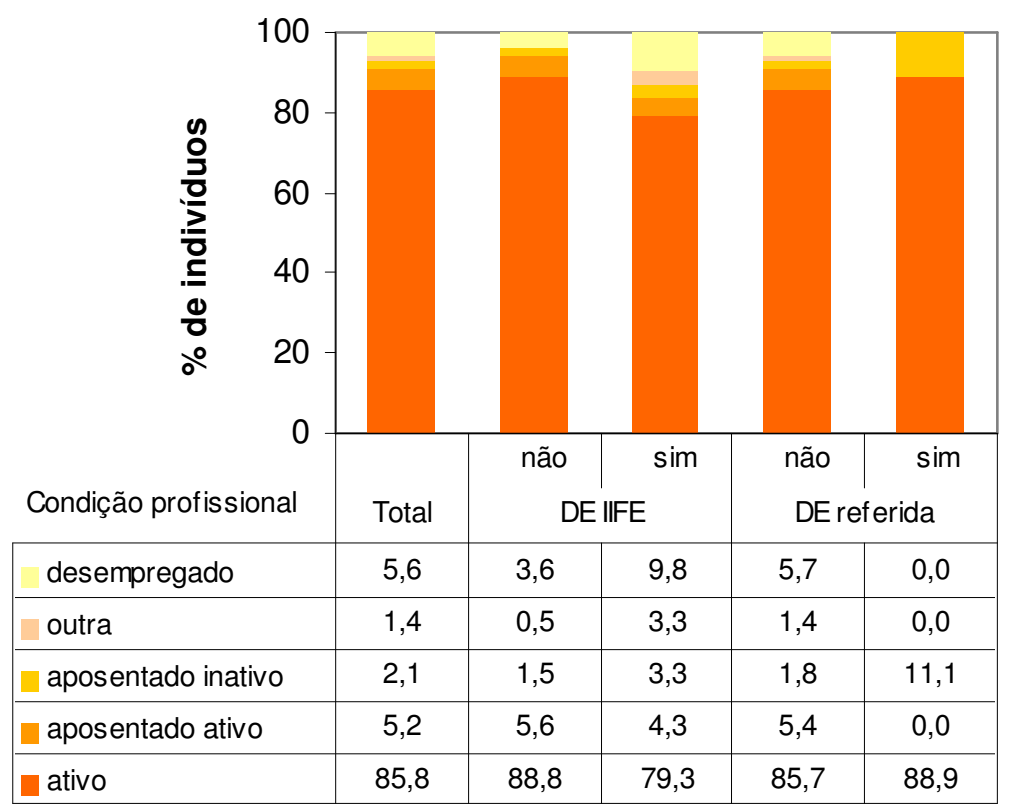


ANEXO I

Figura 7. Distribuição percentual dos indivíduos segundo DE (detectada pelo IIFE e DE referida) e renda mensal

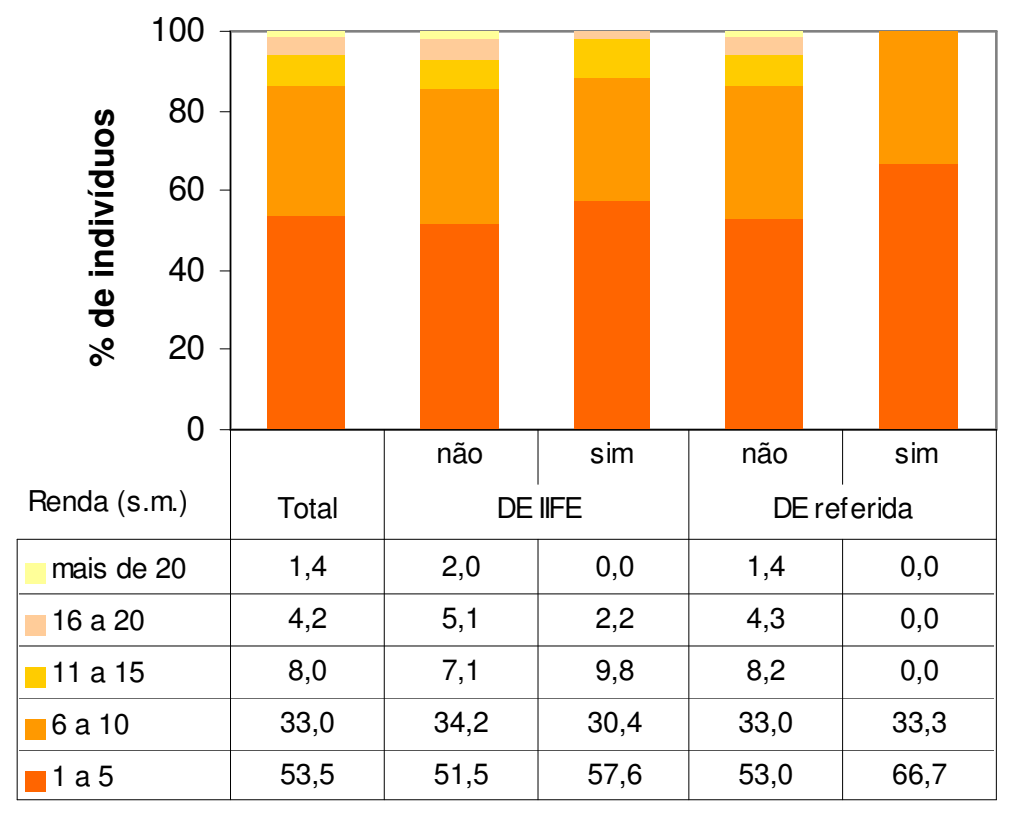

Figura 8. Distribuição percentual dos indivíduos segundo DE (detectada pelo IIFE e DE referida) e idade

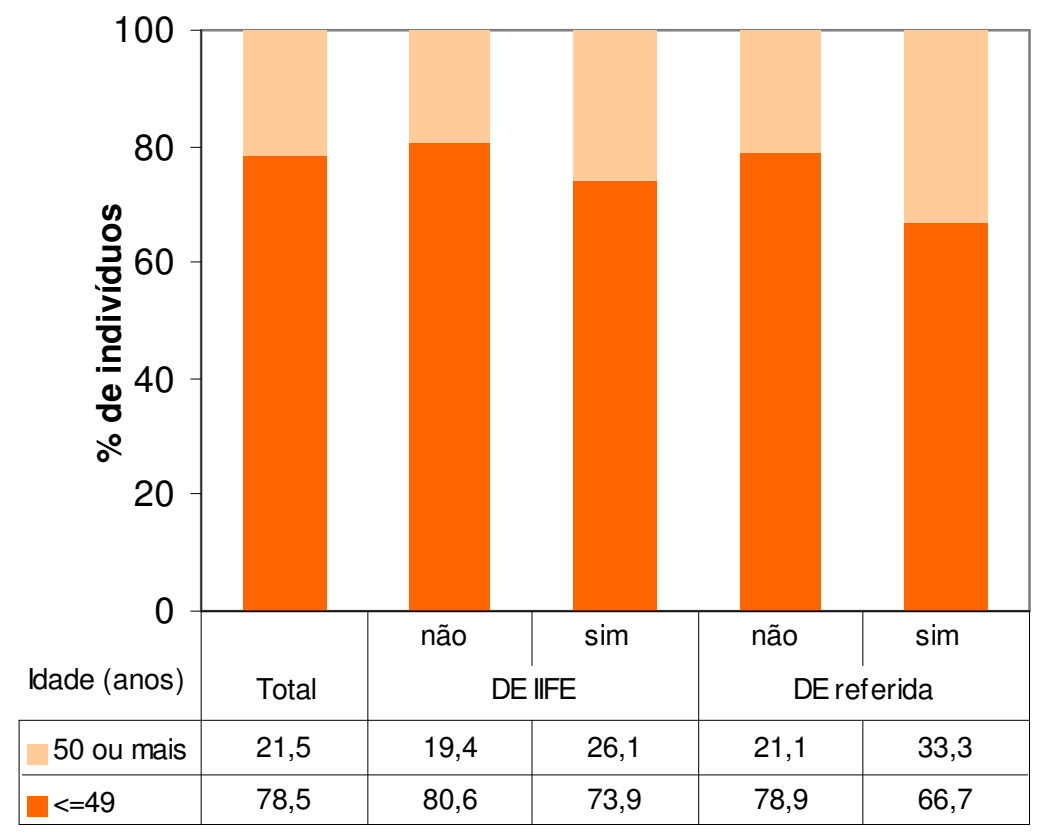


ANEXO I

Figura 9. Distribuição percentual dos indivíduos segundo DE (detectada pelo IIFE e DE referida) e IMC

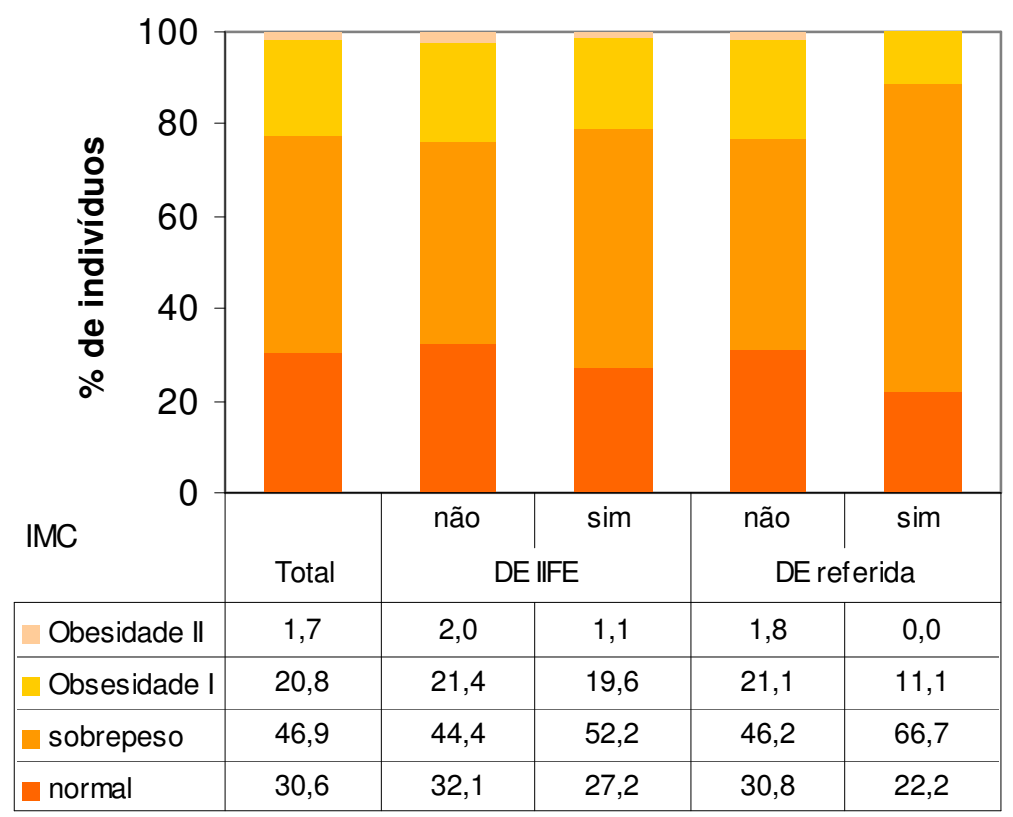

Figura 10. Distribuição percentual dos indivíduos segundo DE (detectada pelo IIFE e DE referida) e a condição de saúde atual quando comparada com um ano atrás

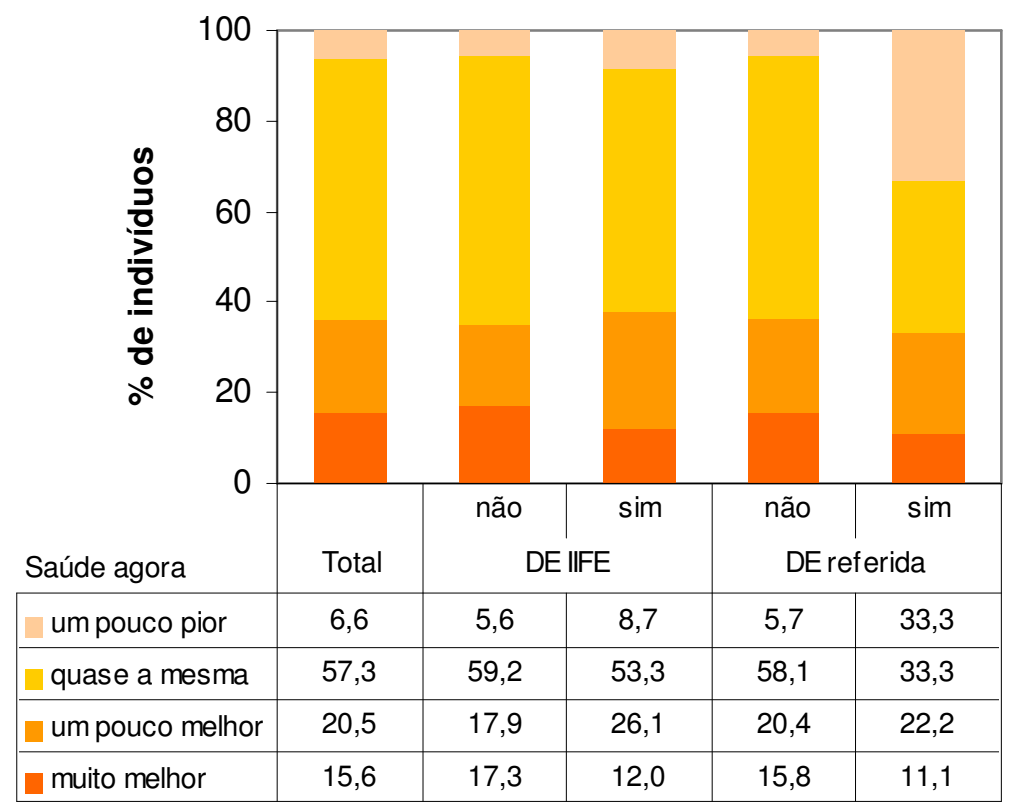


Figura 11. Distribuição percentual dos indivíduos segundo DE (detectada pelo IIFE e DE referida) e escore de capacidade funcional

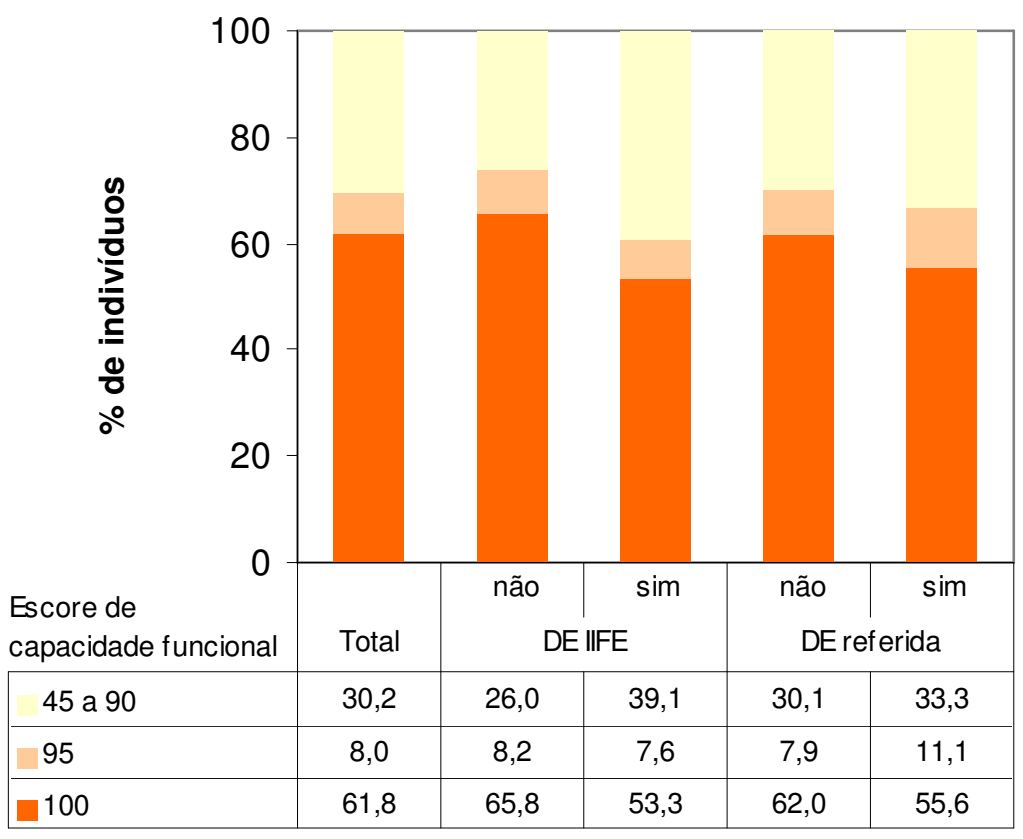

Figura 12. Distribuição percentual dos indivíduos segundo DE (detectada pelo IIFE e DE referida) e escore de aspectos físicos

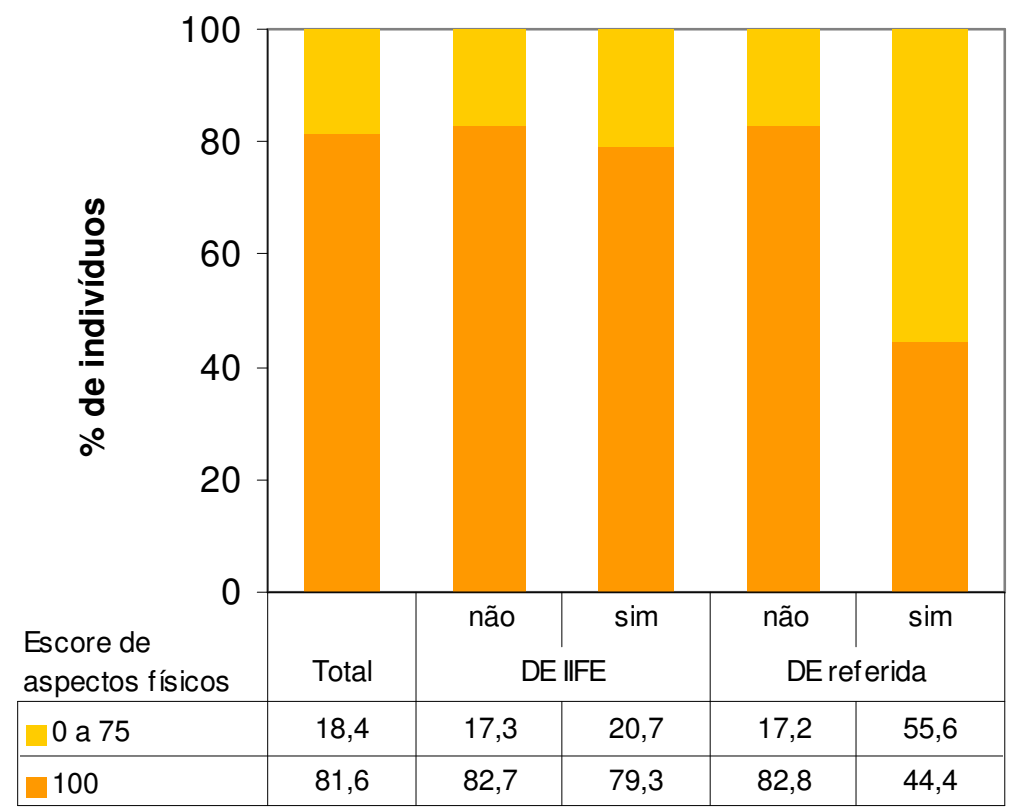


ANEXO I

Figura 13. Distribuição percentual dos indivíduos segundo DE (detectada pelo IIFE e DE referida) e escore de dor

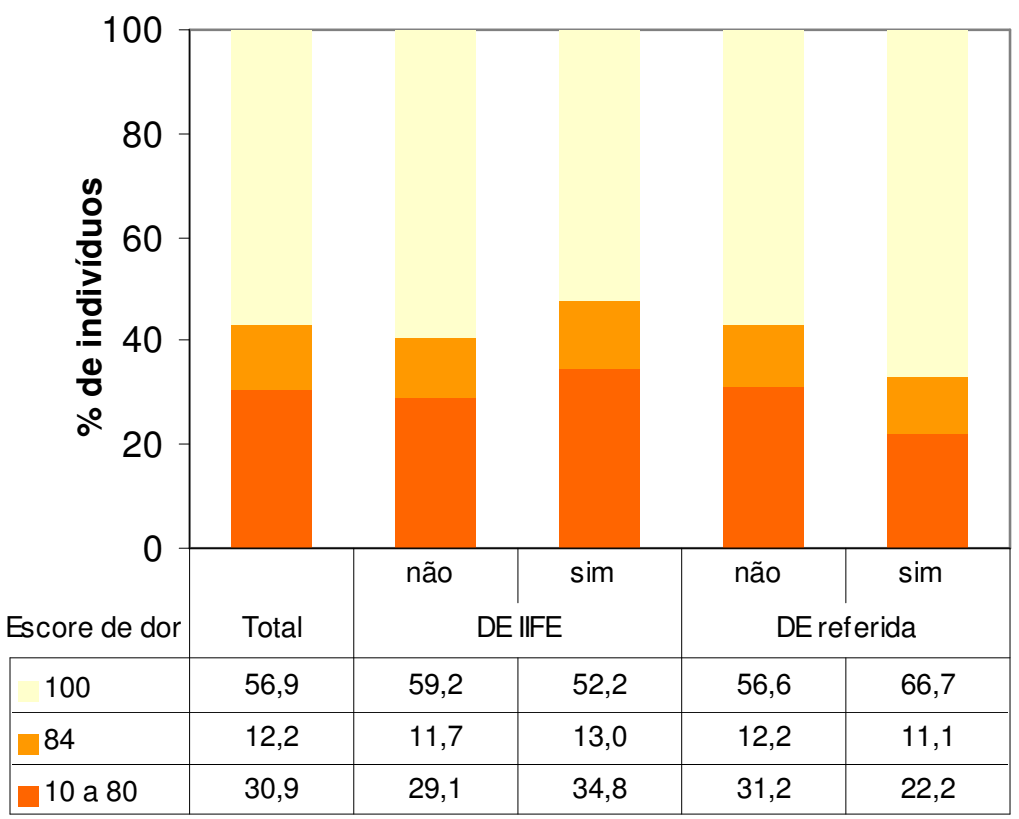

Figura 14. Distribuição percentual dos indivíduos segundo DE (detectada pelo IIFE e DE referida) e escore de aspectos sociais

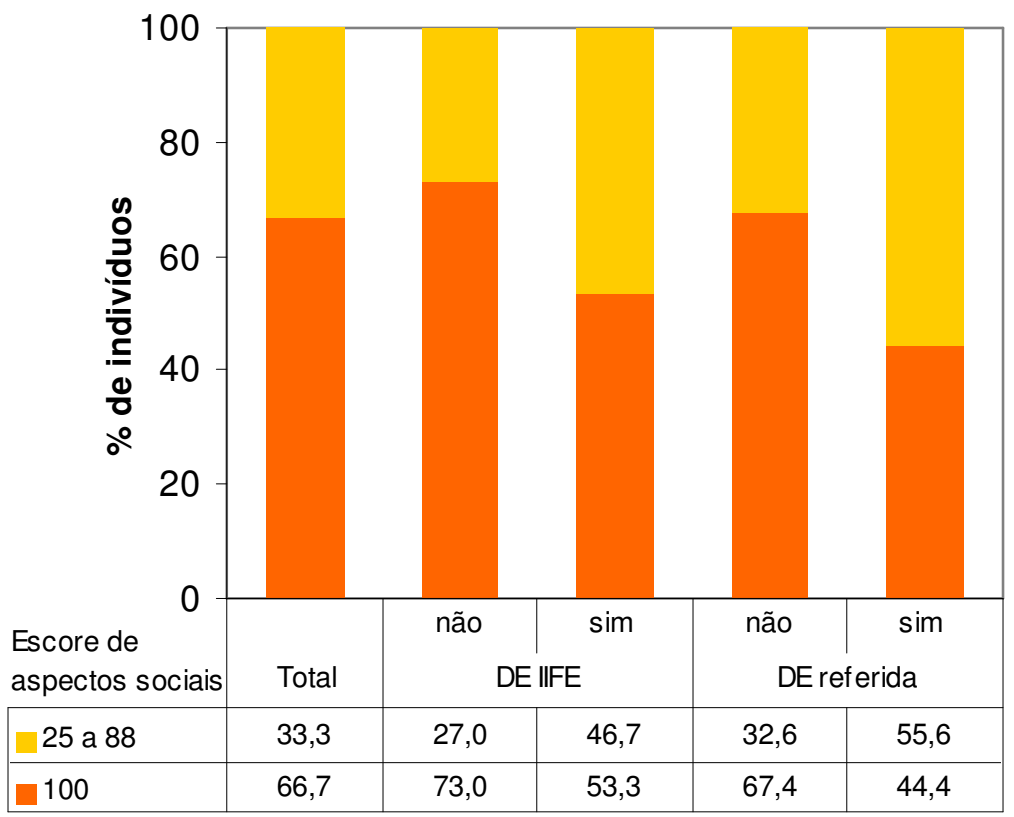


ANEXO I

Figura 15. Distribuição percentual dos indivíduos segundo DE (detectada pelo IIFE e DE referida) e escore de aspectos emocionais

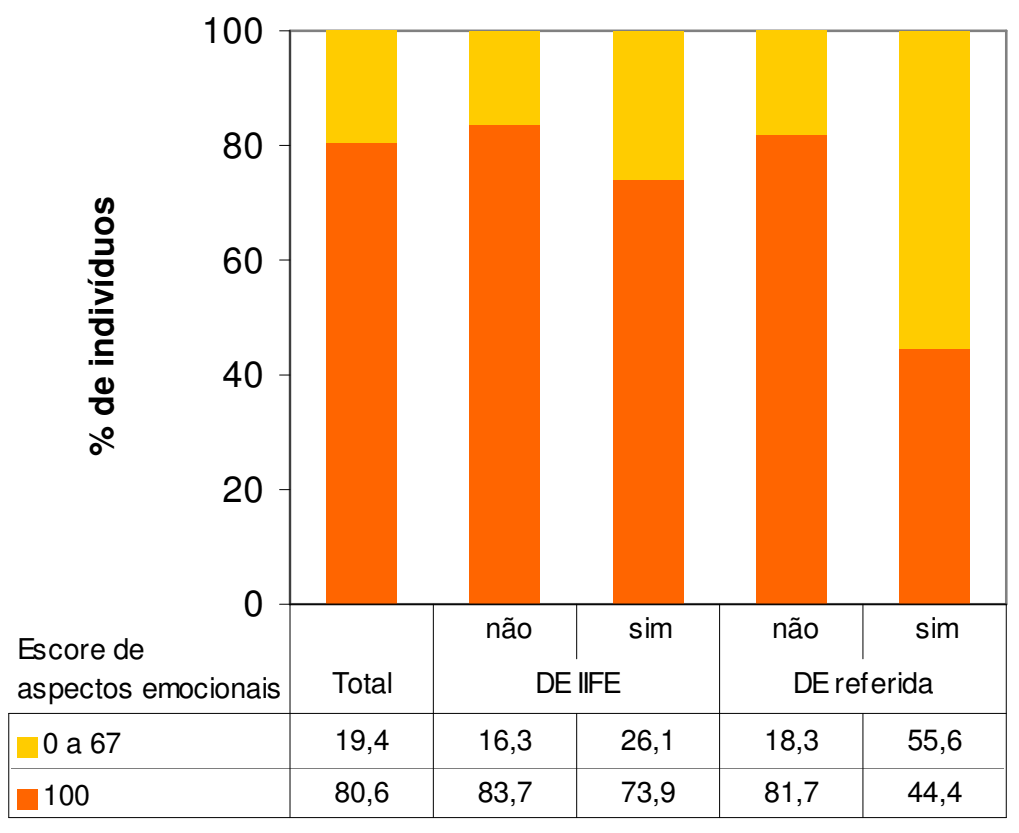

Figura 16. Distribuição percentual dos indivíduos segundo DE (detectada pelo IIFE e DE referida) e escore de estado geral de saúde

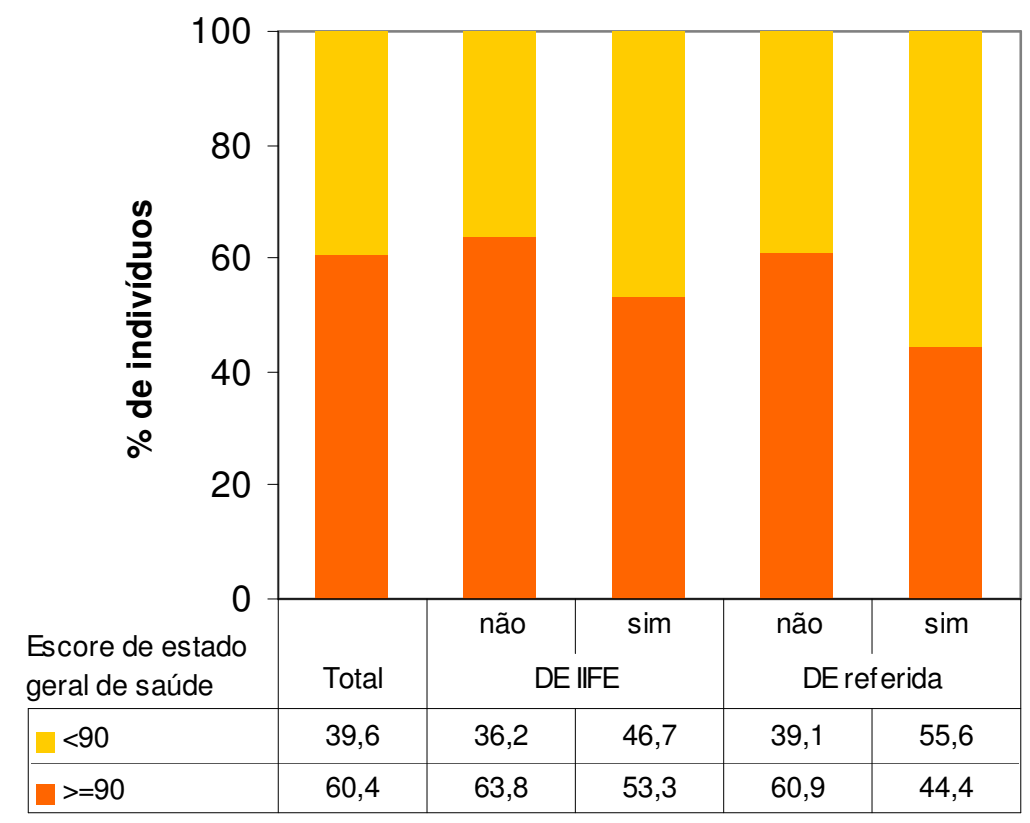


ANEXO I

Figura 17. Distribuição percentual dos indivíduos segundo DE (detectada pelo IIFE e DE referida) e escore de vitalidade

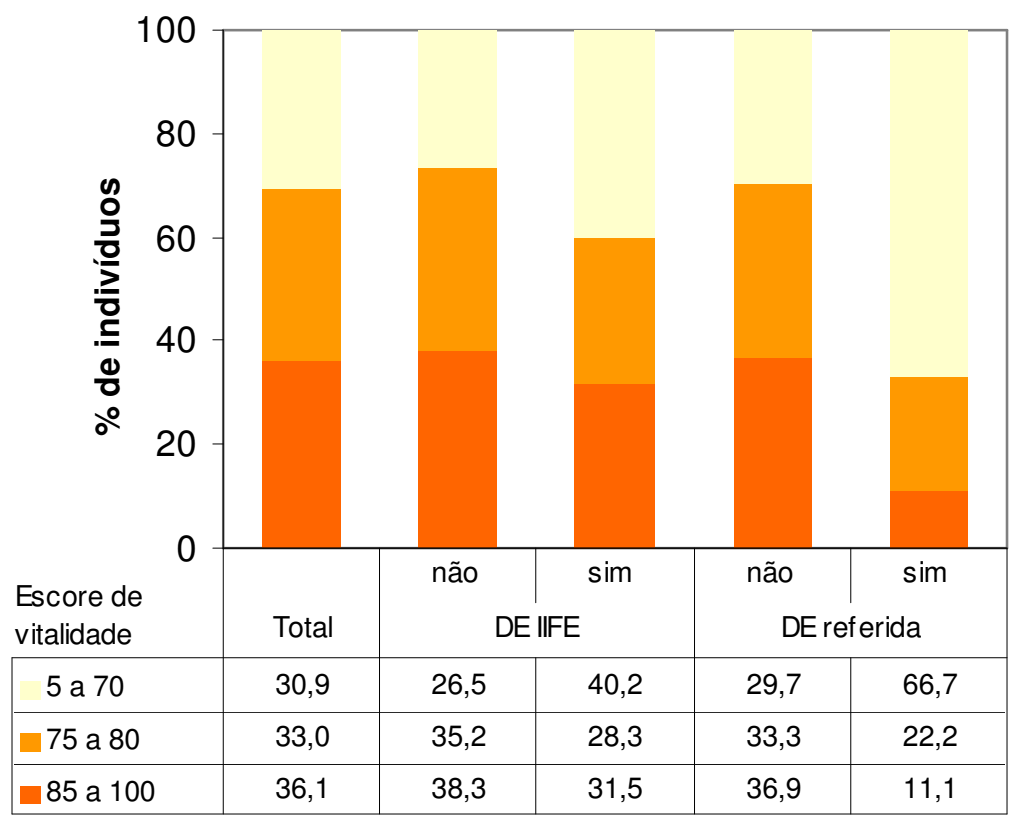

Figura 18. Distribuição percentual dos indivíduos segundo DE (detectada pelo IIFE e DE referida) e escore de saúde mental

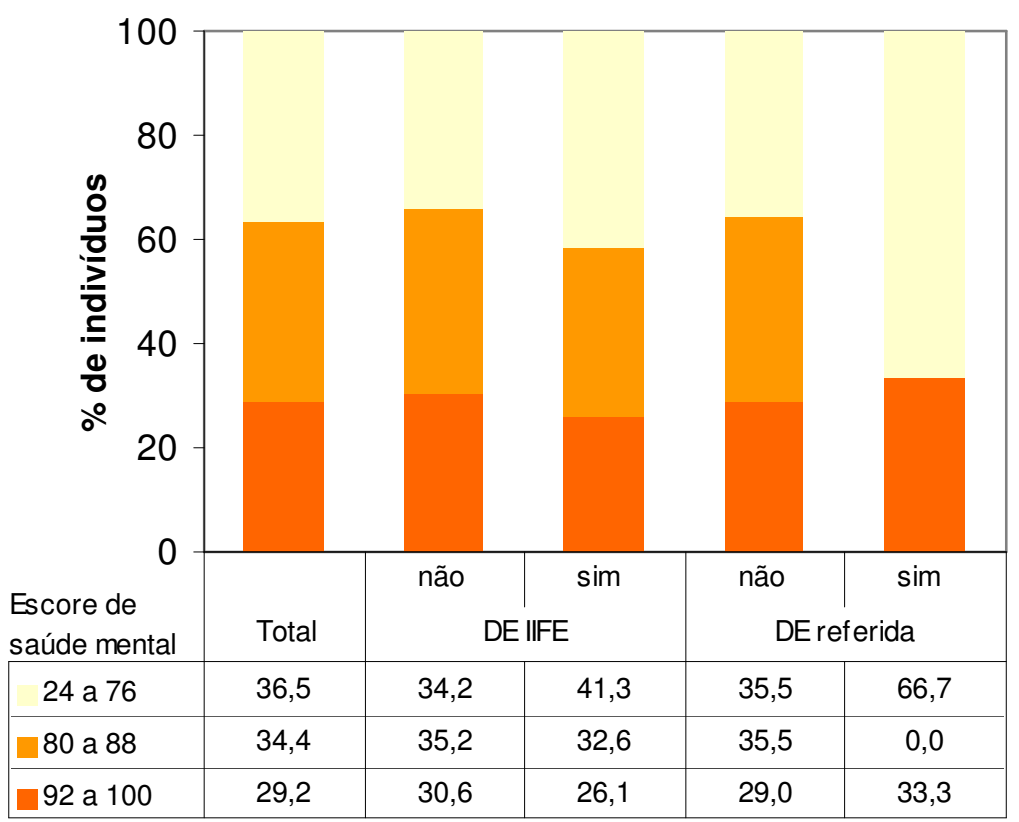


ANEXO I

Figura 19. Distribuição percentual dos indivíduos segundo DE (detectada pelo IIFE e DE referida) e stress

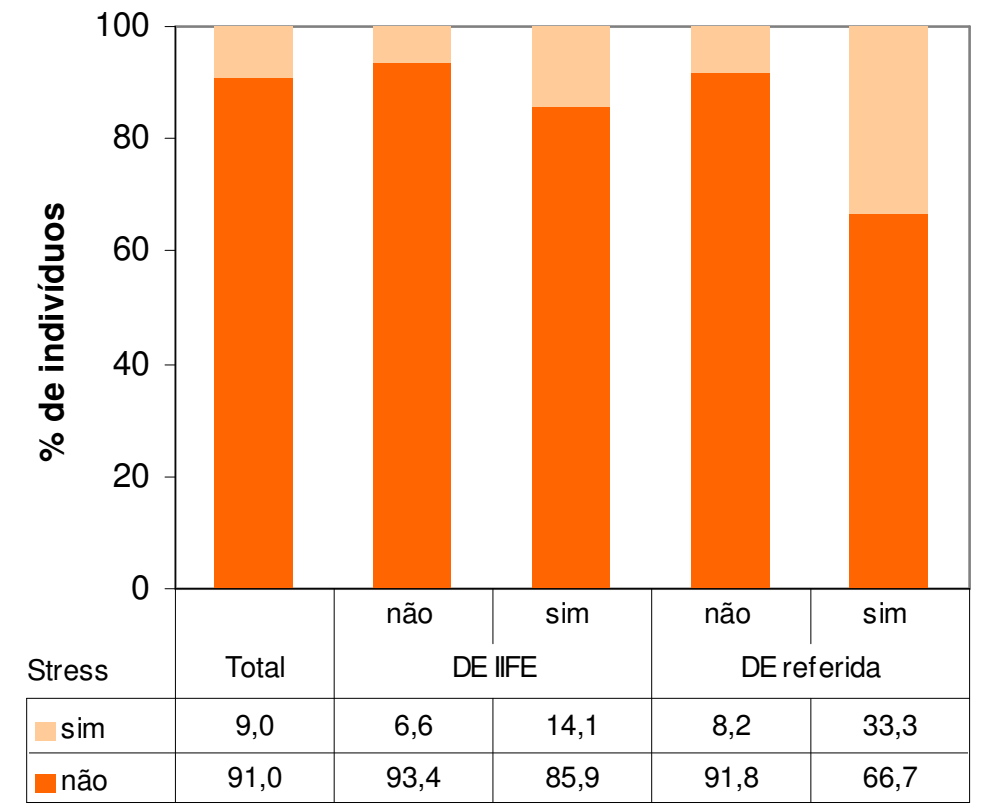

Figura 20. Distribuição percentual dos indivíduos segundo DE (detectada pelo IIFE e DE referida) e transtornos depressivos e/ou ansiosos

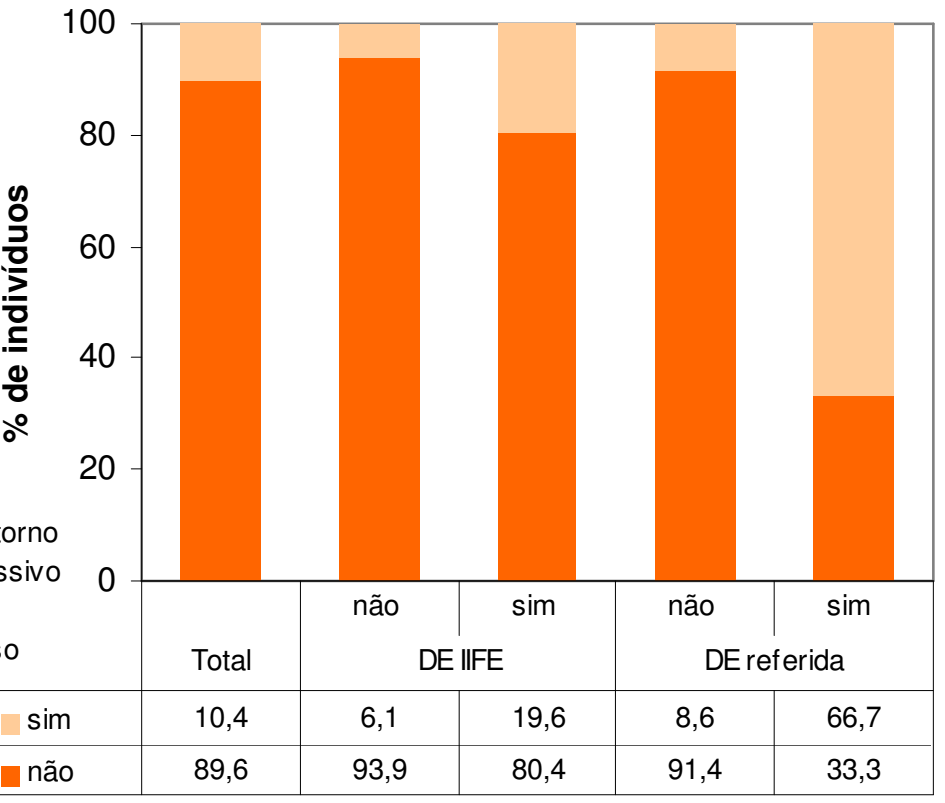


ANEXO I

Figura 21. Distribuição percentual dos indivíduos segundo DE (detectada pelo IIFE e DE referida) e tempo de relacionamento

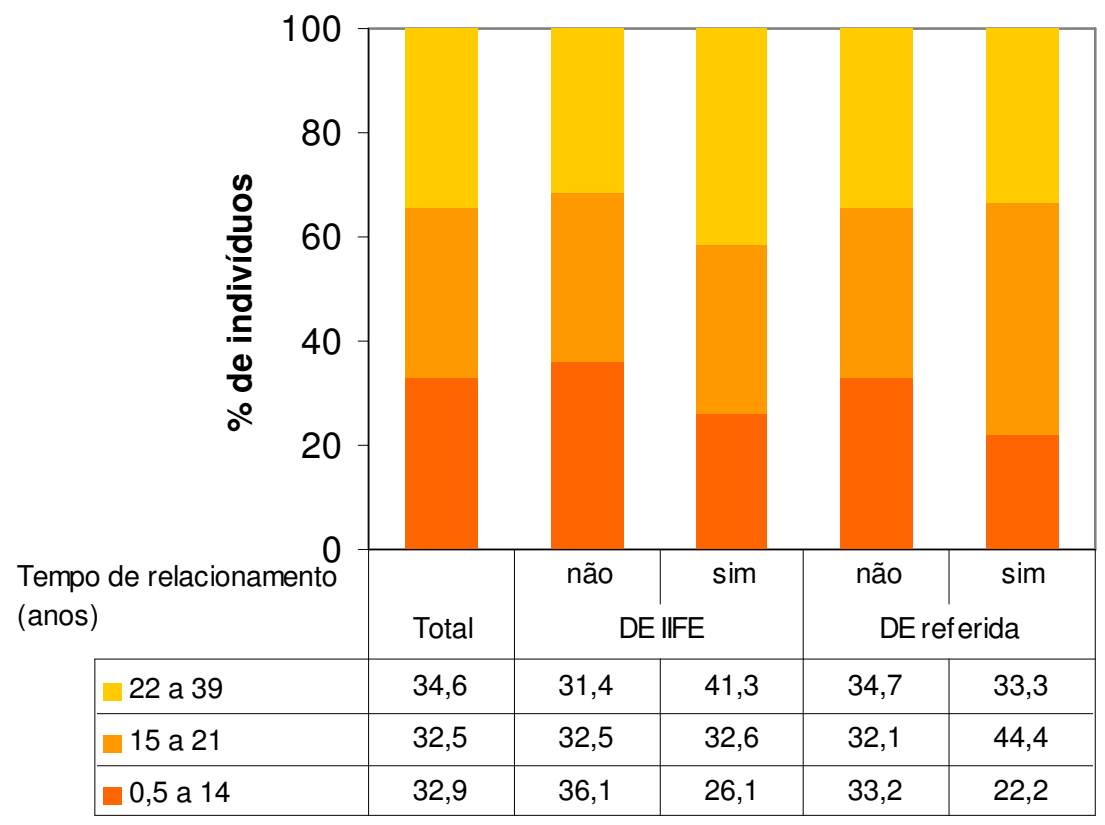

Figura 22. Distribuição percentual dos indivíduos segundo DE (detectada pelo IIFE e DE referida) e grau de satisfação no relacionamento a dois

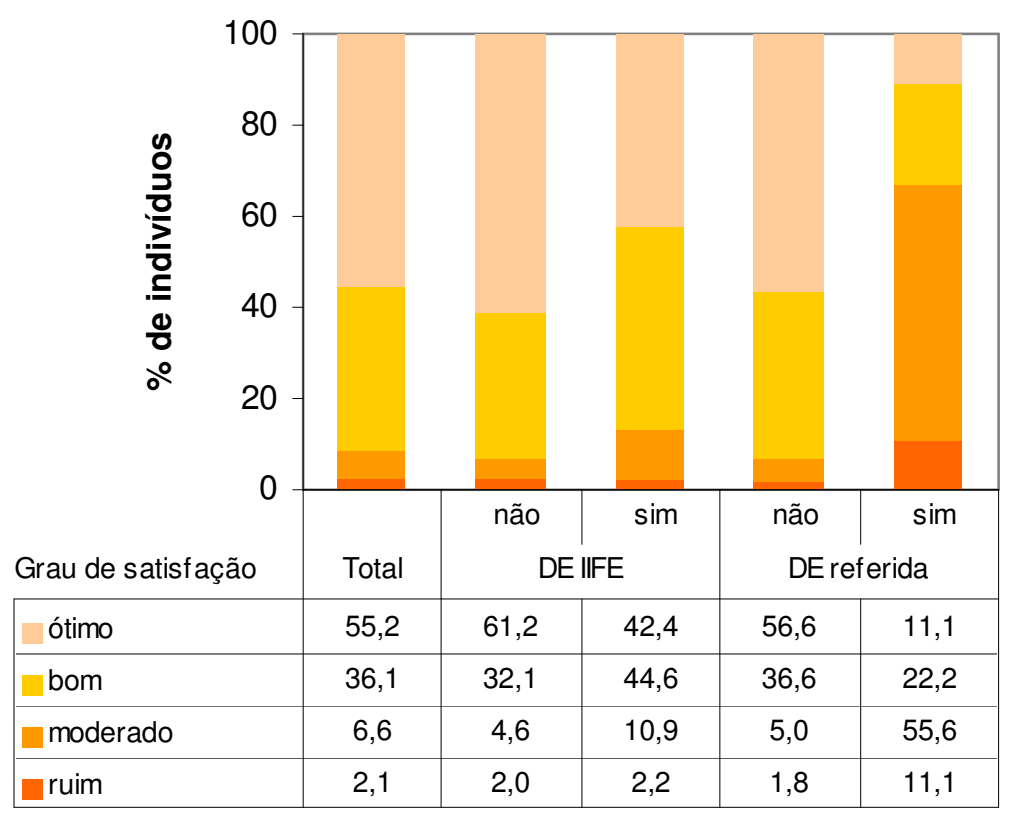


ANEXO I

Figura 23. Distribuição percentual dos indivíduos segundo DE (detectada pelo IIFE e DE referida) e atração sexual pela parceira

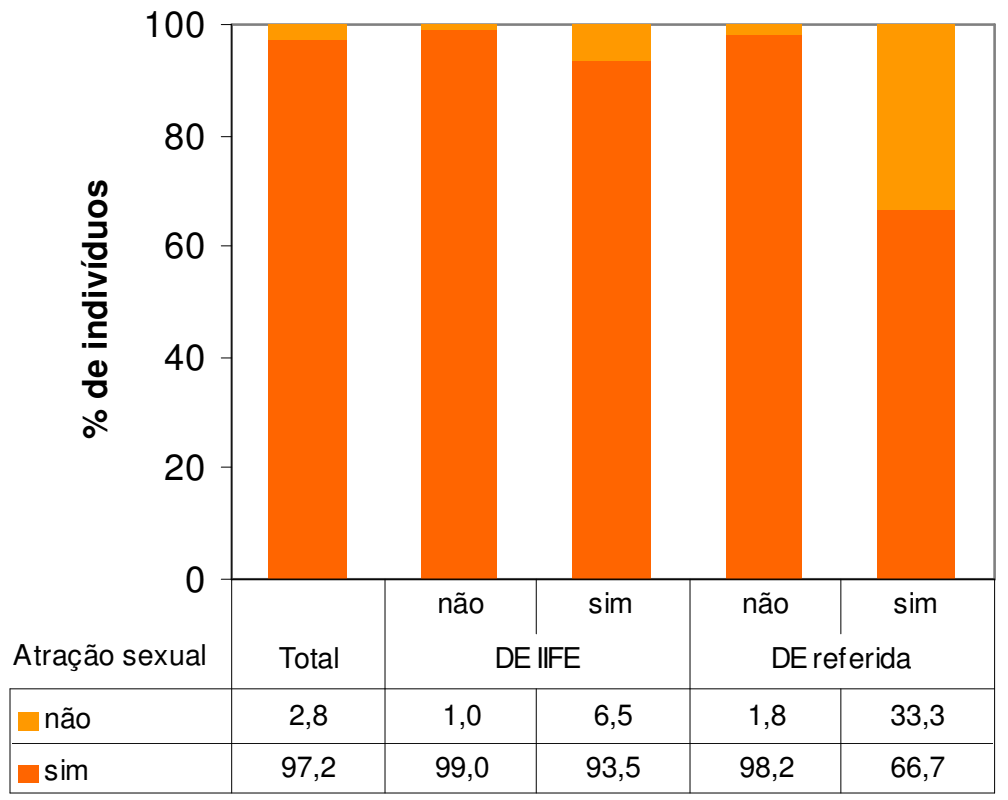

Figura 24. Distribuição percentual dos indivíduos segundo DE (detectada pelo IIFE e DE referida) e preliminares

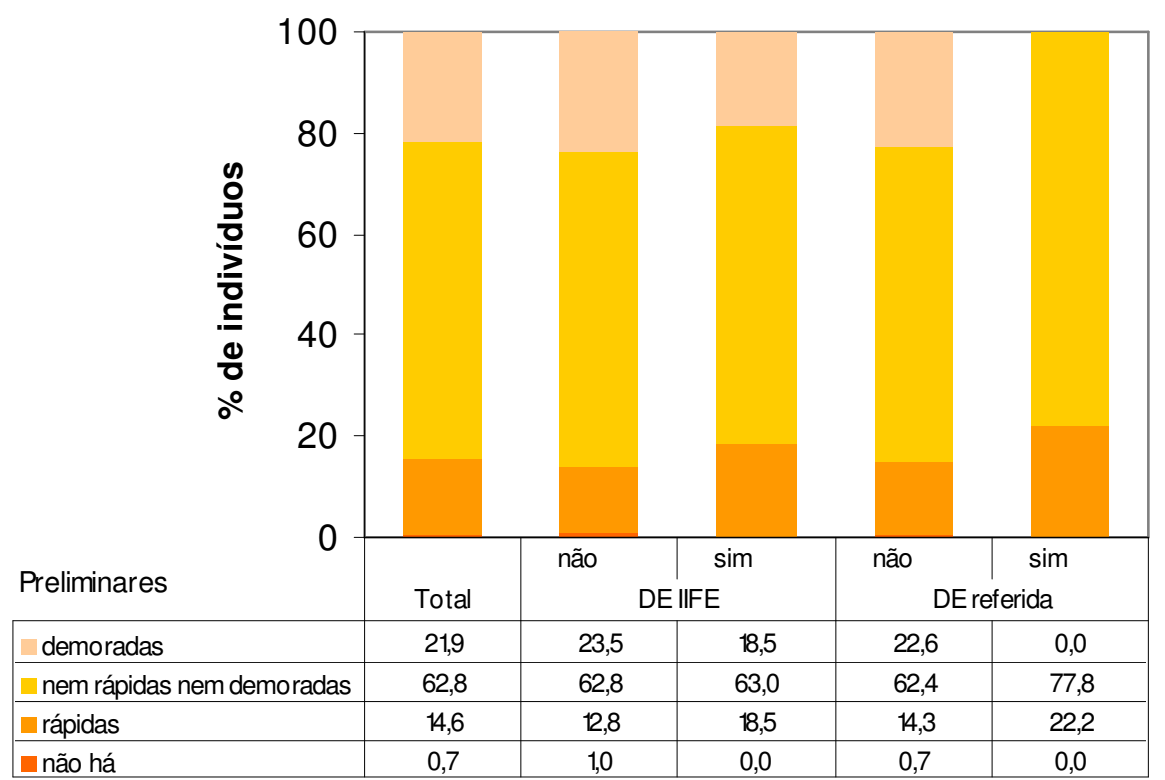


ANEXO I

Figura 25. Distribuição percentual dos indivíduos segundo DE (detectada pelo IIFE e DE referida) e como se sentem ao falar sobre sexo

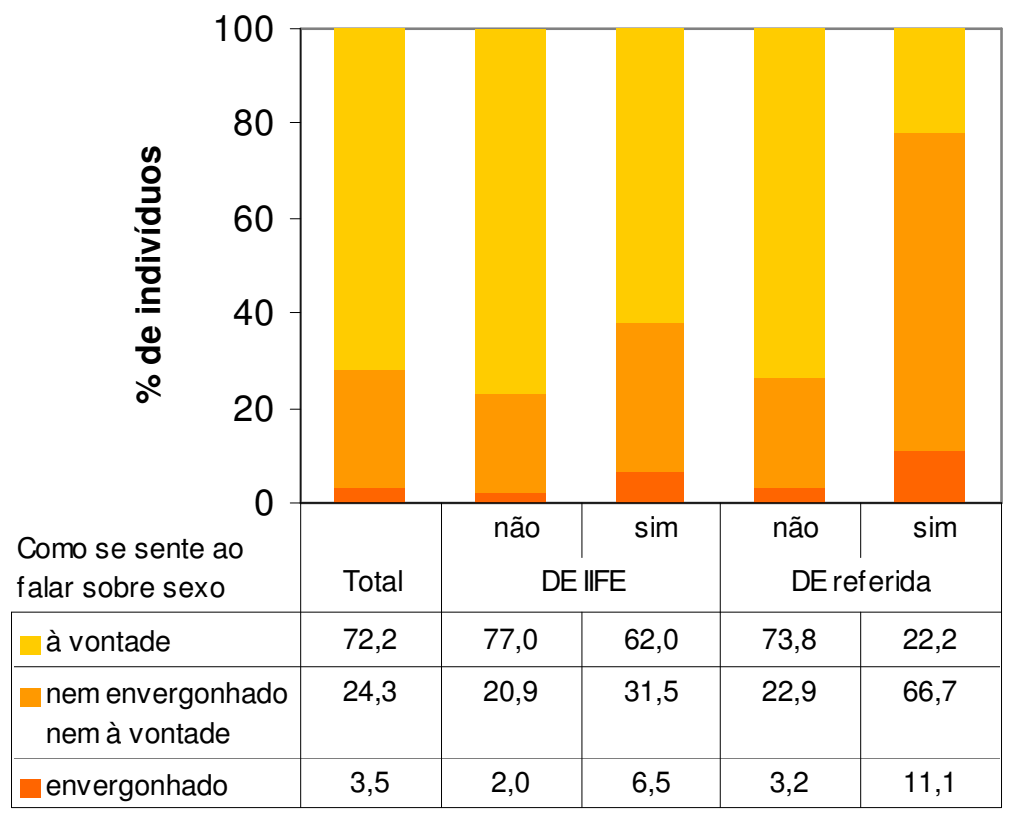

Figura 26. Distribuição percentual dos indivíduos segundo DE (detectada pelo IIFE e DE referida) e curvatura no pênis

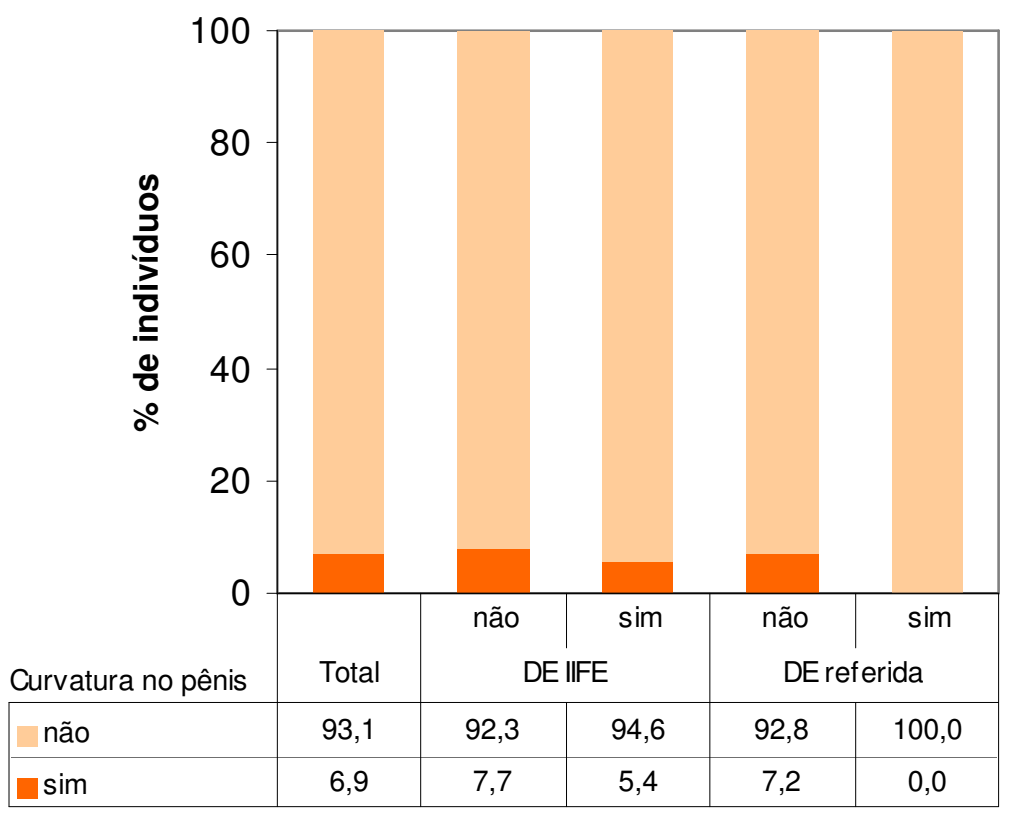


ANEXO I

Figura 27. Distribuição percentual dos indivíduos segundo DE (detectada pelo IIFE e DE referida) e desejo sexual atual

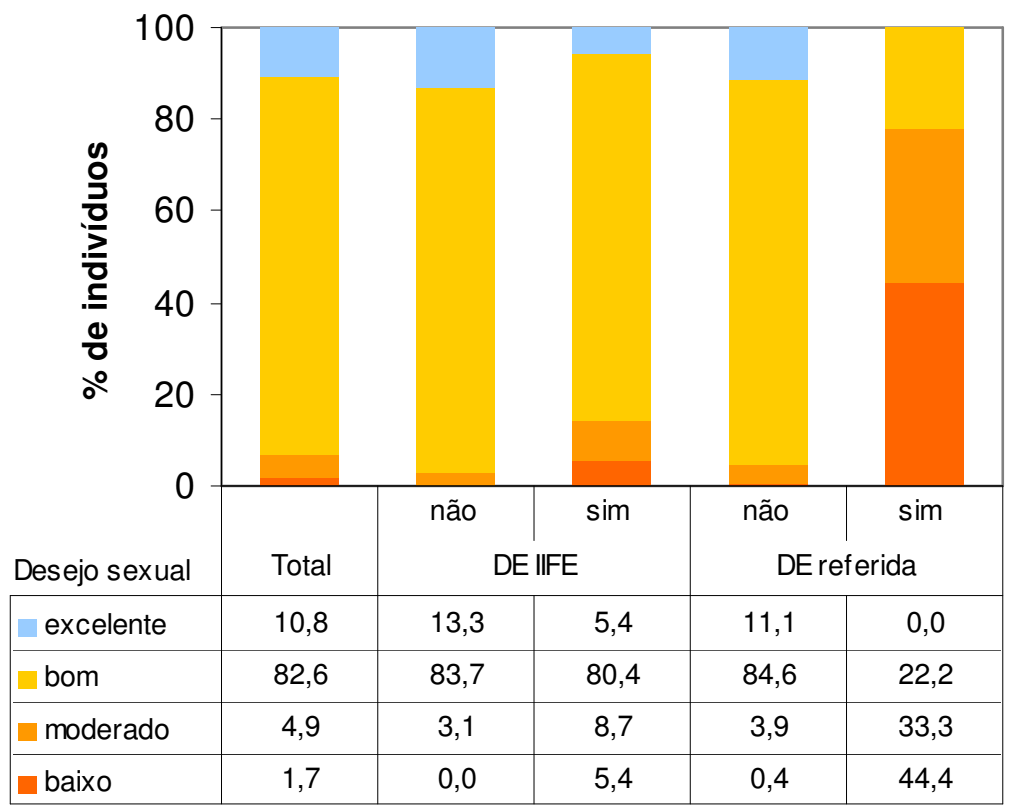

Figura 28. Distribuição percentual dos indivíduos segundo DE (detectada pelo IIFE e DE referida) e satisfação com o tamanho do pênis

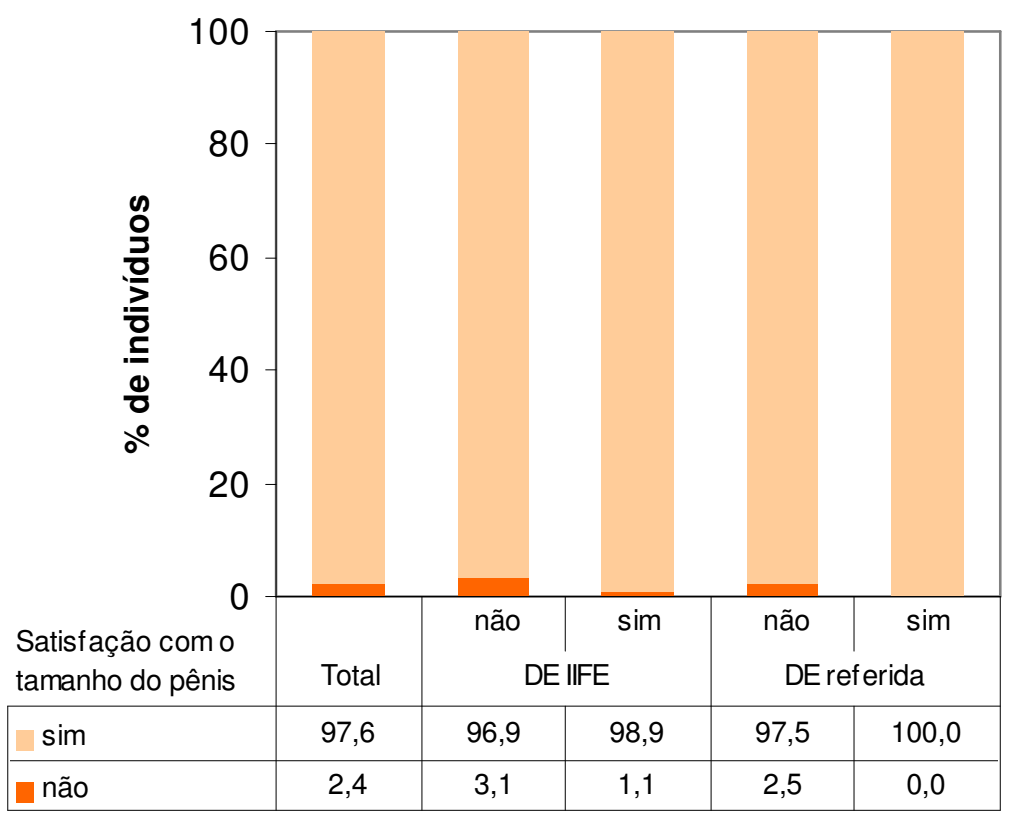


ANEXO I

Figura 29. Distribuição percentual dos indivíduos segundo DE (detectada pelo IIFE e DE referida) e satisfação com o próprio corpo

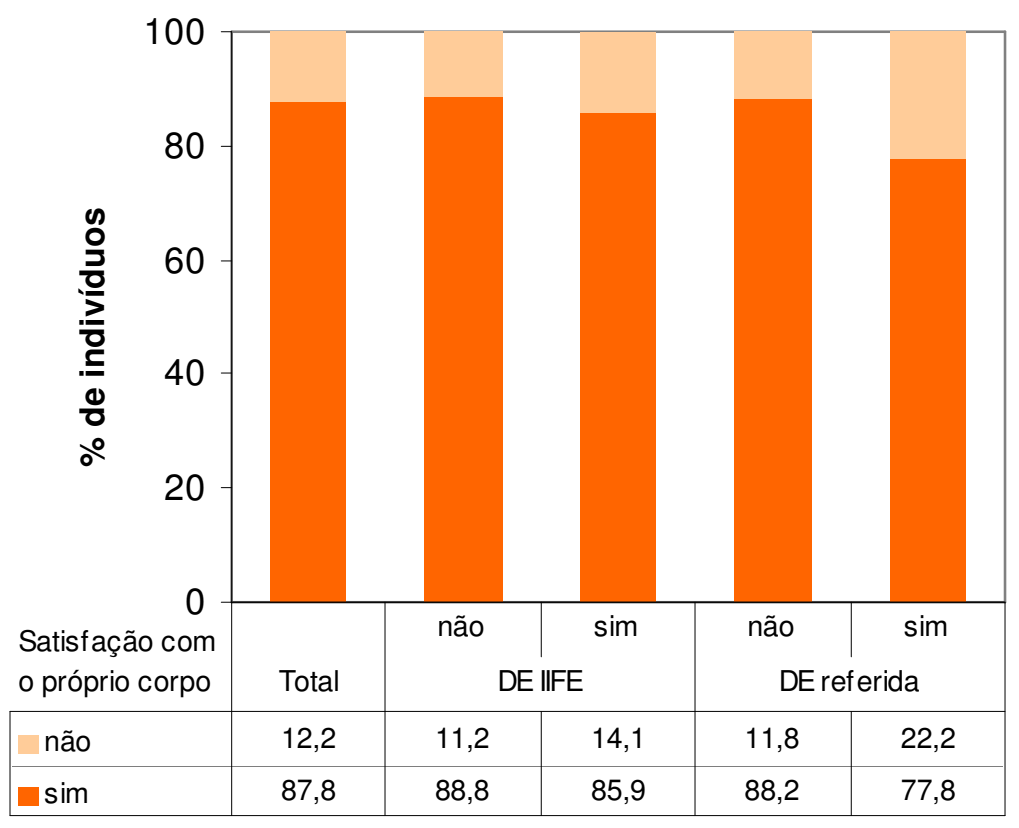

Figura 30. Distribuição percentual dos indivíduos segundo DE (detectada pelo IIFE e DE referida) e satisfação profissional

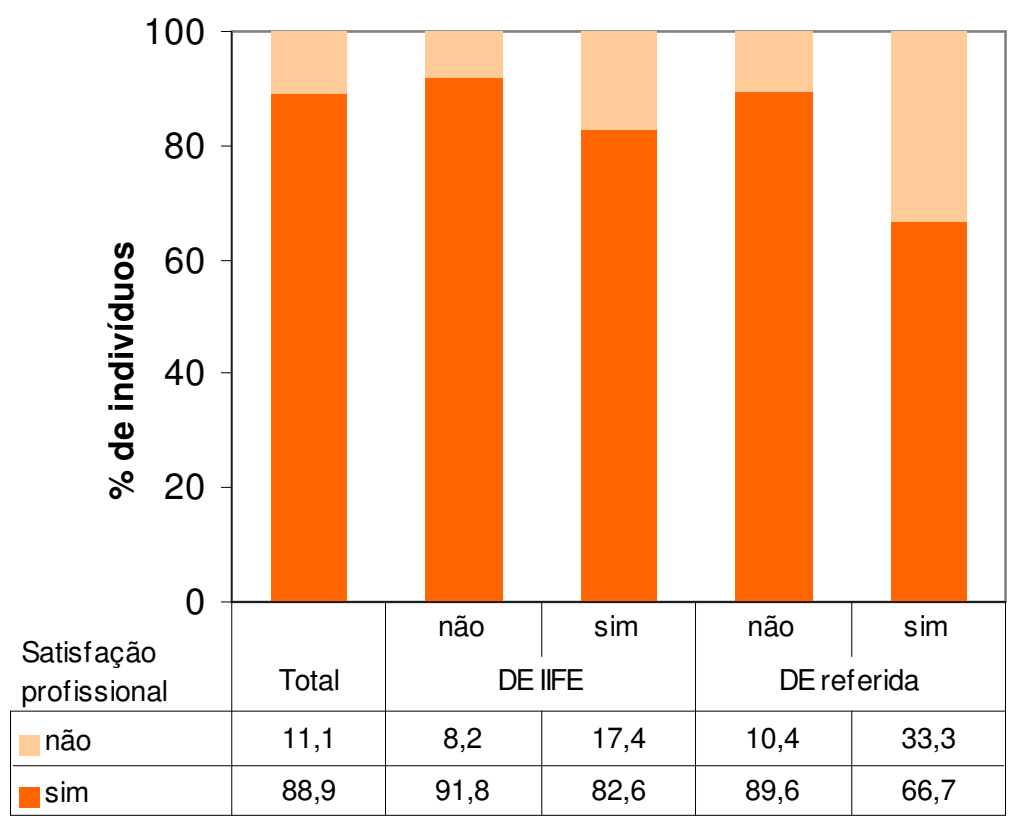


ANEXO I

Figura 31. Distribuição percentual dos indivíduos segundo DE (detectada pelo IIFE e DE referida) e satisfação pessoal

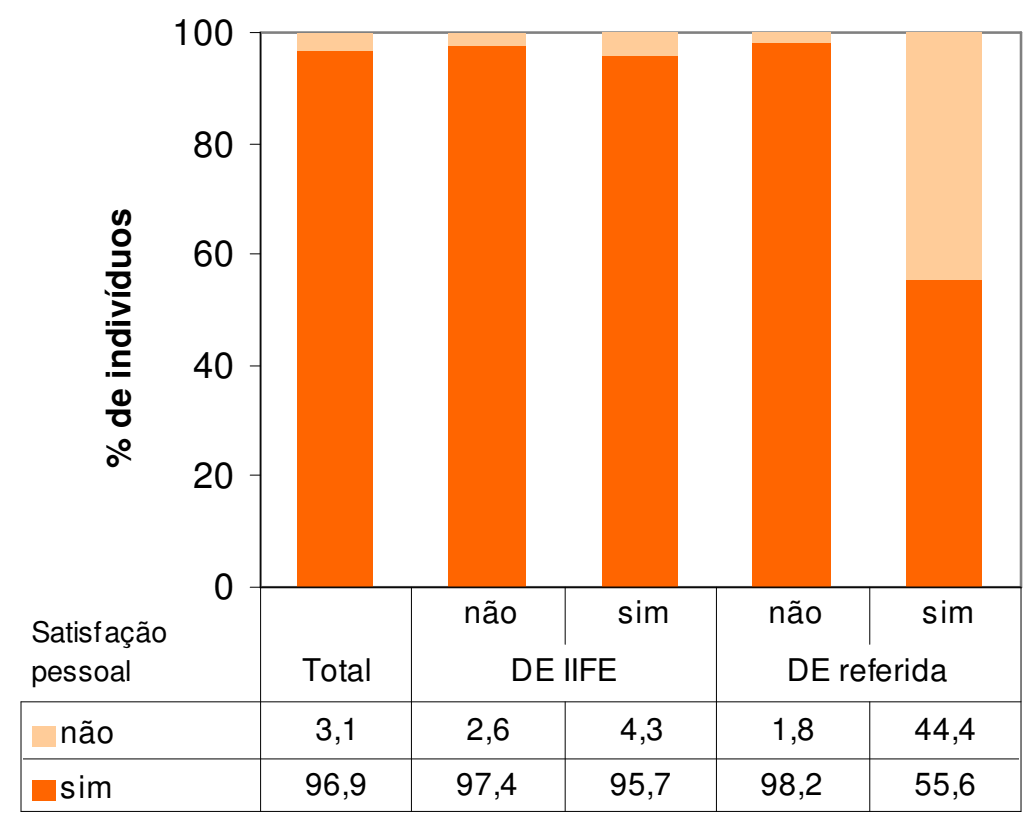

Figura 32. Distribuição percentual dos indivíduos segundo DE (detectada pelo IIFE e DE referida) e qualidade do sono

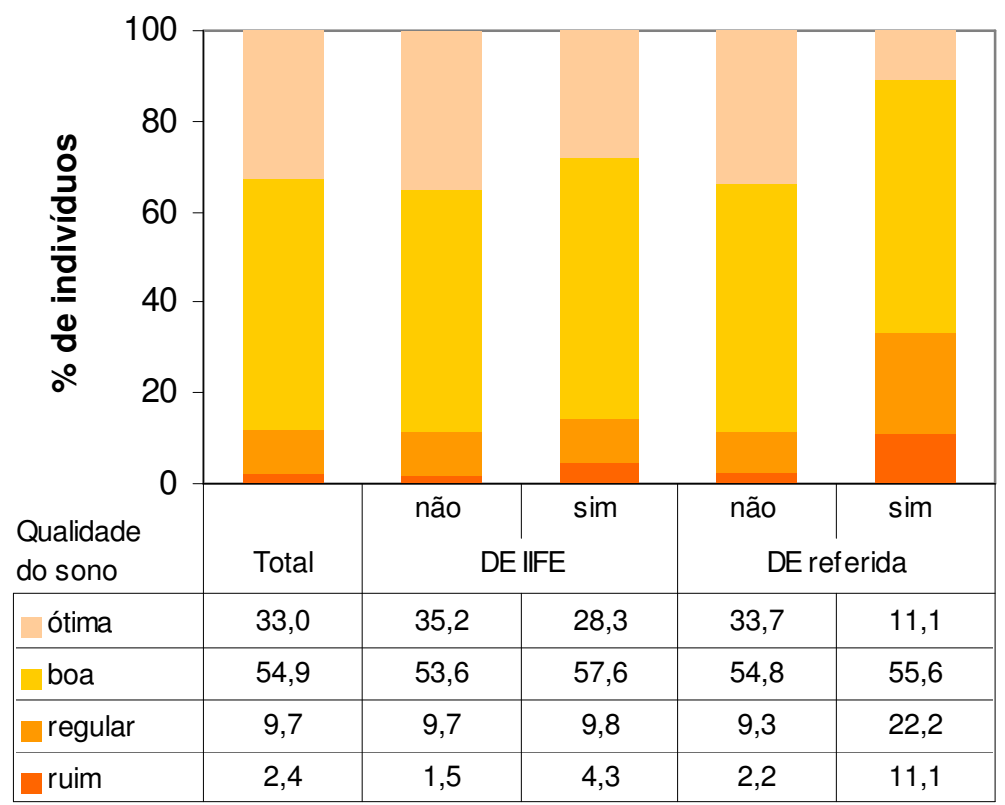


ANEXO I

Figura 33. Distribuição percentual dos indivíduos segundo DE (detectada pelo IIFE e DE referida) e realização de algum tipo de tratamento

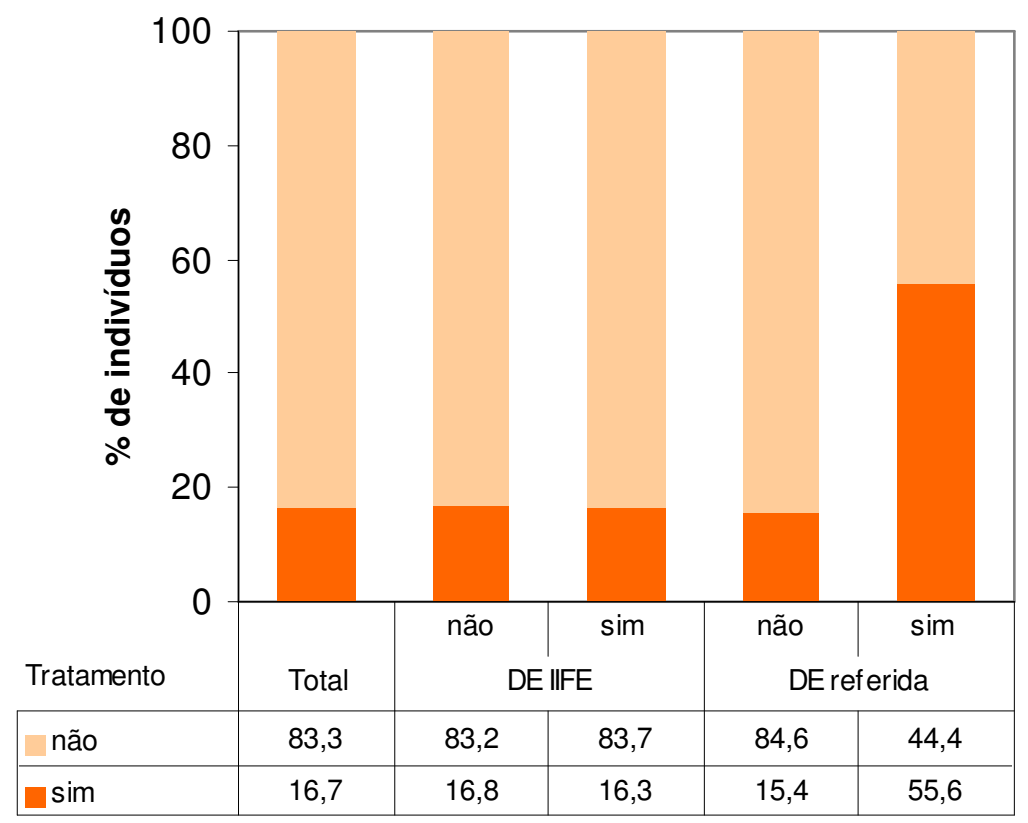

Figura 34. Distribuição percentual dos indivíduos segundo DE (detectada pelo IIFE e DE referida) e realização de tratamento para colesterol

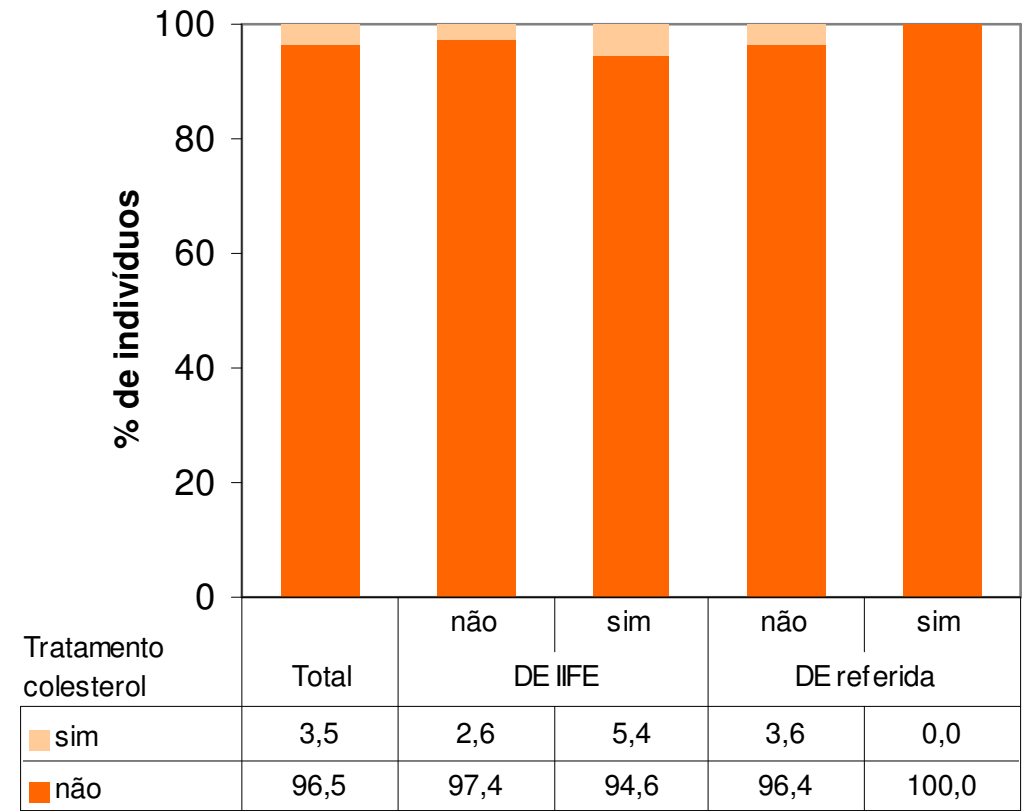


ANEXO I

Figura 35. Distribuição percentual dos indivíduos segundo DE (detectada pelo IIFE e DE referida) e realização de outro tipo de tratamento

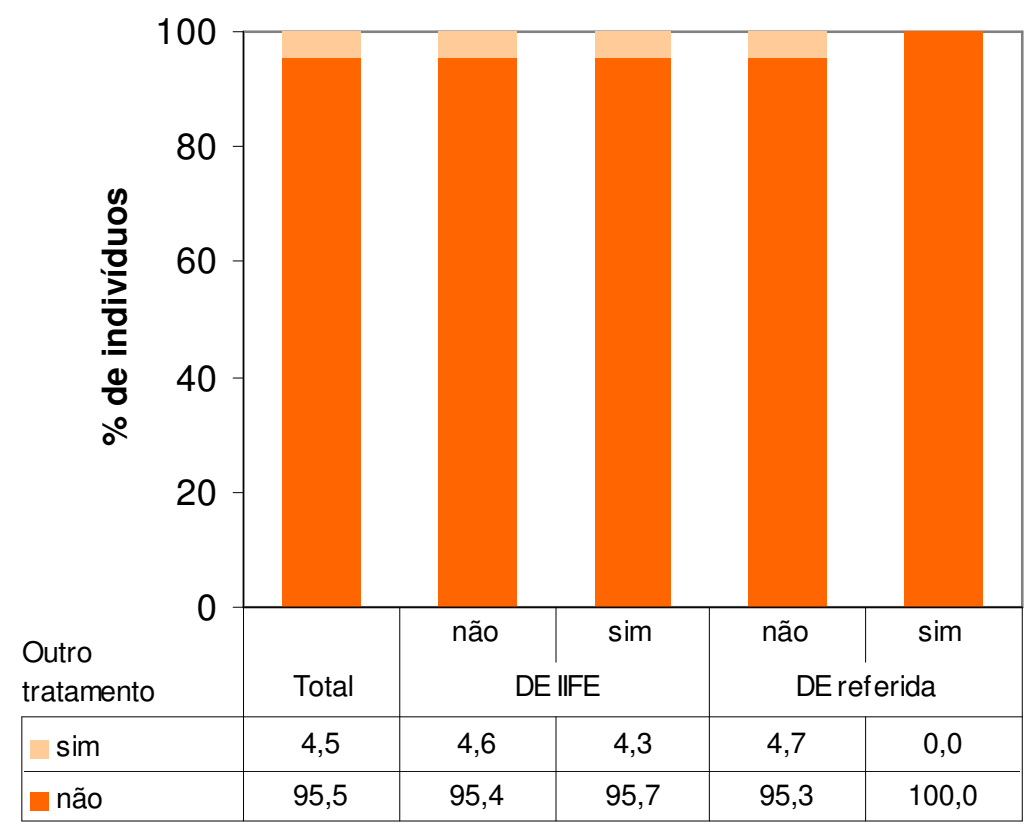

Figura 36. Distribuição percentual dos indivíduos segundo DE (detectada pelo IIFE e DE referida) e uso de medicamentos

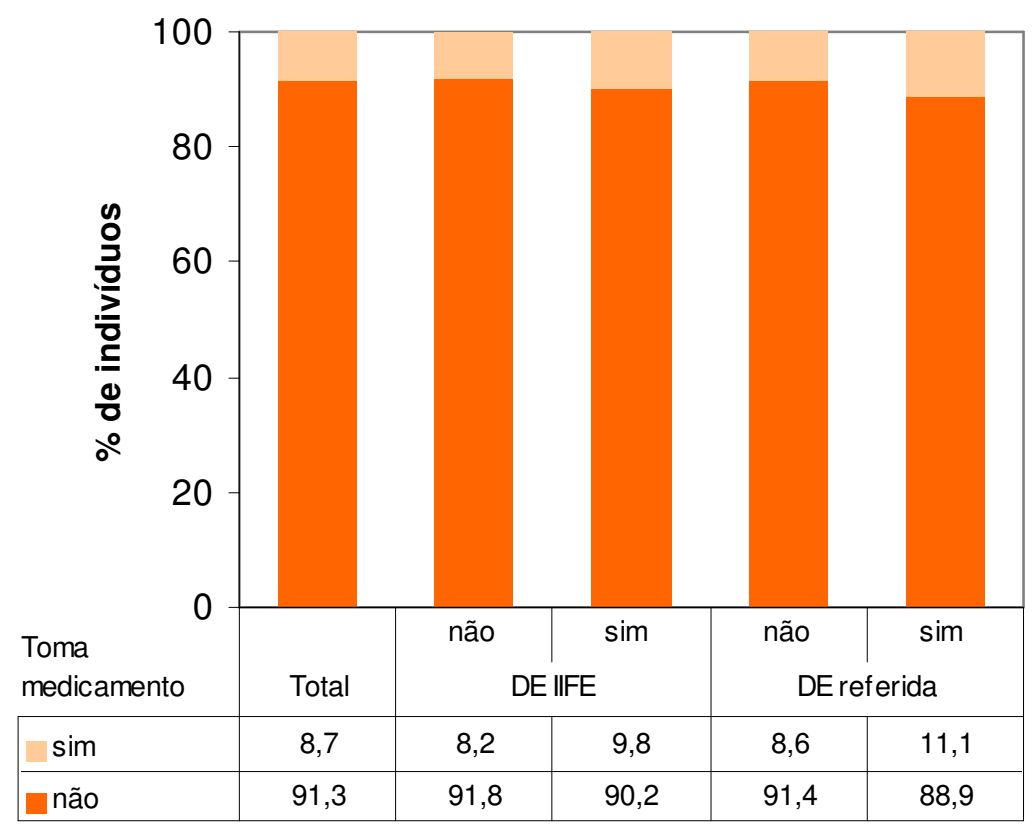


9. REFERÊNCIAS BIBLIOGRÁFICAS 
Abdo CHN, Oliveira Junior WM, Moreira ED, Fittipaldi JAS. Perfil Sexual da população brasileira: resultados do Estudo do Comportamento Sexual (ECOS) do Brasileiro. Rev Bras Med. 2002;59:250-7.

Abdo CHN. Estudo da Vida Sexual do Brasileiro - EVSB. São Paulo: Bregantini; 2004.

Abdo CHN, Oliveira Junior WM, Scanavino MT, Martins FG. Disfunção erétil resultados do estudo da vida sexual do brasileiro. Rev Assoc Med Bras 2006;52:424-29.

Abdo CHN, Abdo JA. Estudo populacional do envelhecimento (EPE): primeiros resultados masculinos. Rev Bras Med. 2007;64:379-83.

Ackerman MD, Carey MP. Psychology's role in the assessment of erectile dysfunction: historical precedents, current knowledge and methods. J Consult Clin Psychol. 1995;63:862-76.

Althof S. When an erection alone is not enough: biopsychosocial obstacles to lovemaking. Int J Impot Res. 2002;14(Supp11):99-104.

Araujo AB, Durante R, Feldman HA, Goldstein I, McKinlay JB. The relationship between depressive symptoms and male erectile dysfunction: Cross-sectional 
results from the Massachesetts Male Agin Study. Psychosom Med. 1998;60:45865.

Arcila JFU. Aproximação a uma teoria geral da função erétil e suas patologias. Arquivos H. Ellis Online [periódico online]. 2006; 2: (11 telas). Disponível em: http://www.arquivoshellis.com.br/revista/03_020307/03_020307_ahellis_01.pdf.

Aytac IA, Mckinlay JB, Krane RJ. The likely worldwide increase in erectile dysfunction between 1995 and 2025 and some possible policy consequences. BJU Int. 1999;84:50-6.

Aytac IA, Araujo AB, Johannes CB, Keinman KP, McKinlay JB. Socioeconomic factors and incidence of erectile dysfunction: findings of the longitudinal Massachesetts Male Aging Study. Soc Sci Med. 2000;51:771-78.

Barlow DH, Sakheim DK, Beck JG. Anxiety increases sexual arousal. J Abnorm Psychol. 1983;92:49-54.

Barlow DH. Causes of sexual dysfunction: the role of anxiety and cognitive interference. J Consult Clin Psychol. 1986;54:140-148.

Beck JS. Terapia cognitiva: teoria e prática. Porto Alegre: Artes Médicas; 1977. 
Bertero E. Impacto econômico da disfunção erétil. Arquivos H. Ellis Online [periódico online]. 2004; 2: (3 telas). Disponível em:

http://www.arquivoshellis.com.br/revista/01_021004/021004_ahellis_01.pdf.

Bogoras NA. Uber die volle plastiche wiederher - stellung eines zum koitus fahigen penis (peniplastica totalis). Zentralbl Chir. 1936;63:1271.

Bourdieu P. A dominação masculina. Rio de Janeiro: Bertrand Brasil; 1999.

Brasil. Ministério da Saúde. Legislação em Vigilância Sanitária. Resolução-RDC $N^{o}$ 153. Brasília: Agência Nacional de Vigilância Sanitária; 2004.

Brindley GS. Cavernosal alpha-blokage: a new technique for investigating and treating erectile impotence. Br J Psychiatry. 1983; 143:332-37.

Brindley GS. Pilot experiments on the actions of drugs injected into human corpus cavernosum penis. Br J Pharmacol. 1986;87:495-500.

Bussab WO, Morettin PA. Estatística básica. $5^{a}$ ed. São Paulo: Saraiva; 2005.

Carey MP. Tratamento Cognitivo-Comportamental das Disfunções Sexuais. In: Caballo VE (Org). Manual para o Tratamento Cognitivo-Comportamental dos Transtornos Psicológicos. São Paulo: Editora Santos; 2003. p.267-298. 
Carson C, Kirby R, Goldstein I (Eds). Textbook of Erectile Dysfunction. Isis Medical Media; 1999.

Chew KK, Earle CM, Stuckey BGA, Jamrozik K, Keogh EJ. Erectile dysfunction in general medicine practice: prevalence and clinical correlates. Int J Impot Res. 2000;12:41-5.

Chew KK, Stuckey B, Bremner A, Earle C, Jamrozik K. Male erectile dysfunction: Its prevalence in Western Australia and associated sociodemographic factors. J Sex Med. 2008;5:60-9.

Chvaicer H. As alterações sexuais do homem idoso. Arquivos H. Ellis Online [periódico online]. 2005; 2: (2 telas). Disponível em:

http:/www.arquivoshellis.com.br/revista/02_021105/02_021105_ahellis_01.pdf.

Ciconelli RM. Tradução para o português e validação do questionário genérico de avaliação de qualidade de vida "Medical outcomes study 36-item short-form health survey (SF-36)" [tese] São Paulo: Escola Paulista de Medicina, Universidade Federal de São Paulo; 1997.

Cranston-Cuebas MA, Barlow DH. Cognitive and affective contributions to sexual functioning. Annu Rev Sex Res. 1990;1:119-161. 
Cunha PRB. Disfunção erétil e o endotélio - diagnóstico e tratamento. Rio de Janeiro: Medsi; 2005.

Derby CA, Araujo AB, Johannes CB, Feldman HA, Mckinlay. Measurement of erectile dysfunction in population-based studies: the use of a single question selfassessment in the Massachusetts Male Aging Study. Int J Impot Res. 2000;12:197-204.

Em busca de diversão. Revista Veja - Edição Especial HOMEM, 2004 ago: [1 tela]. Disponível em: http://veja.abril.com.br/especiais/homem_2004/p_044.html.

Feldman HA, Goldstein I, Hatzichristou DG, Krane RJ, McKinlay JB. Impotence and its medical and psychosocial correlates: Results of the Massachusetts Male Aging Study. J Urol. 1994;151:54-61.

Feldman HA, McKinlay JB, Goldstein I, Longcope C. Erectile dysfunction, cardiovascular disease, and cardiovascular risk factors: prospective results in a large random sample of Massachusetts men. J Urol. 1998;159(Suppl):91.

Ferraz MB, Ciconelli RM. Tradução e adaptação cultural do Índice Internacional de Função Erétil para a língua portuguesa. Rev Bras Med. 1998;55:35-40. 
Garrido R, Menezes PR. O Brasil está envelhecendo: boas e más notícias por uma perspectiva epidemiológica. (Brazil is aging: good and bad news from an epidemiological perspective). Rev Bras Psiquiatr. 2002;24(Supl1):3-6.

Glina S. Esquema geral para a investigação da disfunção erétil. In: Glina S, Puech-Leão P, Reis JMSM dos, Pagani E. Instituto H. Ellis - Disfunção Sexual Masculina, São Paulo: Instituto H. Ellis; 2002. p.131-33.

Glina S. Did sildenafil influence the behavior of patients with erectile dysfunction (ED)?. Int J Imp Res. 2002a;14(suppl3):S105.

Harding TW, Arango MV, Baltazar J, Climent CE, Ibrahim HHA, LadridoIgnacio L, Murthy RS, Wig NN. Mental disorders in primary health care: a study of the frequency and diagnosis in four developing countries. Psychol Med. 1980;10:231-41.

Hauri D. Erectile dysfunction in the elderly man. Urol Int. 2003;70:89-99.

Helgason AR, Adolfsson J, Dickman P, Arver S, Fredrikson M, Steineck G. Factors associated with waning sexual function among elderly men and prostate cancer patients. J Urol. 1997;158:155-9.

Hennekens CH, Buring JE. Epidemiology in Medicine. Boston/Toronto: Little, Brown and Company; 1987. 
Hosmer DW, Lemeshow S. Applied Logistic Regression. New York/Chichester/ Brisbane/Toronto/Singapore: A Wiley-Interscience Publication; 1989.

Izukawa NM. Impotência Sexual Arteriogênica em Pacientes Portadores de Aterosclerose das Artérias Coronárias. [tese] São Paulo: Faculdade de Medicina, Universidade de São Paulo; 1997.

Johannes CB, Araujo AB, Feldman HA, Derby CA, Keinman KP, McKinlay JB. Incidence of erectile dysfunction in men 40 to 69 years old: Longitudinal results from The Massasuchetts Male Aging Study. J Urol. 2000;163:460-3.

Jonler M, Moon T, Brannan W, Stone NN, Heisey D, Bruskewitz RC. The effect of age, ethnicity and geographical location on impotence and quality of life. $\mathrm{Br} J$ Urol. 1995;75:651-5.

Jünemann KP, Alken P. Pharmacotherapy of erectile dysfunction: a review. Int J Imp Res. 1989;1:71-93.

Kaiser FE. Sexuality in the elderly. Urol Clin North Am. 1996;23:99-109.

Kaplan HS. The new sex therapy. New York: Brunner/Mazel; 1974.

Kaplan HS. The new sex therapy: Active treatment of sexual dysfunctions. New York: Brunner/Mazel; 1981. 
Kaplan HS. The concept of presbyrectia. Int J Imp Res. 1989;1:59-65.

Kaplan HS. The Sexual Desire Disorders: Dysfunctional Regulation of Sexual Motivation. New York: Routledge; 1995.

Kinsey AC, Pomeroy WB, Martin CE. Sexual behavior in human male. Philadelphia: WB Saunders; 1948.

Kinsey AC, Pomeroy WB, Martin CE, Gebhard PH. Sexual behavior in the human female. Philadelphia: WB Saunders; 1953.

Kubin M, Wagner G, Fugl-Meyer AR. Epidemiology of erectile dysfunction. Int J Imp Res. 2003;15:63-71.

Kusnetzoff JC. O homem sexualmente feliz: do mito à verdade científica. Rio de Janeiro: Nova Fronteira; 1987.

Latini DM, Penson DF, Lubeck DP, Wallace KL, Henning JM, Lue TF. Longitudinal differences in disease specific quality of life in men with erectile dysfunction: results from the Exploratory Comprehensive Evaluation of Erectile Dysfunction study. J Urol. 2003;169:1437-42.

Laumann EO, Paik A, Rosen RC. Sexual dysfunction in the United States: prevalence and predictors. JAMA. 1999;281:537-44. 
Laumann EO, Nicolosi A, Glasser DB, Paik A, Gingell C, Moreira E, Wang T. Sexual problems among women and men aged 40-80y: prevalence and correlates identified in the Global Study of Sexual Attitudes and Behaviors. Int J Imp Res. $2005 ; 17: 39-57$.

Leiblum SR, Rosen RC. (Orgs). Sexual desire disorders. Nueva York: Guilford; 1988.

Leiblum SR, Rosen RC. Couples therapy for erectile disorders: Conceptual and clinical considerations. J Sex Marital Ther. 1991;17:147-59.

Levine LA. Diagnosis and treatment of erectile dysfunction. Am J Med. 2000;109(9A):3S-12S.

Lipp MEN. Stress: conceitos básicos. In: Lipp MEN (Org). Pesquisas sobre stress no Brasil - Saúde, ocupações e grupos de risco. 2 ed. rev. Campinas: Papirus; 1996. p.17-31.

Lipp MEN. Manual do Inventário de Sintomas de Stress para Adultos de Lipp (ISSL). 2 ed. rev. São Paulo: Casa do Psicólogo; 2002.

Lipp MEN, Pereira MB, Sadir MA. Crenças irracionais como fontes internas de stress emocional. (Irrational beliefs as internal source of emotional stress). Rev Bras Ter Cogn. 2005; 1:29-34. 
Lopes JAM. Prevalência da disfunção erétil em Poços de Caldas - Minas Gerais. Avaliação com 2000 entrevistados. [tese] São Paulo: Escola Paulista de Medicina, Universidade Federal de São Paulo; 2000.

LoPiccolo J, LoPiccolo L. (Orgs). Handbook of sex therapy. New York: Plenum; 1978.

LoPiccolo J, Friedman JM. Broad-spectrum treatment of low sexual desire: Integration of cognitive, behavioral, and systemic therapy. In: Leiblum SR, Rosen RC. (Orgs). Sexual desire disorders. New York: Guilford; 1988.

Mari JJ, Williams P. A validity study of a psychiatric screening questionnaire (SRQ-20) in primary care in the city of São Paulo. Brit J Psychiat. 1986;148:236.

Martin-Morales A, Sanchez-Cruz JJ, Saenz de Tejada I, Rodriguez-Vela L, Jimenez-Cruz JF, Burgos-Rodriguez R. Prevalence and independent risk factors for erectile dysfunction in Spain: Results of the Epidemiologia de la Disfuncion Erectil Masculina Study. J Urol. 2001;166:569-75.

Mascaro AS. O que é velhice. $2^{\mathrm{a}}$ reimpr. São Paulo: Brasiliense, 2004. - (Coleção primeiros passos).

Masters W, Johnson V. Human sexual response. Boston: Little, Brown; 1966. 
Masters W, Johnson V. Human sexual inadequacy. Boston: Little, Brown; 1970.

McCarthy BW. Relapse prevention strategies and techniques in sex therapy. $J$ Sex Marital Ther. 1993;19:142-46.

Melman A. An intermediate approach to impotence evaluation. Contemp Urol. $1995 ; 7: 14-21$.

Melman A, Gingell JC. The epidemiology and pathophysiology of erectile dysfunction. J Urol. 1999;161:5-11.

Michal V. Arterial disease as a cause of impotence. Clin Endocrinol Metab. $1982 ; 11: 725-48$.

Mohr DC, Bleuter LE. Erectile dysfunction: A review of diagnostic and treatment procedures. Clin Psychol Rev. 1990;10:123-50.

Moreira Junior ED, Abdo CHN, Torres EB, Lôbo CFL, Fittipaldi JAS. Prevalence and correlates of erectile dysfunction: results of the Brazilian study of sexual behavior. Urology. 2001;58:583-8.

Moreira Junior ED, Lôbo CFL, Villa M, Nicolosi A, Glasser DB. Prevalence and correlates of erectile dysfunction in Salvador, northeastern Brazil: a populationbased study. Int J Imp Res. 2002;14(Supp12):3-9. 
Moreira Junior ED, Lôbo CFL, Diament A, Nicolosi A, Glasser DB. Incidence of erectile dysfunction in men 40 to 69 years old: results from a population-based cohort study. Urology. 2003;61:431-6.

Moreira Junior ED, Santos DB, Abdo CHN; Wroclawski E, Fittipaldi JAS. Epidemiologia da disfunção erétil no Brasil: resultados da pesquisa nacional do Projeto Avaliar. Rev Bras Med. 2004;61:613-25.

Moreira Junior ED, Glasser D, Santos DB, Gingell C. Prevalence of sexual problems and related help-seeking behaviors among mature adults in Brazil: data from the Global Study of Sexual Attitudes and Behaviors. São Paulo Med J. $2005 ; 123: 234-41$.

Morillo LE, Díaz J, Estevez E, Costa A, Méndez H, Dávila H, Medero N, Rodriguez N, Chaves M, Vinueza R, Ortiz JA, Glasser DB. Prevalence of erectile dysfunction in Colômbia, Ecuador and Venezuela: a population-based study (DENSA). Int J Impot Res. 2002;14(Suppl2):10-8.

Morley JE. Impotence. Am J Med. 1986;80:897-905.

Nascimento AF, Menezes PR. Validade e confiabilidade das escalas de avaliação em Psiquiatria. In: Escalas de avaliacão clínica em Psiquiatria e Psicofarmacologia.1 ed. São Paulo: Lemos Editorial; 2000. p.23-28. 
Nadig PW, Ware JC, Blumoff R. Noninvasive device to produce and maintain an erection-like state. Urology. 1986;27:126-31.

Nicolosi A, Moreira Junior ED, Shirai M, Bin Mohd Tambi MI, Glasser DB. Epidemiology of erectile dysfunction in four countries: cross-national study of the prevalence and correlates of erectile dysfunction. Urology. 2003;61:201-6.

NIH Consensus Development Panel on Impotence. Impotence. JAMA. 1993;70:83-90.

O'Donnell AB, Araujo AB, Goldstein I, Mckinlay. The validity of a singlequestion self-report of erectile dysfunction - results from the Massachusetts Male Aging Study. J Gen Intern Med. 2005;20:515-19.

Oliveira SRC, Abdo CHN. Disfunção erétil e ejaculação precoce: conceito, etiologia e tratamento psiquiátrico. In: Abdo CHN (Org). Sexualidade humana e seus transtornos. 2 ed. rev. e ampl. São Paulo: Lemos Editorial; 2000. p. 79-91.

Ponholzer A, Temml C, Mock K, Marszalek M, Obermayr R, Madersbacher S. Prevalence and risk factors for erectile dysfunction in 2869 men using a validated questionnaire. Eur Urol. 2005;47:80-6. 
Prins J, Blanker MH, Bohnen AM, Thomas S, Bosch JLHR. Prevalence of erectile dysfunction: a systematic review of population-based studies. Int J Impot Res. 2002;14:422-32.

Puech-Leão P. Cirurgia vascular em disfunção erétil. In: Glina S, Puech-Leão P, Reis JMSM dos, Pagani E. Instituto H. Ellis - Disfunção Sexual Masculina, São Paulo: Instituto H. Ellis; 2002. p.243-6.

Ramanathan R, Mulhall J, Rao S, Leung R, Salamanca Martinez JI, Mandhani A, Tewari A. Predictive correlation between the International Index of Erectile Function (IIEF) and Sexual Health Inventory for Men (SHIM): implications for calculating a derived SHIM for clinical use. J Sex Med. 2007;4:1336-44.

Rangé B, Conceição DB. Disfunções Sexuais. In: Rangé B (Org). Psicoterapia Comportamental e Cognitiva de Transtornos Psiquiátricos. Campinas: Livro Pleno; 2001. p.219-30.

Rehman J, Melman A. Fisiopatologia das principais causas da disfunção erétil. In: Glina S, Puech-Leão P, Reis JMSM dos, Pagani E. Instituto H. Ellis Disfunção Sexual Masculina, São Paulo: Instituto H. Ellis; 2002. p.59-79.

Reis JMSM dos, Ribeira JM, Silva MFR, Glina S. Prótese peniana no tratamento da impotência. In: Reis JMSM dos, Rodrigues Júnior OM. Impotência sexual 
abordagem multidisciplinar: um guia para psicoterapeutas, médicos e educadores. São Paulo: Instituto H. Ellis; 1993. p.155-164.

Reis, JMSM dos, Martins LM, Furlan V. Impotência Sexual Vasculogênica. In: Maffei FHA, Lastória S, Yoshida WB, Rollo HA. Doenças Vasculares Periféricas. 3 ed. Vol II. Rio de Janeiro: MEDSI Editora Médica e Científica Ltda; 2002. p.1873-80.

Rhoden EL, Telöken C, Sogari PR, Souto CAV. The use of the simplified International Index of Erectile Function (IIEF-5) as a diagnostic tool to study the prevalence of erectile dysfunction. Int J Impot Res. 2002;14:245-50.

Rosen RC, Leiblum SR, Spector I. Psychologically based treatment for male erectile disorder: A cognitive-interpersonal model. J Sex Marital Ther. 1994;20:67-85.

Rosen RC, Riley A, Wagner G, Osterloh IH, Kirkpatrick J, Mishra A. The International Index of Erectile Function (IIEF): a multidimensional scale for assessment of erectile dysfunction. Urology. 1997;49:822-30.

Rosen RC, Cappelleri JC, Smith MD, Lipsky J, Peña BM. Development and evaluation of an abridged, 5-item version of the International Index of Erectile Function (IIEF-5) as a diagnostic tool for erectile dysfunction. Int J Impot Res. $1999 ; 11: 319-26$. 
Rosen RC. Psychogenic erectile dysfunction: classification and management. Urol Clin North Am. 2001;28:269-78.

Rosen RC, Cappelleri JC, Gendrano N. The International Index of Erectile Function (IIEF): a state-of-science review. Int J Impot Res. 2002;14:226-44.

Rosen RC, Fisher WA, Eardley I, Niederberger C, Nadel A, Sand M. The multinational Men's Attitudes to Life Events and Sexuality (MALES) study: I. Prevalence of erectile dysfunction and related health concerns in the general population. Curr Med Res Opin. 2004;20:607-17.

Sánchez-Cruz JJ, Cabrera-León A, Martín-Morales A, Fernández A, Burgos R, Rejas J. Male erectile dysfunction and health-related quality of life. Eur Urol. $2003 ; 44: 245-53$.

Schiavi RC, Rehmam J. Sexualiaty and aging. Urol Clin North Am. 1995;22:71126.

Scott FB, Bradley WE, Timm GW. Management of erectile impotence: use of implantable inflatable prosthesis. Urology. 1973;2:80.

Seidman SN. Exploring the relationship between depression and erectile dysfunction in aging men. J Clin Psychiatry. 2002;63(Suppl 5):5-12; discussion 23-5. 
Selye H. History and present status of the stress concept. In: Goldberger L, Breznit M. (Orgs). Handbook of stress: Theoretical and clinical aspects. London: Free Press; 1984.

Seyam RM, Albakry A, Ghobish A, Arif H, Dandash K, Rashwan H. Prevalence of erectile dysfunction and is correlates in Egypt: a community-based study. Int $J$ Impot Res. 2003;15:237-45.

Shabsigh R, Fishman IJ, Schum C, Dunn JK. Cigarette smoking and other vascular risk factors in vasculogenic impotence. Urology. 1991;38:227-31.

Sharlip ID. Evaluation and nonsurgical management of erectile dysfunction. Urol Clin North Amer. 1998;25:647-59.

Small MP, Carrion HM, Gordon JA. Samall-Carrion penile-prosthesis: new implant for management of impotence. Urology. 1975;5:479-486.

Sociedad Latinoamericana para el Estudio de la Impotencia y Sexualidad (SLAIS). I Consenso Latinoamericano de Disfunción Eréctil. São Paulo: BG Cultural; 2002.

Sugimori H, Yoshida K, Tanaka T, Baba K, Nishida T, Nakazawa R, Iwamoto T. Relationships between erectile dysfunction, depression, and anxiety in japanese subjects. J Sex Med. 2005;2:390-396. 
Teles AG, Carreira M, Alarcão V, Aragüés JM, Lopes L, Mascarenhas M, Costa JG. Prevalence, severity, and risk factors for Erectile dysfunction in a representative sample of 3,548 portuguese men aged 40 to 69 years attending primary healthcare centers: Results of the Portuguese Erectile Dysfunction Study. J Sex Med [periódico online] 2008 Jan 10. Disponível em: http://www.blackwellsynergy.com/doi/full/10.1111/j.1743-6109.2007.00745.x?prevSearch=allfield\% $3 \mathrm{~A} \% 28$ teles+ag\%29.

Tess V, Pugliese V. Disfunções sexuais. In: Ito LM (Org). Terapia cognitivocomportamental para transtornos psiquiátricos. Porto Alegre: Artes Médicas; 1998. p.123-33.

Torres LO, Glina S. Tratamento da disfunção erétil com M.U.S.E. In: Glina S, Puech-Leão P, Reis JMSM dos, Pagani E. Instituto H. Ellis - Disfunção Sexual Masculina, São Paulo: Instituto H. Ellis; 2002. p.227-9.

Virag, R. Intracavernous injection of papaverine for erectile failure. Lancet. 1982;2:938.

Virag R, Bouilly P, Frydman D. Is impotence an arterial disorder? A study of arterial risk factors in 440 impotent men. Lancet. 1985;1:181-4. 
Walz J, Perrotte P, Suardi N, Hutterer G, Jeldres C, Bérnard F, Valiquette L, Graefen M, Montorsi F, Karakiewicz PI. Baseline Prevalence of erectile dysfunction in a prostate cancer screening population. J Sex Med. 2008;5:428-35.

Wannmacher L. Sildenafil: mais potencial que potência. Uso Racional de Medicamentos - Temas selecionados -OPAS (série online). Maio de 2006; 3(6):[6 páginas]. Disponível em: http://www.opas.org.br/medicamentos/site/ UploadArq/HSE_URM_SIL_0306.pdf.

Ware JE, Sherbourne CD. The MOS 36-Item Short-Form Health Survey (SF-36). I. Conceptual framework and item selection. Med Care. 1992;30:473-83.

WHO Consultation on Obesity. Preventing and Managing the Global Epidemic. Geneva: World Health Organization; 1998.

Wu CJ, Hsieh JT, Lin JS, Hwang TI, Jiann BP, Huang ST, Wang CJ, Lee SS, Chiang HS, Chen KK, Lin HD. Comparison of prevalence between self-reported erectile dysfunction and erectile dysfunction as defined by five-item International Index of Erectile Function in Taiwanese men older than 40 years. Urology. 2007;69:743-7.

Zilbergeld B. The New Male Sexuality. New York: Bantam Books; 1992. 